\title{
Sistemas de partículas interagentes aplicados a dinâmicas sociais: modelos de confiança limitada
}

\author{
Ivan Costa Bernardo
}

\author{
DisSERTAÇÃO APRESENTADA \\ AO \\ Instituto DE MATEMÁtica E Estatística \\ DA \\ Universidade de São Paulo \\ PARA \\ OBTENÇÃ̃ DO TÍTULO \\ $\mathrm{DE}$ \\ Mestre em CiÊnCIAS
}

\author{
Programa: Estatística \\ Orientador: Prof. Dr. Fábio Prates Machado
}

Durante o desenvolvimento deste trabalho, o autor recebeu auxílio financeiro do CNPq.

São Paulo, 10 de junho de 2016 


\section{Sistemas de partículas interagentes aplicados a dinâmicas sociais: modelos de confiança limitada}

Esta versão da dissertação contém as correções e alterações sugeridas pela Comissão Julgadora durante a defesa da versão original do trabalho, realizada em 5/4/2016. Uma cópia da versão original está disponível no

Instituto de Matemática e Estatística da Universidade de São Paulo.

Comissão Julgadora:

- Prof. Dr. Fábio Prates Machado (orientador) - IME-USP

- Prof. Dr. Élcio Lebensztayn - IMECC-Unicamp

- Prof. Dr. Valdivino Vargas Júnior - IME-UFG 


\section{Agradecimentos}

Agradeço primeiramente ao meu orientador Fábio Prates Machado a paciência e a disposição. Foram dezenas de horas de conversa, em que pude presenciar sua dedicação e atenção. Também as observações dos demais integrantes da banca - Valdivino Vargas Júnior e Élcio Lebensztayn - foram de grande relevância para este trabalho e para mim.

Igualmente meus outros professores tiveram papel essencial nesta conquista. Expresso aqui, em especial, minha gratidão à professora Elisabeti Kira, minha primeira professora de uma disciplina de estatística na graduação, orientadora de iniciação científica e da qual fui monitor em duas ocasiões. Aprendi com ela muito mais do que probabilidade.

Meus colegas, tanto da graduação como do mestrado, representaram um importante apoio ao longo de todo este tempo. Alguns deles viraram bons amigos, dando-me suporte em várias outras questões além das acadêmicas. Cito aqui, por exemplo, Gabriela, Simone, Jaime e Rafael.

Serei eternamente grato aos meus pais, que estiveram ao meu lado em todos os momentos, com muito carinho e um tanto de sacrifício.

Reconheço ainda o papel da USP, a qual me proporcionou uma visão plural, maior senso crítico e contato com diversas pessoas e realidades. 


\section{Resumo}

BERNARDO, I. C. Sistemas de partículas interagentes aplicados a dinâmicas sociais. 2016. 81 f. Dissertação (mestrado) - Instituto de Matemática e Estatística, Universidade de São Paulo, São Paulo, 2016.

Aplicações de processos estocásticos a dinâmicas sociais constituem tema de grande relevância nos últimos anos. Especialmente desafiadores são os modelos de opinião com confiança limitada dada a sua falta de linearidade. Com isso, simulações e resultados numéricos possuem elevada importância. Neste trabalho, focamos em dois dos principais modelos de confiança limitada, nomeadamente os modelos de Hegselmann-Krause e de Deffuant-Weisbuch. Em ambos os casos, é necessário que a diferença de opiniões entre dois dados agentes seja menor que o limite de confiança, parâmetro do modelo. Porém, enquanto no modelo de Hegselmann-Krause a interação a cada etapa se dá entre todos os agentes vizinhos entre si, no modelo de Deffuant-Weisbuch a interação ocorre entre apenas dois agentes por vez. Apresentamos aqui uma revisão da literatura associada ao tema, incluindo resultados numéricos e analíticos sobre o comportamento de ambos os modelos, principalmente no tocante à convergência e condições em que se estabelecem o consenso ou a fragmentação de opiniões.

Palavras-chave: Dinâmicas de opinião, confiança limitada, Hegselmann-Krause, DeffuantWeisbuch. 


\begin{abstract}
BERNARDO, I. C. Interacting particle systems applied to social dynamics: bounded confidence models. 2016. 81 f. Dissertação (mestrado) - Instituto de Matemática e Estatística, Universidade de São Paulo, São Paulo, 2016.

Applications of stochastic processes to social dynamics constitute a prominent research field of the last years. Especially challenging are opinion models with bounded confidence, given their lack of linearity. Thus, simulations and numerical results are highly important. In this work, we focus on two of the main bounded confidence models, namely Hegelsemann-Krause and Deffuant-Weisbuch models. In both cases, it is necessary that the difference between two agents' opinions is less than the confidence bound, a parameter of the model. However, while at the Hegselmann-Krause model the interaction at each step occurs among all neighboring agents, at the Deffuant-Weisbuch model the interaction happens between only two agents each time. We present here a review of the literature concerned to the subject, including numerical and analytical results about the behavior of both models, mainly those related to convergence and conditions under which consensus or fragmentation take place.
\end{abstract}

Keywords: Opinion dynamics, bounded confidence, Hegselmann-Krause, Deffuant-Weisbuch. 


\section{Sumário}

Lista de Símbolos $\quad$ ix

1 Introdução 1

1.1 Considerações preliminares e objetivo . . . . . . . . . . . . . . . 1

1.2 Organização do trabalho . . . . . . . . . . . . . . . . . . 2

2 Dinâmica de opinião $\quad 5$

2.1 Modelos de dinâmica de opinião . . . . . . . . . . . . . . . . . 7

2.1.1 Modelo do votante . . . . . . . . . . . . . . . . . 7

2.1.2 Modelo da regra da maioria . . . . . . . . . . . . . . . . . 8

2.1.3 Modelo de Sznajd . . . . . . . . . . . . . . . . . . . . . 9

2.1.4 Modelo de consenso de DeGroot . . . . . . . . . . . . . . 9

2.1.5 Modelo geral de dinâmica de opinião
(Hegselmann e Krause [27]) . . . . . . . . . . . . . . . . 10

3 Modelo de Hegselmann-Krause $\quad 13$

3.1 Caracterização do modelo . . . . . . . . . . . . . . . . . . . 13

3.2 Consenso e fragmentação . . . . . . . . . . . . . . . . . . . . . . . . . . . . . . . . . . . .

3.3 Intervalos de confiança assimétricos . . . . . . . . . . . . . . . . 19

3.4 Tempo de encerramento . . . . . . . . . . . . . . 20

3.5 Limites de confiança heterogêneos . . . . . . . . . . . . . . . 23

3.6 Outros tipos de média . . . . . . . . . . . . . . . . 25

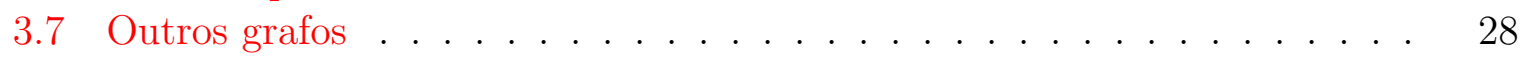

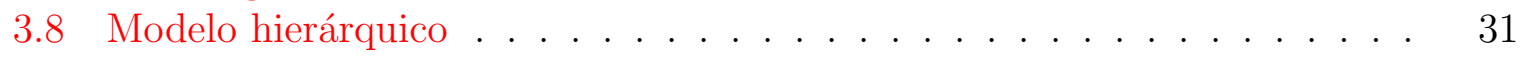

3.9 Modelo baseado na densidade . . . . . . . . . . . . . . . . 33

3.10 Cadeias de Markov interativas . . . . . . . . . . . . . . . 34

3.11 Opinião multidimensional . . . . . . . . . . . . . . . . . . . 38

3.12 Estabilidade com respeito a um agente perturbador . . . . . . . . . . . 40

4 Modelo de Deffuant-Weisbuch 43

4.1 Caracterização do modelo . . . . . . . . . . . . . . . . . 43

4.2 Número finito de agentes, opinião unidimensional . . . . . . . . . . . . . 44

4.3 Número finito de agentes, opinião multidimensional . . . . . . . . . . . . 50

4.4 Número infinito de agentes, opinião unidimensional . . . . . . . . . . . 52

4.5 Número infinito de agentes, opinião multidimensional . . . . . . . . . . . 56

4.6 Modelo baseado na densidade . . . . . . . . . . . . . . . . . 62

4.7 Generalizando os modelos de Hegselmann-Krause e Deffuant . . . . . . . 65

$\begin{array}{lll}5 & \text { Conclusão } & 71\end{array}$ 


\section{Lista de Símbolos}

$\begin{array}{ll}A & \text { Matriz de pesos para modelos de dinâmica de opinião } \\ \varepsilon & \text { Confiança de todos os agentes no modelo homogêneo } \\ \varepsilon_{i} & \text { Confiança do agente } i \\ G=(V, E) & \text { Grafo com respectivos conjuntos de vértices e elos } \\ I(i, \boldsymbol{x}(t)) & \text { Conjunto de confiança do agente } i \text { com relação ao perfil } \boldsymbol{x}(t) \\ \mu & \text { Parâmetro de convergência } \\ n & \text { Número de agentes (nos modelos com número finito de agentes) } \\ \underline{n} & \text { Conjunto de agentes }\{1, \ldots, n\} \\ P(x, t) & \text { Função de taxa para o modelo baseado na densidade } \\ S & \text { Espaço de opiniões } \\ T & \text { Tempo de encerramento/convergência } \\ \boldsymbol{x}(t)=\left(x_{1}(t), \ldots, x_{n}(t)\right) & \text { Perfil de opinião no instante } t\end{array}$




\section{Lista de Figuras}

3.1 Simulações para o modelo de Hegselmann-Krause com 3 valores para o parâmetro $\varepsilon: 0,01 ; 0,15 ; 0,25 \ldots \ldots \ldots \ldots$

3.2 Frequência relativa média das opiniões para 40 valores de $\varepsilon: 0,01 ; 0,02 ; \ldots ; 0,4020$

3.3 simulações para o modelo de Hegselmann-Krause com viés dependente da opinião. Três valores de $\bar{\varepsilon}: 0,2 ; 0,4 ; 0,6.26$ valores de $m: 0 ; 0,04 ; \ldots ; 0,96 ; 1.21$

3.4 Simulação do modelo de Hegselmann-Krause no grafo completo . . . . . 30

3.5 Simulação do modelo de Hegselmann-Krause no grafo reticulado quadrado com condições de fronteira periódicas . . . . . . . . . . . . . . . .

3.6 Simulação do modelo de Hegselmann-Krause baseado na densidade com

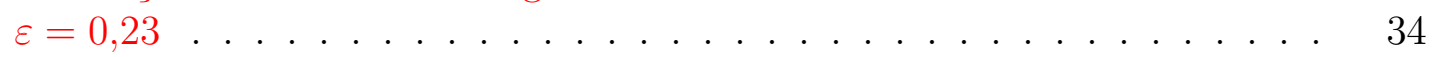

3.7 Clusters no equilíbrio para diversos valores do limite de confiança . . . . 35

3.8 Diagrama de bifurcação para o modelo de HK. $n=1001 ; k=50, \ldots, 300 . \quad 37$

4.1 Opiniões dos agentes em função do tempo para os parâmetros $\varepsilon=0,5, \mu=$ $0,5, n=1000$. Uma unidade de tempo equivale à amostragem de 1000 pares de agentes . . . . . . . . . . . . . . . . .

4.2 Opiniões dos agentes em função do tempo para os parâmetros $\varepsilon=0,2, \mu=$ $0,5, n=1000$. Uma unidade de tempo equivale à amostragem de 1000 pares de agentes. . . . . . . . . . . . . . . . .

4.3 Opiniões finais dos agentes dispostos nos vértices de um quadriculado de tamanho 29 por 29. Valores dos parâmetros: $\varepsilon=0,3, \mu=0,3$. Número de iterações: 100.000 .

4.4 Opiniões finais dos agentes dispostos nos vértices de um quadriculado de tamanho 29 por 29. Valores dos parâmetros: $\varepsilon=0,15, \mu=0,3$. Número

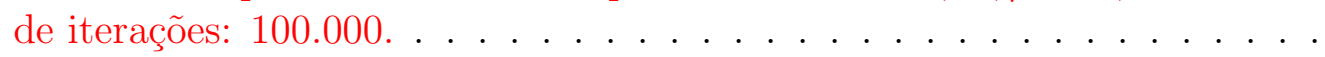

4.5 Estimativas para a probabilidade de consenso para o modelo de Deffuant no grafo reticulado quadrado com condições de fronteira periódicas . . .

4.6 Estimativas para a probabilidade de consenso para o modelo de Deffuant no grafo reticulado quadrado com condições de fronteira periódicas . . .

4.7 Valores das opiniões no equilíbrio para diferentes valores de $\varepsilon$ e $\mu$. . . .

4.8 Simulação para o modelo de Deffuant no grafo completo com opinião multidimensional com 20 tópicos com opiniões binárias. $n=5,10,15,20$. .

4.9 Simulação para o modelo de Deffuant com opinião multidimensional com 20 tópicos com opiniões binárias. $n=5,10,20,30 \ldots \ldots$

4.10 Simulação para o modelo de Deffuant com opinião multidimensional com 50 tópicos com opiniões binárias. $n=5,10,15,20 \ldots \ldots$. . . . . .

4.11 Simulação para o modelo de Deffuant com opinião multidimensional com 100 tópicos com opiniões binárias. $n=3,5,7,10 \ldots \ldots$. . . . . . . 
4.12 Localização dos clusters no equilíbrio em função do valor de $\Delta$. As setas indicam as três primeiras bifurcações. . . . . . . . . . . . . . . . . 64

4.13 Diagrama de bifurcação para o modelo de Deffuant . . . . . . . . . . . 64

4.14 Resultados de simulações para o modelo de Urbig e Lorenz com $n=100$ com opiniões iniciais determinadas aleatoriamente . . . . . . . . . . . 67

4.15 Estimativa da probabilidade de certos números de clusters em função do número de agentes comunicantes para três valores de $\varepsilon: 0,15 ; 0,25 ; 0,35$. $\quad 67$

4.16 Exemplos para $\varepsilon=0,25, \mathrm{n}=\mathrm{m}=100$ e 3 valores de $\mu: 0 ; 0,3 ; 0,6 \ldots 68$

4.17 Número médio de clusters e tempo médio de convergência para diferentes valores de $\mu$ (azul representa $\mu=0$, e vermelho, $\mu=0,9$ ) e três valores de $m: 2,20$ e $100=n \ldots \ldots \ldots \ldots$ 


\section{Capítulo 1}

\section{Introdução}

\subsection{Considerações preliminares e objetivo}

A ideia de que comportamentos sociais são em grande parte influenciados pelos outros indivíduos do grupo social vem de longa data. No século XIX, Mackay [46] e Le Bon [38] já haviam abordado a "loucura das multidões" e a "estupidez das multidões", respectivamente. O primeiro mostra como o comportamento de massas levou a bolhas econômicas, popularizou a alquimia, reforçou as Cruzadas e proporcionou a matança de milhares de pessoas consideradas bruxas entre os séculos XVI e XVII. O segundo defende que a multidão só tem poder destrutivo, pois não é disciplinada nem consegue pensar no futuro; apenas age instintivamente.

Mais tarde, porém, outros pesquisadores abordariam dinâmicas sociais sob o ponto de vista da construção de opiniões coletivas por meio do consenso ou da polarização dessas opiniões. Os agentes não simplesmente se comportam como uma massa, mas também discutem, trocam ideias e atualizam suas opiniões baseados nessas interações. Moscovici e Zavalloni [48], por exemplo, cunharam o termo "polarização" para referirem-se à tendência dos membros de um grupo de adotarem posições mais extremas que a média das opiniões iniciais [24]. DeGroot [11], por sua vez, foi um dos primeiros a estudar a construção do consenso num grupo social e as condições para que ele seja atingido.

Desde então, foi proposta uma vasta série de modelos de dinâmica de opinião, grande parte deles adotando técnicas comuns à física estatística. Também os problemas estudados assemelham-se àqueles do contexto ferromagnético e de percolação, como transição de fase e valores críticos para os parâmetros envolvidos.

O objetivo principal deste trabalho é a apresentação de dois dos principais modelos de dinâmica de opinião sob confiança limitada, a saber, o modelo de Hegselmann-Krause e o modelo de Deffuant. Não fazemos aqui uma análise exaustiva desses modelos; procuramos apenas expor os principais resultados e variações de cada processo. Também apresentamos uma breve história dos processos estocásticos aplicados a dinâmicas sociais, no Capítulo 2, e os dois modelos mencionados servem como um bom exemplo da aplicação a dinâmicas sociais de técnicas normalmente utilizadas na física estatística e em outros processos estocásticos. 


\subsection{Organização do trabalho}

Esta dissertação está dividida da forma que se segue. No Capítulo 2, expomos a origem dos modelos de dinâmica de opinião, comentando alguns trechos da história que nos leva desde a física estatística até o que hoje alguns pesquisadores denominam de sociofísica. Esse ramo de estudos aborda, entre outros processos, as dinâmicas de opinião, isto é, como as opiniões de agentes (pessoas ou grupos) a respeito de certos tópicos evoluem ao longo do tempo principalmente por meio do contato e interação com opiniões alheias.

O foco deste trabalho, porém, consiste em um tipo especial de dinâmica de opinião: com confiança limitada. Trata-se da dinâmica de opinião em que os agentes confiam somente em agentes com opiniões próximas das suas, isto é, que não difiram da sua própria opinião mais do que um valor (parâmetro) $\varepsilon$, de acordo com uma distância préestabelecida. As possíveis opiniões cujas distâncias até a opinião de um agente específico são pequenas o suficiente formam a chamada região de confiança desse agente. Independentemente dos processos de encontro entre os indivíduos (ou grupos) e dos grafos subjacentes à sua estrutura de relacionamento, somente agentes com opiniões dentro da região de confiança de um determinado agente exercem influência sobre ele podendo, assim, alterar sua opinião.

Os Capítulos 3 e 4 discorrem sobre dois dos principais modelos de confiança limitada. No primeiro desses capítulos, é abordado o modelo de Hegselmann-Krause, apresentado por Krause [32] e [34]. A atualização das opiniões nesse modelo dá-se por meio da média aritmética das opiniões de todos os agentes vizinhos ao agente considerado cuja opinião esteja dentro da região de confiança desse agente. Enunciamos os principais resultados já descobertos a respeito de condições para o consenso, estudamos o tempo de encerramento do processo (tempo até que se atinja o equilíbrio) e abordamos algumas variações básicas do modelo. A primeira é a utilização de limites de confiança heterogêneos, isto é, quando o limite de confiança não é idêntico para todos os agentes. A segunda, outros tipos de média - além da média geométrica - na atualização das opiniões dos agentes. Outra variação é constituída pelos diferentes grafos que se pode usar, já que não necessariamente os agentes se encontram num grafo completo, onde todos podem interagir com todos - como considerado na versão original do modelo. São abordados ainda o modelo hierárquico proposto por Dittmer [12]; cadeias de Markov interativas, de acordo com o modelo baseado na densidade; o caso em que a opinião é multidimensional; a possibilidade de as opiniões dos agentes serem atualizadas de acordo com uma média ponderada entre as opiniões no instante atual e o valor "correto" do parâmetro que a coletividade busca estimar. Por último, estuda-se a estabilidade do sistema com relação a um agente perturbador, adicionado ao grupo original de agentes após terem atingido o equilíbrio e, em seguida, retirado.

No Capítulo 4, o alvo é o modelo de Deffuant-Weisbuch ou simplesmente Deffuant. Ao contrário do modelo de Hegselmann-Krause, em que cada atualização de cada agente se dá com todos os vizinhos cuja opinião esteja na região de confiança do agente especificado, no modelo de Deffuant as interações são sempre em pares. Isso significa que, a cada oportunidade de interação, o agente atualiza sua opinião baseado apenas na própria opinião e na de um vizinho - caso a diferença entre as opiniões esteja dentro do limite de confiança. Dada a grande diversidade de apresentações desse modelo, este capítulo está organizado de forma distinta do anterior. Após a apresentação formal do modelo, cada seção estuda uma combinação de duas características do modelo: se o número de agentes é finito ou infinito e se a opinião é unidimensional ou multidimensional. Ao longo dessas 
seções buscamos apresentar aspectos como a divisão dos agentes em clusters, condições para o consenso, utilização de diferentes tipos de grafos, tempos contínuo e discreto, entre outros.

Ainda que se tenham incluído ideias de provas ou explicações de alguns resultados, demonstrações formais fogem do escopo deste trabalho. Além disso, salvo menção em contrário, as imagens ao longo desta dissertação foram retiradas dos próprios artigos nos quais se embasa o texto. As referências bibliográficas dizem respeito, portanto, simultaneamente ao conteúdo escrito e às figuras. 


\section{Capítulo 2}

\section{Dinâmica de opinião}

Quando Daniel Bernoulli expôs em seu tratado Hydrodynamica, de 1738, sua Teoria Cinética dos Gases, ele foi quase ignorado. Naquela época, apenas seus compatriotas suíços J. A. de Luc (1727-1817) e Georges-Louis Le Sage (1724-1803) e o russo Mikhail Lomonossov (1711-1765) citaram seu estudo. Ainda se encontrava em voga a chamada Teoria Calórica, segundo a qual o calor era uma substância denominada calórico - fluido composto de partículas que se repeliam umas às outras. Pensava-se que todos os corpos fossem circundados por uma "atmosfera" de calórico, cuja densidade aumentava com a temperatura. Acreditava-se que as forças atrativas entre partículas de matéria tivessem origem gravitacional assim como as forças entre o Sol e os planetas. A uma certa distância entre partículas de matéria, haveria equilíbrio entre a repulsão calórica e a atração gravitacional. Quando a temperatura subisse, cada partícula de matéria ganharia mais calórico, e consequentemente a repulsão calórica aumentaria, deslocando para fora o ponto de equilíbrio. Assim se explicava a expansão térmica da matéria incluindo os gases. Porém, no fim do século XVIII, apareceram vários argumentos contra a Teoria Calórica e, já no século seguinte, uma série de pesquisadores fez descobertas no sentido de invalidar tal teoria.

Um desses nomes foi James Clerk Maxwell (1831-1879). Seu primeiro artigo sobre a Teoria Cinética [47] assumiu, pela primeira vez, movimento aleatório para as moléculas. Até então, o valor absoluto das velocidades das moléculas era considerado uniforme. Em 1872, Ludwig Boltzmann (1844-1906) generalizou a abordagem de Maxwell quanto à complexidade das moléculas e à interação térmica entre ensembles.

O termo Mecânica Estatística foi cunhado pelo físico americano Josiah Willard Gibbs em 1884 durante um encontro da Associação Americana para o Avanço da Ciência, na Filadélfia. Ele observou que os artigos de Maxwell e Boltzmann haviam suscitado uma nova disciplina, a qual faria uso de leis da estatística para tratar de corpos arbitrariamente complexos movendo-se de acordo com as leis da mecânica. Em 1902, Gibbs publicou seu tratado Elementary Principles in Statistical Mechanics [23].

Com Maxwell, Boltzmann e Gibbs, não mais se focava em cada partícula. O sistema era caracterizado como um todo por meio de um conjunto de parâmetros e suas distribuições entre as partículas. E essa ideia não ficou restrita à Física. Logo pesquisadores de outras áreas perceberam que seus sistemas poderiam ser estudados sob o mesmo enfoque: apesar de cada elemento constituinte do sistema contribuir para a determinação das características de interesse do conjunto, a importância de cada "partícula" é desprezível a ponto de só darmos relevância a agregados de elementos.

Na segunda metade do século XX, as ciências sociais tornaram-se um desses campos a 
adotarem métodos da Física Estatística. Um dos primeiros trabalhos nesse contexto foi o artigo de Wolfgang Weidlich de 1971 [56], no qual modelos probabilísticos originalmente empregados na descrição de ensembles de spins (partículas) foram reformulados de modo a estudar a estrutura de grupos sociais cujos integrantes se influenciam mutuamente com respeito às suas decisões. Mais precisamente, Weidlich discorreu sobre como o modelo de Ising, apresentado em 1925 por Ernst Ising e usualmente adotado para descrever o ferromagnetismo, poderia ser interpretado num contexto sociológico.

Vamos, então, aqui abrir parênteses para explicar resumidamente do que se trata o modelo de Ising, o mais amplamente estudado modelo de spins. Consideremos um grafo $G=(V, E)$ com $V$ representando o conjunto de vértices de $G$, e $E$ o conjunto de elos. O valor $\sigma(v)$ é o spin no vértice $v$. A interpretação física é que ímãs, cada um dos quais com possíveis orientações +1 e -1 , são dispostos nos vértices do grafo; as orientações do conjunto de spins determinam uma configuração. No modelo de Ising de vizinho mais próximo, a energia de uma configuração $\sigma$ é definida como

$$
H(\sigma)=-\sum_{\substack{v, w \in V \\ v \sim w}} J_{v w} \sigma(v) \sigma(w) .
$$

A notação $v \sim w$ significa que $v$ e $w$ são vizinhos mais próximos. A equação acima mostra que a energia aumenta à medida que há mais pares de vértices vizinhos com spins discordantes (ou seja, um vizinho tem spin +1 e outro, -1 ). O parâmetro $J_{v w}$ modela a força de interação; eventualmente podemos considerar $J_{v w}=J$ para todos $v, w \in V$ com $v \sim w$.

Seja $\Omega$ o espaço de todas as configurações possíveis em $V$. A distribuição de probabilidade $\mu$ em $\Omega$ associada à configuração $\sigma$ é dada pela distribuição de Gibbs (ou de Boltzmann), definida como

$$
\mu(\sigma)=\frac{1}{Z(\beta)} e^{-\beta H(\sigma)},
$$

em que $Z(\beta)$ - denominada função de partição - é a constante normalizadora exigida para que $\mu$ seja uma distribuição de probabilidade:

$$
Z(\beta):=\sum_{\sigma \in \Omega} e^{-\beta H(\sigma)}
$$

O parâmetro $\beta \geq 0$ determina a importância da função energia. A interpretação física é que $\beta$ corresponde ao inverso da temperatura (em graus Kelvin). No caso hipotético em que a temperatura é infinita $(\beta=0), H$ não exerce nenhum papel, e $\mu$ é uniforme em $\Omega$. Além disso, não há interação entre os spins de vértices distintos, de modo que as variáveis aleatórias $\{\sigma(v)\}_{v \in V}$ são independentes. À medida que $\beta>0$ aumenta, a tendência de $\mu$ em direção a configurações de baixa energia também aumenta. (Notemos em (2.2) que, quanto menor a energia $H(\sigma)$, maior a probabilidade associada à configuração $\sigma$.)

Assim como os spins num ensemble de partículas interagentes, as opiniões individuais podem ser caóticas num primeiro momento - isto é, sem uma estrutura em larga escala - mas posteriormente alinhar-se por meio de interações para, então, passar por uma transição da desordem para a ordem. Ordem aqui significa que o sistema apresenta regularidades em larga escala no longo prazo e, no contexto físico, seria associado a um estado de baixa energia. Assim como na Física Estatística, um dos questionamentos mais relevantes em dinâmicas sociais é sob quais circunstâncias as interações no nível micro 
levam a tal transição no nível macro. Mais informações sobre a história de modelos de física estatística podem ser consultadas em Flamm [15].

Em 1982, Galam et al [22] procuraram estabelecer uma estrutura global para "um novo campo de pesquisa" [21] denominado por eles Sociofísica. Nesse artigo, modelaram o processo de greve em grandes empresas usando o modelo de Ising. Apesar de não ser propriamente a primeira contribuição para a Sociofísica, Galam [21] considera esse trabalho um manifesto sobre os objetivos, limites e perigos de tal vertente de estudo.

\subsection{Modelos de dinâmica de opinião}

Desde o artigo de Weidlich [56], foi criada uma extensa série de modelos de sistemas de partículas interagentes aplicados a dinâmicas sociais. Uma ampla revisão desses modelos pode ser encontrada, por exemplo, em Castellano et al [8], o qual aborda modelos de dinâmicas culturais, dinâmicas de linguagem, comportamento de multidões, formação de hierarquias, entre outros. No presente trabalho, o foco são os modelos de dinâmica de opinião e, mais especificamente, os modelos de opinião com confiança limitada. No que segue, "agente" pode referir-se a indivíduo, corporação, país ou qualquer outro grupo agindo conjuntamente. Em modelos de dinâmica de opinião, consideramos um grupo de agentes, cada um com uma opinião acerca de um ou mais tópicos. De acordo com a dinâmica do processo, cada agente, em tempos determinados, observa ou deduz a opinião de outros agentes para, com isso, atualizar - ou não - sua própria opinião.

Nos modelos a seguir e naqueles dos próximos dois capítulos, em caso de omissão, o conjunto de agentes - finito ou infinito enumerável - é $V$. Também salvo consideração em contrário, o tempo é discreto, isto é, $T \in\{0,1,2, \ldots\}$. Para um agente fixo $i \in V$, denotamos sua opinião no tempo $t$ por $x_{i}(t)$. Assim, $\boldsymbol{x}(t)=\left\{x_{i}(t), i \in V\right\}$ representa o perfil de opinião (ou a configuração do sistema) no tempo $t$. O espaço de estados para cada agente é $S$. Nos modelos de spins, esse espaço, de forma geral, é dado por $S=\{0,1\}$ ou $S=\{-1,+1\}$ - ou seja, cada agente pode assumir um dos valores 0 ou 1 no primeiro caso e -1 ou +1 no segundo. Em outros modelos, as opiniões podem ser contínuas, por exemplo, no intervalo $[0,1]$.

\subsubsection{Modelo do votante}

O modelo do votante foi apresentado originalmente em 1973 por Clifford e Sudbury [9] como um modelo para a competição entre espécies e recebeu o nome modelo do votante em 1975 por Holley e Liggett [30] pela sua interpretação natural como dinâmica de opinião entre eleitores. Trata-se de um sistema de spins $(S=\{0,1\})$ cujas taxas são dadas por

$$
c(i, \boldsymbol{x})=\sum_{j} p(i, j)\left|x_{i}-x_{j}\right|
$$

em que $p(i, j) \geq 0$ para $i, j \in V$ e

$$
\sum_{j} p(i, j)=1 \text { para } i \in V
$$

Supõe-se que $p(i, j)$ é tal que a cadeia de Markov com estas probabilidades de transição é irredutível. A interpretação que dá nome ao modelo considera $V$ um grupo de agentes, cada um dos quais com uma de duas opiniões possíveis (0 ou 1) em alguma questão 
política, por exemplo. Cada indivíduo periodicamente - de acordo com um processo de Poisson de taxa unitária - reavalia sua opinião da seguinte forma: ele escolhe outro agente de acordo com uma distribuição de probabilidades dada por $p(x, y)$ e adota a opinião desse agente. Numa interpretação alternativa, consideram-se $\left\{i \in V: x_{i}=0\right\}$ e $\left\{i \in V: x_{i}=1\right\}$ como dois territórios ocupados respectivamente pelas populações 0 e 1 . (Na analogia, os territórios correspondem aos eleitores, e as populações, às opiniões.)

Pelas taxas em (2.4), fica claro que as configurações $\boldsymbol{x} \equiv 0$ e $\boldsymbol{x} \equiv 1$ são invariantes para o processo, isto é, são estados absorventes. Poderíamos pensar nessas configurações como representações de consenso, em que todos os agentes chegam a uma opinião comum.

Uma variação do modelo do votante de especial interesse é o modelo do votante restrito, proposto por Vazquez et al [55], em que são considerados três estados possíveis para os agentes: esquerda, centro e direita. Cada agente só pode interagir com agentes no mesmo estado que ele ou no estado vizinho - o que, na prática, inviabiliza o contato entre direitistas e esquerdistas. Tem-se aí, portanto, a versão de confiança limitada do modelo do votante. Veremos mais adiante do que se trata o princípio da confiança limitada.

\subsubsection{Modelo da regra da maioria}

Proposto por Galam [19] para descrever debates públicos, o modelo da regra da maioria considera um grupo de $n$ agentes, dos quais uma proporção $p_{+}$possui opinião +1 e o restante, -1 . Suponhamos que a rede social seja um grafo completo, isto é, um grafo em que o conjunto das arestas coincide com o conjunto dos pares não ordenados dos vértices. A cada iteração, um subgrupo de tamanho $r$ é escolhido aleatoriamente, e todos os agentes desse subgrupo adotam a opinião da maioria entre eles. O tamanho $r$ do subgrupo escolhido pode ser aleatório, proveniente de uma distribuição, e deve ser especificada uma regra para lidar com empates entre opiniões positivas e negativas - por exemplo, introduzir um viés em favor de alguma das opiniões.

Seja $p_{+}^{0}$ a proporção inicial de agentes com opinião +1 . A dinâmica apresenta um valor crítico de $p_{+}^{0}$, o qual denotaremos por $p_{c}$. Para $p_{+}^{0}>p_{c}$, todos os agentes terão opinião +1 no longo prazo. Por outro lado, simetricamente, se $p_{+}^{0}<p_{c}$, então todos os agentes terão opinião -1 . Se $r$ for sempre ímpar, teremos $p_{c}(r)=1 / 2$. Porém, se houver $r$ par, teremos $p_{c}<1 / 2$. Para mais informações sobre este modelo, conferir Castellano et al [8].

Um modelo de dinâmica semelhante é o modelo da maioria de votos, apresentado por Liggett [39]. Nesse modelo também são consideradas as opiniões +1 e -1 . A cada iteração, um agente atualiza sua opinião da seguinte forma: com probabilidade $q$, o agente adota a opinião da maioria de seus vizinhos; com probabilidade $1-q$, a opinião da minoria; em caso de empate entre +1 's e -1 's, o agente pode adotar cada opinião com probabilidade $1 / 2$. O caso com $q=0$ corresponde ao modelo de Ising com temperatura nula. Já se mostrou que, para este modelo, existe transição de fase ao aumentar o valor do parâmetro $q$.

Outro modelo de regra da maioria proposto por Galam [20] foi o modelo da regra da maioria hierárquico. Consideram-se $r^{k}$ agentes, os quais, no início, têm opinião +1 com probabilidade $p_{0}$ e opinião $-1 \mathrm{com}$ probabilidade $1-p_{0}$. Em cada rodada, os agentes são divididos aleatoriamente em grupos de $r$ integrantes. Cada grupo elege um representante, que passará para a próxima rodada. Esse representante é definido aleatoriamente entre aqueles que possuírem a opinião majoritária. Em caso de empate entre as opiniões, o representante é escolhido aleatoriamente (de maneira equiprovável) entre todos os membros 
do grupo.

\subsubsection{Modelo de Sznajd}

Na versão mais conhecida do modelo de Sznajd-Weron e Sznajd [49], os agentes são alocados nos vértices de um grafo e novamente podem ter opiniões iguais a +1 ou -1 . A cada iteração, um par de agentes (ligados por um elo) é escolhido. Se suas opiniões forem concordantes (isto é, os dois com opinião +1 ou os dois com -1 ), todos os seus vizinhos adotam essa opinião. Caso contrário, nada acontece. O princípio por trás é que, quando outros agentes parecem concordar entre si, um agente observador é convencido mais facilmente.

A versão original considera os agentes dispostos em uma cadeia linear, e as opiniões também são binárias. As opiniões são atualizadas numa ordem aleatória sequencial da forma que se segue. Suponhamos que, numa dada iteração, os agentes $i$ e $i+1$, com opiniões respectivamente iguais a $s_{i}$ e $s_{i+1}$, sejam os escolhidos. Se $s_{i}=s_{i+1}$, então $s_{i-1} \mathrm{e}$ $s_{i+2}$ terão seus valores atualizados para $s_{i}=s_{i+1}$. Caso contrário, o agente $i-1$ terá sua opinião modificada (ou mantida) para $s_{i+1}$, e o agente $i+2$ ficará com a opinião $s_{i-1}$.

\subsubsection{Modelo de consenso de DeGroot}

Em artigo de 1974, DeGroot [11] considera um grupo de $n$ indivíduos, cada um dos quais com distribuição inicial de probabilidade acerca de um parâmetro com valor desconhecido. É apresentado um modelo que descreve como os agentes, atuando como um time, podem chegar a um consenso sobre a estimativa do valor do parâmetro uma vez que tenham exposto suas distribuições de probabilidade em relação ao parâmetro. Tal modelo consiste numa série de equações de recorrência representando a atualização das distribuições de cada agente em virtude das distribuições de todos os agentes no passo anterior. Mais formalmente, o agente $i \in \underline{n}$ inicia com uma distribuição $F_{i}(0)$ e, na $k$-ésima revisão, atualiza sua distribuição de opiniões atribuindo peso $a_{i j}$ ao agente $j$ :

$$
F_{i}(k)=\sum_{j=1}^{n} a_{i j} F_{j}(k-1)
$$

Matricialmente, temos:

$$
\boldsymbol{F}(k)=A \boldsymbol{F}^{T}(k-1),
$$

em que $\boldsymbol{F}(k)=\left(F_{1}(k), \ldots, F_{n}(k)\right)$ e $A=\left(a_{i j}\right)_{i, j \in \underline{n}}$.

A equação de recorrência (2.6) pode ser vista como uma cadeia de Markov e, portanto, aplicam-se os teoremas sobre condições para a estacionariedade de uma cadeia de Markov comum em tempo discreto:

Teorema 2.1 (DeGroot [11]). Se houver um inteiro positivo $k$ tal que todo elemento de pelo menos uma coluna de A seja positivo, então o consenso é atingido.

Teorema 2.2 (DeGroot [11]). Se todos os estados recorrentes da cadeia de Markov se comunicam uns com os outros e são aperiódicos, então o consenso é atingido.

No que diz respeito à forma do consenso, o próximo teorema estabele a relação entre o peso de cada distribuição inicial de opiniões e a distribuição estacionária de uma cadeia de Markov com probabilidades de transição dadas pela matriz $A$. 
Teorema 2.3 (DeGroot [11]). Supondo que um consenso seja atingido, então a distribuição comum das opiniões dos agentes será dada por $\sum_{i=1}^{n} \pi_{i} F_{i}(0)$, em que $\boldsymbol{\pi}=\left(\pi_{1}, \ldots, \pi_{n}\right)$ é o vetor único de probabilidade estacionária da cadeia de Markov com probabilidades de transição dadas por A.

\subsubsection{Modelo geral de dinâmica de opinião (Hegselmann e Krause [27])}

Nos próximos capítulos, abordaremos outros modelos de opinião, mas a forma geral seguinte continuará sendo útil. Dadas distribuições iniciais $F_{1}(0), \ldots, F_{n}(0)$ para as opiniões dos agentes, suas opiniões são atualizadas de acordo com os pesos $a_{i j}(t)$ como se segue:

$$
F_{i}(t+1)=\sum_{j=1}^{n} a_{i j}(t) F_{j}(t), \quad i \in \underline{n}:=\{1, \ldots, n\}
$$

Observemos que a equação (2.6) é um caso específico de (2.7) supondo os pesos $a_{i j}(t)$ constantes ao longo do tempo. Por outro lado, em todos os modelos que apresentaremos, as distribuições $F_{1}(0), \ldots, F_{n}(0)$ são degeneradas em $x_{1}(0), \ldots, x_{n}(0)$, de modo que, para os nossos propósitos, o modelo geral em tempo discreto é como exposto em Hegselmann e Krause [27]:

$$
\boldsymbol{x}(t+1)=A(t, \boldsymbol{x}(t)) \boldsymbol{x}(t) \text { para } t \in \mathbb{N} .
$$

Hegselmann e Krause [27] apresentam resultados analíticos e numéricos sobre o modelo representado pela Equação (2.8). Para enunciá-los, é conveniente apresentar primeiramente a seguinte definição de consenso:

Definição 2.1. O modelo $\boldsymbol{x}(t+1)=A \boldsymbol{x}(t), t \in \mathbb{N}$ apresenta a propriedade do consenso se, para todo $\boldsymbol{x}(0) \in \mathbb{R}^{n}$, há $c \in \mathbb{R}$ tal que $\lim _{t \rightarrow \infty} x_{i}(t)=c$ para todo $i \in \underline{n}$.

O primeiro resultado que vamos citar é exposto também em Krause [32], o qual citaremos de forma adaptada.

Teorema 2.4 (Krause [32]). Para o modelo na Equação (2.8), suponhamos que existam números $0 \leq \delta_{t} \leq 1$ tais que $\sum_{t=0}^{\infty} \delta_{t}=\infty$ e $\sum_{k=1}^{n} \min \left\{a_{i k}(t, \boldsymbol{x}(t)), a_{j k}(t, \boldsymbol{x}(t))\right\} \geq \delta_{t}$ para todo $i, j \in \underline{n}=\{1, \ldots, n\}$, todo $t \in \mathbb{N}$. Então, para todo $\boldsymbol{x}(0) \in S^{n}$ existe um número $a(\boldsymbol{x}(0))$ tal que $\lim _{t \rightarrow \infty} x_{i}(t)=a(\boldsymbol{x}(0))$ para todo $i \in \underline{n}$.

Observemos que, no caso específico em que $A(t)=A$ para todo $t \in \mathbb{N}$, ou seja, $A(t)$ é constante, a condição acima pode ser simplificada da seguinte maneira: se, para todo $i, j \in \underline{n}$ existir algum $k \in \underline{n}$ tal que $a_{i k}>0$ e $a_{j k}>0$, então valerá a propriedade do consenso.

De maneira mais geral, podemos considerar outras formas de atualização, como fez Krause [33]. Denotemos por $f_{i}\left(x_{1}, \ldots, x_{n}\right)$ a opinião adotada pelo agente $i$ após observar as opiniões $x_{1}, \ldots, x_{n}$. Para $x_{1}, \ldots, x_{n}$, o casco convexo conv $\left\{x_{1}, \ldots, x_{n}\right\}$, composto por todas as combinações convexas $\alpha_{1} x_{1}+\ldots+\alpha_{n} x_{n}$ com $\alpha_{i} \geq 0$ para todo $i$ e $\alpha_{1}+\ldots+\alpha_{n}=1$, também está contido no espaço de opiniões $S$. O mapeamento $f: S^{n} \rightarrow S^{n}$ é denominado um mapa de acordo (compromise map em inglês) em $S$ se

$$
\operatorname{conv}\left\{f_{1}(\boldsymbol{x}), \ldots, f_{n}(\boldsymbol{x})\right\} \subseteq \operatorname{conv}\left\{\mathrm{x}_{1}, \ldots, \mathrm{x}_{\mathrm{n}}\right\}
$$


valer para todo $\boldsymbol{x} \in S^{n}$. Se, além disso, para todos $x_{1}, \ldots, x_{n}$ não iguais, valer a relação de continência "ᄃ" em (2.9) mas não "=", então o mapa é classificado como próprio.

Teorema 2.5 (Krause [33]). Para um mapa de acordo $f$ contínuo e próprio, o algoritmo de acordo dado pela equação recursiva

$$
x_{i}(t+1)=f_{i}\left(x_{1}(t), \ldots, x_{n}(t)\right) \text { para todo } i \in \underline{n}, \text { todo } t \in \mathbb{N}
$$

sempre converge para um consenso $c$, isto é, existe $c=c(\boldsymbol{x}(0))$ tal que

$$
\lim _{t \rightarrow \infty} x_{i}(t)=c \quad \text { para todo } i \in \underline{n}, \boldsymbol{x}(0)=\left(x_{1}(0), \ldots, x_{n}(0)\right) \in S^{n} .
$$

Pode-se mostrar que, para um mapa de acordo linear, se a matriz $A$ for misturada, ou seja, se para todo par de linhas $i$ e $j$ existir uma coluna $k$ tal que $a_{i k}>0$, então o mapa é próprio, e assim vale o Teorema 2.5.

Outros resultados que valem neste contexto são os Teoremas 2.1 e 2.2. 


\section{Capítulo 3}

\section{Modelo de Hegselmann-Krause}

No capítulo anterior, abordamos alguns pontos marcantes da história dos modelos de dinâmica de opinião, além de alguns exemplos. Propositalmente excluímos os modelos de confiança limitada, pois serão tratados neste capítulo e no próximo. Dado a extensa pesquisa sobre tais modelos, vamos focar aqui em dois dos principais e primeiros modelos de confiança limitada, a saber, o modelo de Hegselmann-Krause e o de Deffuant-Weisbuch. No presente capítulo, trataremos do primeiro deles.

\subsection{Caracterização do modelo}

Antes de exibir o modelo, é importante explicar o conceito de confiança limitada. Tal expressão significa que cada agente leva em conta apenas opiniões que difiram de sua opinião no máximo um certo valor (parâmetro) $\varepsilon$. Mais formalmente, dado um perfil de opinião $\boldsymbol{x}(t)$, o agente $i$ terá, no instante $t$, um conjunto de confiança

$$
I(i, \boldsymbol{x}(t)):=\left\{j \sim i:\left|x_{i}(t)-x_{j}(t)\right| \leq \varepsilon_{i}\right\},
$$

em que $\varepsilon_{i}$ é o nível de confiança do agente $i$. No caso em que esse parâmetro assume o mesmo valor para todos os agentes, dizemos que o modelo é homogêneo quanto ao nível de confiança. Notemos ainda que podemos generalizar mais o modelo de forma a considerar níveis de confiança diferentes para cada agente à direita ou à esquerda ou os mesmos níveis de cada lado para cada agente.

Modelos de dinâmica de opinião podem ser expressos de basicamente duas formas: baseados no agente e baseados na densidade. No primeiro caso, a variável que indica o estado do sistema é um perfil de opinião $\boldsymbol{x}(t)=\left(x_{1}(t), \ldots, x_{n}(t)\right) \in S^{n}$, o qual, no caso com opinião $d$-dimensional, é um vetor de vetores, cada um dos quais com $d$ coordenadas, referindo-se a $d$ quesitos formadores da opinião de cada indivíduo. Dado um perfil inicial $\boldsymbol{x}(0)$, a dinâmica é definida recursivamente por $\boldsymbol{x}(t+1)=f(t) \boldsymbol{x}(t)$, de modo que o par $(S, f)$ constitui um sistema dinâmico discreto. Essa é a forma que mais trataremos.

Em modelos baseados na densidade, por sua vez, a variável de estado é uma função de densidade $P(\cdot, t): S \rightarrow \mathbb{R}_{\geq 0}$ no espaço de opiniões, com $\int_{S} P(x, t) \mathrm{d} x=1$ para todo t. Dada uma função de densidade inicial $P(\cdot, 0)$, a dinâmica é definida como a evolução da função de densidade ao longo do tempo - por vezes discreto e outras vezes, contínuo. No caso contínuo, procuramos soluções para a equação diferencial

$$
\frac{\partial}{\partial t} P(x, t)=g(P(x, t)),
$$


em que $g$ opera no espaço de funções de densidade. Já no caso discreto, temos a equação de diferenças

$$
\Delta P(x, t+1)=P(x, t+1)-P(x, t)=g(P(x, t))
$$

O modelo abordado neste capítulo e ao qual se costuma chamar modelo de HegselmannKrause apareceu originalmente em Krause [32]. Consideremos um grupo de $n$ agentes $\underline{n}:=\{1,2, \ldots, n\}$. O tempo é discreto, ou seja, $t \in \mathbb{N}=\{0,1,2, \ldots\}$. Convencionemos que todas as opiniões são estritamente positivas e definamos o conjunto $K$ como o cone de todos os vetores (coluna) $i \in \mathbb{R}^{n}$ com componentes estritamente positivos, de modo que $\boldsymbol{x}(t) \in K$ para todo $t \in \mathbb{N}$. Krause [32] não faz menção explícita ao grafo que indicaria com quais outros agentes cada elemento poderia interagir. Considera, em vez disso, que as interações em cada etapa são reguladas apenas pelos conjuntos $I(i, \boldsymbol{x}(t)), i \in \underline{n}$, $t \in \mathbb{N}$. Como todos os agentes potencialmente interagem com todos os outros - ainda que não necessariamente atualizem suas opiniões -, pode-se adotar um grafo completo para representar a estrutura dos agentes.

A dinâmica de atualização é dada pelo seguinte conjunto de equações de recorrência:

$$
x_{i}(t+1)=\frac{1}{|I(i, \boldsymbol{x}(t))|} \sum_{j \in I(i, \boldsymbol{x}(t))} x_{j}(t) \quad \text { para } i \in \underline{n}, t \in \mathbb{N}
$$

Na equação acima, $|\cdot|$ denota o número de elementos de um conjunto finito.

Com relação à forma geral (2.7),

$$
a_{i j}(t, \boldsymbol{x}(t))= \begin{cases}|I(i, \boldsymbol{x}(t))|^{-1} & \text { para } j \in I(i, \boldsymbol{x}(t)) \\ 0 & \text { para } j \notin I(i, \boldsymbol{x}(t))\end{cases}
$$

Esses pesos serão úteis na demonstração de certos resultados.

\subsection{Consenso e fragmentação}

Vamos começar por alguns teoremas já presentes no artigo original de Krause [32]. Todos eles dizem respeito a condições necessárias ou suficientes para que se atinja o consenso, aqui entendido como o fato de todas as opiniões convergirem para um único valor, ou seja, existir $c$ tal que

$$
\lim _{t \rightarrow \infty} x_{i}(t)=c \text { para todo } i \in \underline{n} .
$$

Teorema 3.1 (Krause [32]). Para o modelo de Hegselmann-Krause conforme descrito pela Equação (3.4), consideremos a condição de que existe algum $t_{0} \in \mathbb{N}$ tal que, para todo $t \geq t_{0}$,

$$
I(i, \boldsymbol{x}(t)) \cap I(j, \boldsymbol{x}(t)) \neq \varnothing \operatorname{para} i, j \in \underline{n},
$$

(i) A condição acima implica consenso.

(ii) Para $n=2$, a condição em (3.7) é também necessária para que se atinja o consenso $e$ é equivalente a

$$
\left|x_{1}(0)-x_{2}(0)\right| \leq \max \left\{\varepsilon_{1}, \varepsilon_{2}\right\} .
$$

Além disso, se tal condição valer, o consenso será atingido após um número finito $m+1$ de passos, em que

$$
m=\left\lceil\log _{2} \frac{\left|x_{1}(0)-x_{2}(0)\right|}{\min \left\{\varepsilon_{1}, \varepsilon_{2}\right\}}\right\rceil .
$$




\section{( \lceil\rceil denota o menor número natural maior ou igual a z.)}

A prova do item (i) consiste em notar que a condição (3.7) implica que

$$
\sum_{k=1}^{n} \min \left\{a_{i k}(x), a_{j k}(x)\right\} \geq \frac{1}{n} \text { para todo } x \in K \text { e todos } i, j \in \underline{n} \text {. }
$$

Com isso, podemos aplicar o Teorema 2.4 ou a Proposição 3.1. No item (ii), o agente com o maior coeficiente de confiança reduz pela metade a distância entre a sua opinião e a de seu parceiro a cada etapa enquanto o coeficiente de confiança deste último for menor que a diferença de opiniões. No instante em que a diferença de opiniões é menor que os coeficientes de confiança dos dois agentes, obtém-se o consenso em um único passo.

O próximo teorema fornecerá uma condição necessária para o modelo homogêneo quanto ao nível de confiança. Antes de enunciá-lo, porém, vamos apresentar uma definição:

Definição 3.1. Para um certo número real $\varepsilon \geq 0$, chamamos perfil $\varepsilon$ ou cadeia $\varepsilon$ a um vetor $\boldsymbol{x} \in \mathbb{R}_{+}^{n}$ se existe uma ordenação $x_{i_{1}} \leq x_{i_{2}} \leq \ldots \leq x_{i_{n}}$ dos componentes de $\boldsymbol{x}$ tal que todo par de componentes adjacentes tem distância menor ou igual a $\varepsilon$, isto é,

$$
x_{i_{k+1}}-x_{i_{k}} \leq \varepsilon \text { para todo } k \in\{1, \ldots, n-1\} .
$$

Mostraremos a seguir que tal ordenação permanecerá no próximo passo e, por indução, em todos os passos seguintes. Suponhamos $x_{i_{j}}(t) \leq x_{i_{l}}(t)$. Assim, todo elemento $i_{k} \in I\left(i_{j}, \boldsymbol{x}(t)\right) \backslash I\left(i_{l}, \boldsymbol{x}(t)\right)$ será tal que $x_{i_{k}}<x_{i_{k}^{\prime}}$ para todo $i_{k^{\prime}} \in I\left(i_{j}, \boldsymbol{x}(t)\right)$. Para aliviar visualmente a notação, denotemos $I\left(i_{j}, \boldsymbol{x}(t)\right) \backslash I\left(i_{l}, \boldsymbol{x}(t)\right)$ por $I_{-l}\left(i_{j}, \boldsymbol{x}(t)\right)$. Ademais, definamos $I_{j}\left(i_{l}, \boldsymbol{x}(t)\right)=I_{l}\left(i_{j}, \boldsymbol{x}(t)\right)=I\left(i_{j}, \boldsymbol{x}(t)\right) \cap I\left(i_{l}, \boldsymbol{x}(t)\right)$.

$$
\begin{aligned}
x_{i_{j}}(t+1) & =\frac{\left|I_{-l}\left(i_{j}, \boldsymbol{x}(t)\right)\right|}{\mid I\left(i_{j}, \boldsymbol{x}(t) \mid\right.} \times \frac{\sum_{i_{k} \in I_{-l}\left(i_{j}, \boldsymbol{x}(t)\right)} x_{i_{k}}(t)}{\left|I_{-l}\left(i_{j}, \boldsymbol{x}(t)\right)\right|}+\frac{\left|I_{l}\left(i_{j}, \boldsymbol{x}(t)\right)\right|}{\left|I\left(i_{j}, \boldsymbol{x}(t)\right)\right|} \times \frac{\sum_{i_{k} \in I_{l}\left(i_{j}, \boldsymbol{x}(t)\right)} x_{i_{k}}(t)}{\left|I_{l}\left(i_{j}, \boldsymbol{x}(t)\right)\right|} \\
& \leq \frac{\sum_{i_{k} \in I_{l}\left(i_{j}, \boldsymbol{x}(t)\right)}^{\left|I_{l}\left(i_{j}, \boldsymbol{x}(t)\right)\right|} x_{i_{k}}(t)}{\leq x_{i_{l}}(t+1)}=\frac{\left|I_{l}\left(i_{j}, \boldsymbol{x}(t)\right)\right|}{\left|I\left(i_{l}, \boldsymbol{x}(t)\right)\right|} \times \frac{\sum_{i_{k} \in I_{l}\left(i_{j}, \boldsymbol{x}(t)\right)} x_{i_{k}}(t)}{\left|I_{l}\left(i_{j}, \boldsymbol{x}(t)\right)\right|}+\frac{\left|I_{-j}\left(i_{l}, \boldsymbol{x}(t)\right)\right|}{\mid I\left(i_{l}, \boldsymbol{x}(t) \mid\right.} \times \frac{i_{i_{k} \in I_{-j}\left(i_{l}, \boldsymbol{x}(t)\right)}(t)}{\left|I_{-j}\left(i_{l}, \boldsymbol{x}(t)\right)\right|}
\end{aligned}
$$

Se, por outro lado, $x_{i_{k+1}}-x_{i_{k}}>\varepsilon$ para algum $k>0$, então dizemos que há uma quebra entre os agentes $i_{k}$ e $i_{k+1}$. E se houver uma quebra entre dois agentes no passo $t$, essa quebra permanecerá no passo $t+1$ e, por indução, em todos os passos seguintes. Assim, para que se atinja o consenso, é necessário que não haja quebras entre qualquer par de agentes em nenhum passo.

Krause [32] mostrou que, para um consenso ser atingido no modelo de HegselmannKrause (Equação (3.4)) com $\varepsilon_{i}=\varepsilon$ para todo $i \in \underline{n}$, é necessário que $\boldsymbol{x}(t)$ seja um perfil $\varepsilon$ para todo $t \in \mathbb{N}$. Dittmer [12] melhorou esse resultado, provando o seguinte teorema:

Teorema 3.2 ((Dittmer [12]). No modelo de Hegselmann-Krause homogêneo, será atingido consenso se e somente se o perfil de opinião $\boldsymbol{x}(t)$ for uma cadeia $\varepsilon$ para todo $t \in \mathbb{N}_{0}$. Tal consenso será atingido em tempo finito. 
Se, para algum $t \in \mathbb{N}_{0}$, o perfil $\boldsymbol{x}(t)$ não for uma cadeia $\varepsilon$, a partir desse momento teremos cadeias $\varepsilon$ com dinâmicas independentes espaçadas de pelo menos $\varepsilon$, e o consenso obviamente não será atingido. Por outro lado, se para todo $t \in \mathbb{N}_{0}$ tivermos uma (única) cadeia $\varepsilon$, pode-se mostrar [12] que a quantidade $\max \left\{x_{1}(t), \ldots, x_{n}(t)\right\}-\min \left\{x_{1}(t), \ldots, x_{n}(t)\right\}$ convergirá para zero, e portanto o sistema chegará ao consenso.

Hegselmann e Krause [27] apontam ainda como propriedade de um perfil $\varepsilon$ o fato de que, para $n=2,3,4$, o consenso é atingido se e somente se o perfil inicial for um perfil $\varepsilon$. Além disso, para $n=5$, se o perfil inicial de opiniões for um perfil $\varepsilon$ equidistante, isto é, as distâncias entre opiniões adjacentes forem iguais, então o consenso será atingido.

No mesmo trabalho, os autores também usam o conceito de cadeia. Trata-se aí, porém, de uma cadeia de confiança ao longo do tempo.

Definição 3.2. Uma cadeia de confiança do agente $i$ até o agente $j$, do instante $s$ até o instante $t>s$ é uma sequência de agentes $\left(i_{0}, i_{1}, \ldots, i_{t-s}\right)$ tal que $i_{0}=i, i_{t-s}=j$ e $i_{k} \in I\left(i_{k-1}, \boldsymbol{x}(s+k-1)\right)$ para todo $k \in\{1, \ldots, t-s\}$.

O lema seguinte - versão reduzida de teorema apresentado por Hegselmann e Krause [27] - é a base da prova do próximo teorema:

Lema 3.1 (Hegselmann e Krause [27]). Para $s, t \in \mathbb{N}_{0}$ com $s<t$, definamos a matriz $B(t, s)=\left(b_{i j}(t, s)\right):=A(t-1) A(t-2) \cdots A(s)$. Suponhamos que existam uma sequência $0=t_{0}<t_{1}<t_{2}<\ldots$ em $\mathbb{N}_{0}$ e uma sequência $\delta_{1}, \delta_{2}, \ldots$ em $[0,1]$ com $\sum_{m=1}^{\infty} \delta_{m}=\infty$ tais que $\sum_{k=1}^{n} \min \left\{b_{i k}\left(t_{m}, t_{m-1}\right), b_{j k}\left(t_{m}, t_{m-1}\right)\right\} \geq \delta_{m}$ para todo $m \geq 1$, todo $1 \leq i, j \leq n$. Então, para todo perfil inicial $\boldsymbol{x}(0)$ ocorre consenso .

Com base na definição acima e no lema recém-mencionado, Hegselmann e Krause [27] expõem o seguinte teorema sobre uma condição suficiente para o consenso:

Teorema 3.3 (Hegselmann e Krause [27]). No modelo de Hegselmann-Krause, se para quaisquer agentes $i$ e $j$ existir um terceiro agente, $k$, tal que haja cadeias de confiança de $i$ até $k$ e de $j$ até $k$, do instante $s$ até $s+h$, para $h \geq 1$ fixado e todo $s$, então o consenso será atingido em tempo finito, ou seja, para algum $t_{0} \in \mathbb{N}$,

$$
x_{i}(t)=c(\boldsymbol{x}(0)) \text { para todo } i \in \underline{n} \text { e } t \geq t_{0} .
$$

Também sobre a formação de consenso em modelos de opinião contínua, Lorenz [40] estudou condições para a convergência de opiniões e o consenso em classes de agentes. Essas condições dizem respeito à matriz de pesos $A(t, \boldsymbol{x}(t))$ exposta no capítulo anterior e devem valer para todo $t \in \mathbb{N}_{0}$.

(i) Todo agente tem um pouco de autoconfiança: a diagonal de $A(t, \boldsymbol{x}(t))$ é positiva, isto é, para todo agente $i \in \underline{n}$, vale que $a_{i i}(t, \boldsymbol{x}(t))>0$.

(ii) A confiança é mútua: as entrada nulas de $A(t, \boldsymbol{x}(t))$ são simétricas. Para quaisquer dois agentes $i, j \in \underline{n}$, vale que $a_{i j}(t, \boldsymbol{x}(t))>0 \Leftrightarrow a_{j i}(t, \boldsymbol{x}(t))>0$.

(iii) Os pesos positivos não convergem para zero: há $\delta>0$ tal que a menor entrada positiva de $A(t, \boldsymbol{x}(t))$ é maior que $\delta$. 
O teorema a seguir afirma que as condições acima são suficientes para a convergência das opiniões e as caracteriza. "Matriz de consenso" é uma matriz estocástica com linhas iguais.

Teorema 3.4 (Lorenz [40]). Seja $(A(t))_{t \in \mathbb{N}_{0}} \in \mathbb{R}_{\geq 0}^{n \times n}$ uma série de matrizes de confiança, e definamos a matriz de acumulação entre os passos $t_{0}$ e $t_{1}, t_{1}>t_{0}$ como

$$
A\left(t_{0}, t_{1}\right):=A\left(t_{1}-1\right) A\left(t_{1}-2\right) \cdots A\left(t_{0}+1\right) A\left(t_{0}\right) .
$$

Se cada matriz $A(t)$ atender às condições (i) a (iii), haverá um passo to e classes de agentes $\mathcal{I}_{1}, \ldots, \mathcal{I}_{p}$ tais que $\mathcal{I}_{1} \cup \ldots \cup \mathcal{I}_{p}=\underline{n}$,

$$
\lim _{t \rightarrow \infty} A(0, t)=\left[\begin{array}{ccc}
K_{1} & & 0 \\
& \ddots & \\
0 & & K_{p}
\end{array}\right] A\left(0, t_{0}\right)
$$

e $K_{1}, \ldots, K_{p}$ são matrizes de consenso quadráticas dos mesmos tamanhos que $\mathcal{I}_{1}, \ldots, \mathcal{I}_{p}$. (Para a estrutura em blocos, precisamos organizar os indices da matriz de acordo com $\left.\mathcal{I}_{1}, \ldots, \mathcal{I}_{p}.\right)$

Pode-se mostrar que tanto o modelo de Hegselmann-Krause homogêneo em relação a $\varepsilon$ como o modelo de Deffuant-Weisbuch (na sua forma básica e também homogêneo em relação ao limite de confiança) atendem às condições (i) a (iii), de modo que o Teorema 3.4 é válido para ambos os modelos.

"Matrizes de consenso quadráticas" acima significa que, ao multiplicarmos uma das matrizes $K_{i}$ por um vetor arbitrário, obteremos um vetor com todas as entradas iguais. Assim, o que o teorema nos diz é que todo perfil de opiniões inicial se desenvolve até um passo $t_{0}$, em que os agentes se separam em classes independentes. As opiniões dos agentes convergem para um consenso em cada uma dessas classes.

Tratando-se do consenso geral, isto é, a situação em que as opiniões de todos os agentes convergem para um mesmo valor, temos a seguinte proposição, equivalente ao Teorema 2.4:

Proposição 3.1 (Lorenz [40]). Seja $(A(t))_{t \in \mathbb{N}_{0}} \in \mathbb{R}_{\geq 0}^{n \times n}$ uma série de matrizes estocásticas, e seja $\left(\delta_{t}\right)_{t \in \mathbb{N}_{0}}>0$ uma série com $\sum_{t=0}^{\infty} \delta_{t}=+\infty$ e $\delta_{t}>0$ para todo t. Se, para todo $t \in \mathbb{N}_{0}$, valer que $\min _{i, j} \sum_{k=1}^{n} \min \left\{a_{i k}(t), a_{j k}(t)\right\} \geq \delta_{t}$, então haverá uma matriz de consenso $K$ tal que $\lim _{t \rightarrow \infty} A(0, t)=K$.

Notemos que $\delta_{t}$ não necessariamente corresponde aos $\delta$ 's da condição (iii). Além disso, a Proposição 3.1 - equivalente ao Teorema 2.4 - é um caso particular do Lema 3.1. Sua prova ([40], [32] e [45]) deriva do fato de que, para uma matriz arbitrária $B \in \mathbb{R}^{n \times n}$, o diâmetro $d(B)$ (maior distância euclidiana entre duas linhas quaisquer de $B$ ) diminui da seguinte forma quando $B$ é multiplicada à esquerda por uma matriz $A \in \mathbb{R}^{n \times n}$ :

$$
d(A B) \leq\left(1-\min _{i, j} \sum_{k=1}^{n} \min \left\{a_{i k}, a_{j k}\right\}\right) d(B)
$$

Como, por hipótese, $\min _{i, j} \sum_{k=1}^{n} \min \left\{a_{i k}(t), a_{j k}(t)\right\} \geq \delta_{t}$, ficamos com

$$
d(A(0, t+1)) \leq\left(1-\delta_{t}\right) d(A(0, t)) \leq e^{-\delta_{t}} d(A(0, t)) \leq e^{-\sum_{i=0}^{t} \delta_{t}} d(A(0))
$$


de modo que $\lim _{t \rightarrow \infty} d(A(0, t))=0$ e, consequentemente, $\lim _{t \rightarrow \infty} A(0, t)=K$.

Blondel et al [5] analisam, além de condições para o consenso, como se dá a fragmentação, caso esta ocorra, no caso em que as opiniões iniciais são equidistantes ao longo do intervalo do espaço de opiniões. O modelo considerado é homogêneo para o parâmetro do nível de confiança. Uma particularidade da abordagem de Blondel et al [5] é que adotam o nível de confiança como valendo sempre 1 e variam o comprimento do espaço de opiniões em vez de variarem $\varepsilon$. Tal método é equivalente ao "tradicional" e, para passar de um para o outro, basta fazer as contas devidas para encontrar a escala correta. Exemplo: o limite de confiança igual a 1 com comprimento do intervalo do espaço de opiniões $L$ pode ser convertido para um limite de confiança igual a $1 / L$ com comprimento de intervalo igual a 1. Dito isso, passemos aos resultados do artigo de acordo com a abordagem usual - limite de confiança $\varepsilon$ e espaço de opiniões $[0,1]$, sobre o qual as opiniões iniciais estão colocadas de forma equidistante.

Suponhamos $n$ ímpar, de modo que um dos agentes tenha opinião inicial $(t=0)$ igual a $1 / 2$. Pode-se mostrar que, para a primeira iteração, isto é, $t=1$, todas as opiniões pertencem a $\left[\frac{\varepsilon}{2}, 1-\frac{\varepsilon}{2}\right]$. Para $t=2$, as opiniões encontram-se todas no intervalo $\left[\frac{11 \varepsilon}{12}, 1-\frac{11 \varepsilon}{12}\right]$. Observemos que o sistema não pode produzir mais de um cluster final se todas as opiniões estiverem em $\left(\frac{1}{2}-\varepsilon, \frac{1}{2}+\varepsilon\right)$, uma vez que o agente originalmente com opinião $1 / 2$ se manterá assim até o fim, por simetria, e os demais estarão a uma distância menor que $\varepsilon$ até ele. Consequentemente, poderá haver só um cluster se

$$
\frac{11 \varepsilon}{12}>\frac{1}{2}-\varepsilon \Leftrightarrow \varepsilon>\frac{6}{23} .
$$

Além de resultados analíticos, Hegselmann e Krause [27] também fornecem resultados de simulações. Primeiramente o cenário analisado tem espaço de opiniões $S=[0,1]$ e limites de confiança simétricos - o limite é o mesmo à esquerda e à direita - e homogêneos, isto é, o mesmo valor do limite de confiança é adotado para todos os agentes. As opiniões iniciais são geradas aleatoriamente no intervalo $[0,1]$ para 625 agentes. As atualizações de opinião são simultâneas. O resultado dos 15 primeiros passos de três execuções para o mesmo perfil inicial está na Figura 3.1. (O equilíbrio é atingido em menos de 15 passos nos três casos.) Para $\varepsilon=0,01$, formaram-se 38 clusters no final; para $\varepsilon=0,15,2$ clusters; e para $\varepsilon=0,25$, é atingido o consenso.

Com o intuito de ter uma visão mais ampla do comportamento do processo, os autores realizaram ainda 50 execuções da mesma dinâmica para 40 valores distintos de $\varepsilon$ : 0,$01 ; 0,02 ; \ldots ; 0,40$. Os resultados estão exibidos na Figura 3.2. O eixo $x$ representa os valores das opiniões (mais precisamente, 100 intervalos de valores de igual amplitude para as opiniões), o eixo $y$ indica os valores de $\varepsilon$ multiplicados por 100 , e no eixo $z$ estão as frequências relativas das opiniões para cada valor de $\varepsilon$. Observamos diferentes características ao longo da faixa de variação de $\varepsilon$ :

- Para $\varepsilon$ até aproximadamente 0,05, há agentes com opiniões finais em todos os subintervalos de $[0,1]$.

- Para $\varepsilon$ aproximadamente entre 0,05 e 0,12 , a região com opiniões começa a estreitarse.

- Para $\varepsilon$ entre cerca de 0,12 e 0,25, formam-se três grupos de opiniões.

- Para $\varepsilon$ maior que aproximadamente 0,25, volta a haver apenas um intervalo de valores, mais estreito que as faixas anteriores, o que aumenta a concentração de opiniões em torno de 0,5 . 


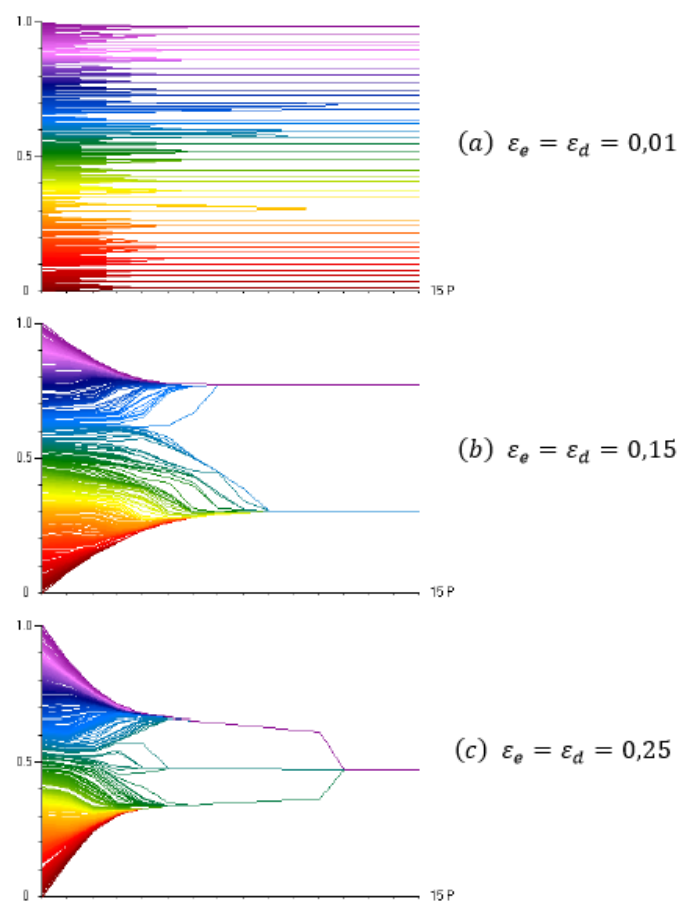

Figura 3.1: Simulações para o modelo de Hegselmann-Krause com 3 valores para o parâmetro $\varepsilon$ : 0,$01 ; 0,15 ; 0,25$

\subsection{Intervalos de confiança assimétricos}

Hegselmann e Krause [27] também simularam o modelo que leva seus nomes com conjuntos de confiança assimétricos, da forma

$$
I(i, \boldsymbol{x}(t))=\left\{j \in \underline{n}:-\varepsilon_{e} \leq x_{j}(t)-x_{i}(t) \leq \varepsilon_{d}\right\}
$$

em dois casos: quando essa assimetria é a mesma para todos os agentes, independentemente das respectivas opiniões, e quando os limites de confiança de cada lado dependem das opiniões dos agentes. No primeiro caso, são analisados quatro conjuntos de combinações de $\varepsilon_{e}$ e $\varepsilon_{d}: \varepsilon_{e}=0,9 \varepsilon_{d} ; \varepsilon_{e}=0,75 \varepsilon_{d} ; \varepsilon_{e}=0,5 \varepsilon_{d} ; \varepsilon_{e}=0,1 \varepsilon_{d}$. Para cada conjunto de combinações, $\varepsilon_{d}$ vai de 0,01 a 0,4 em variações de 0,01 . As principais conclusões foram:

- Para valores muito pequenos de $\varepsilon_{e}$ e $\varepsilon_{d}$, a dinâmica estabiliza-se com uma pluralidade de opiniões remanescentes.

- Quando $\varepsilon_{e}$ e $\varepsilon_{d}$ aumentam, passa-se a observar uma polarização de opiniões. Os dois campos de opiniões ficam cada vez mais à direita à medida que cresce a disparidade entre $\varepsilon_{e}$ e $\varepsilon_{d}$.

- Para valores ainda maiores de $\varepsilon_{e}$ e $\varepsilon_{d}$, os quatro caminhos de elevação dos parâmetros levam ao consenso. Porém, este é atingido cada vez mais à direita no intervalo $[0,1]$ quanto mais a proporção entre $\varepsilon_{e}$ e $\varepsilon_{d}$ fica mais favorável ao último.

Para modelar a assimetria dependente da opinião, os autores adotam para $\varepsilon_{e}$ e $\varepsilon_{d}$ as seguintes funções de $x$ (opinião do agente) e $\bar{\varepsilon}$ (comprimento do intervalo de confiança):

$$
\varepsilon_{e}(x, \bar{\varepsilon})=\left(\frac{1+m}{2}-m x\right) \bar{\varepsilon}
$$




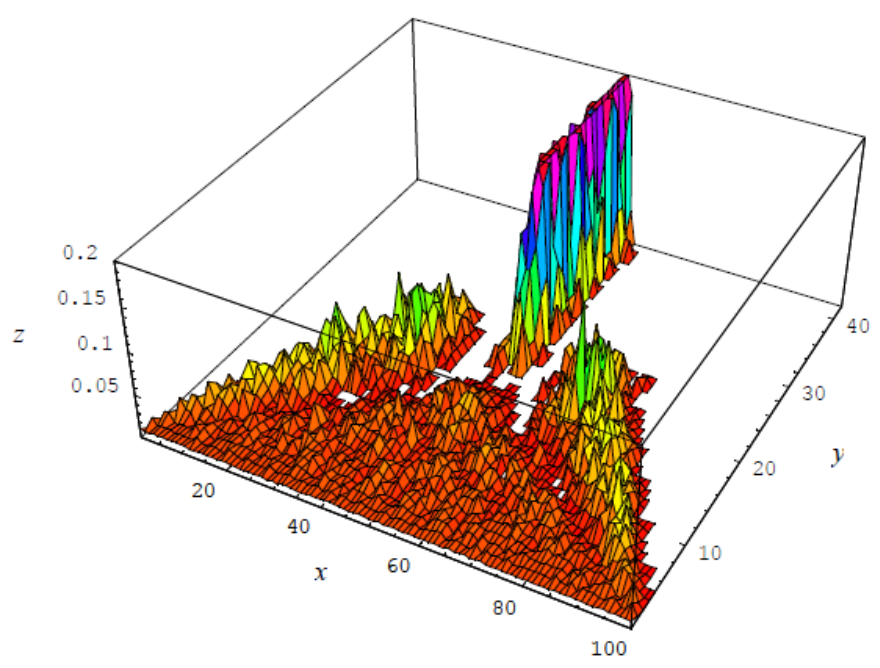

Figura 3.2: Frequência relativa média das opiniões para 40 valores de

$$
\begin{gathered}
\varepsilon: 0,01 ; 0,02 ; \ldots ; 0,40 \\
\varepsilon_{d}(x, \bar{\varepsilon})=\left(\frac{1-m}{2}+m x\right) \bar{\varepsilon}
\end{gathered}
$$

Os valores usados nas simulações foram as 78 combinações de $m=0 ; 0,04 ; \ldots ; 0,96 ; 1$ $\operatorname{com} \bar{\varepsilon}=0,2 ; 0,4 ; 0,6$. Quanto maior o valor de $m$, maior o viés para o lado em que a opinião do agente se encontra em relação ao ponto central do espaço de opinião. Em outras palavras, para opiniões acima (abaixo) de 0,5, a elevação em $m$ resulta em maior viés à direita (esquerda). Para $m=0$, não há viés. Para $m=1$, o intervalo de confiança é unilateral em relação à opinião do agente. Os resultados da simulação foram resumidos graficamente na Figura 3.3.

\subsection{Tempo de encerramento}

O tempo até que as opiniões dos agentes se estabilizem - ainda que não haja consenso é denominado tempo de encerramento (termination time em inglês), denotado aqui por $T$. Bullo et al [7] estudaram o modelo de HK sob o nome de rendez-vous e mostraram que o tempo de encerramento é, no mínimo, da ordem de $n$ e, no máximo, da ordem de $n^{5}$. Touri e Nedić [52], porém, obtiveram um limite superior mais preciso para o processo. Para expô-lo, precisamos introduzir alguns conceitos. Primeiramente, vamos definir formalmente o tempo de encerramento $T$ :

$$
T:=\min _{t \geq 0}\left\{t_{0}: x_{i}(t+1)=x_{i}(t) \text { para todo } i \in \underline{n} \text { e todo } t \geq t_{0}\right\}
$$

Também é possível definir o tempo de encerramento de um agente específico. Para tanto, vamos antes definir o grafo de conectividade para uma certa configuração $\boldsymbol{x}$ do processo, no tempo $t$. Trata-se do grafo com conjunto de vértices $\underline{n}$ e conjunto de elos

$$
E(t)=\left\{\{i, j\}: i, j \in \underline{n},\left|x_{i}(t)-x_{j}(t)\right| \leq \varepsilon\right\}
$$

(considerando-se um modelo homogêneo em relação a $\varepsilon$ ). 

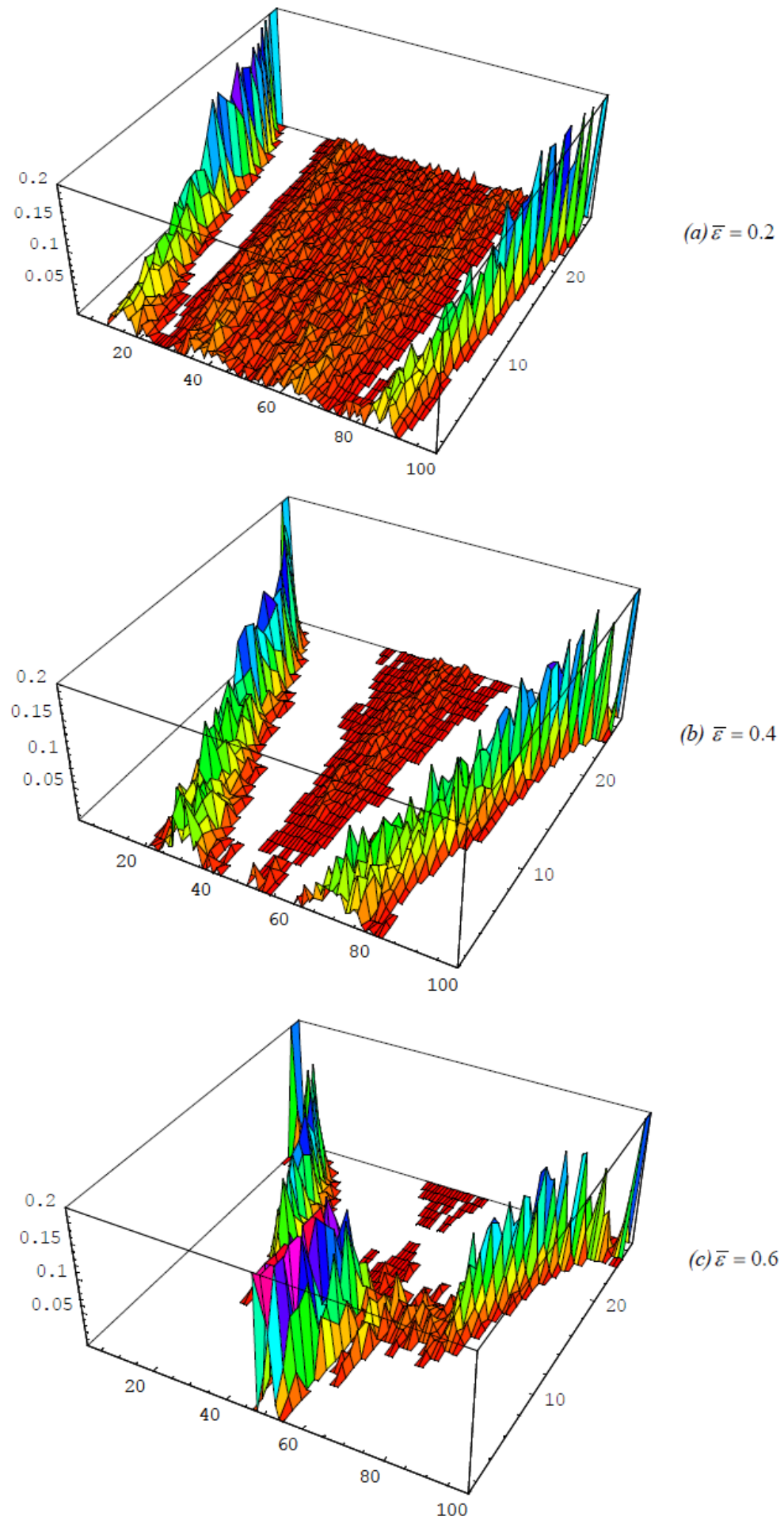

Figura 3.3: simulações para o modelo de Hegselmann-Krause com viés dependente da opinião. Três valores de $\bar{\varepsilon}: 0,2 ; 0,4 ; 0,6$. 26 valores de $m: 0 ; 0,04 ; \ldots ; 0,96 ; 1$. 
Para $i \in \underline{n}$, seu componente conexo $C_{i}(t)$ na etapa $t$ é o conjunto dos agentes (incluindo i) ligados a $i$ por um caminho no grafo de conectividade definido acima. Com isso, definimos o tempo de encerramento $T_{i}$ para o agente $i$ :

$$
T_{i}=\min \left\{t \geq 0: x_{i}(t)=x_{j}(t) \text { para todo } j \in C_{i}(t)\right\} .
$$

Em palavras, $T_{i}$ seria o instante no qual todos os elementos do componente conexo de $i$ chegam a um acordo. Pode-se mostrar que $T=\max _{i \in \underline{n}} T_{i}$. Seja $S^{*} \subset \underline{n}$ o conjunto dos agentes cujo tempo de encerramento é igual a $T$. Assim,

$$
S^{*}=\left\{i \in \underline{n}: T_{i}=T\right\} .
$$

Touri [51] havia mostrado que, para a dinâmica de HK, existe uma sequência única de vetores estocásticos $\left\{\pi^{\prime}(t)\right\}$ tal que

$$
\pi^{\prime}(t)=\pi^{\prime}(t+1) A(t)
$$

Essa é a dinâmica adjunta em relação à original. Definimos, então, a seguinte dinâmica adjunta especial:

$$
\begin{aligned}
\hat{\pi}_{i}(T) & =\left\{\begin{array}{l}
\frac{1}{S^{*}} \text { para } i \in S^{*} \\
0 \text { para } i \notin S^{*}
\end{array}\right. \\
\hat{\pi}^{\prime}(t) & =\hat{\pi}^{\prime}(t+1) A(t) \text { para } t=0, \ldots, T-1 \\
\hat{\pi}^{\prime}(t+1) & =\hat{\pi}^{\prime}(t) \text { para } t \geq T
\end{aligned}
$$

Seja, então, $V_{\pi}(t)$ a função de comparação definida por

$$
V_{\pi}(\boldsymbol{x}, t)=\sum_{i=1}^{n} \pi_{i}(t)\left(x_{i}-\pi^{\prime}(t) \boldsymbol{x}\right)^{2} .
$$

O seguinte teorema fornece um limite superior para o tempo de encerramento.

Teorema 3.5 (Touri e Nedić [52]). Para a dinâmica de Hegselmann-Krause, temos

$$
T-2 \leq \frac{32 n^{2}}{\varepsilon^{2}} V_{\hat{\pi}}(\boldsymbol{x}(0), 0) .
$$

Podemos limitar $V_{\hat{\pi}}$ superiormente considerando o "pior caso":

$$
\begin{aligned}
V_{\hat{\pi}}(\boldsymbol{x}(0), 0) & =\sum_{i=1}^{n} \hat{\pi}_{i}(0)\left(x_{i}(0)-\hat{\pi}^{\prime}(0) x(0)\right)^{2} \\
& \leq \sum_{i=1}^{n} \hat{\pi}_{i}(0)\left(x_{i}(0)-\min _{k \in \underline{n}} x_{k}(0)\right)^{2} \\
& \leq \sum_{i=1}^{n} \hat{\pi}_{i}(0)\left(\min _{j \in \underline{n}} x_{j}(0)-\min _{k \in \underline{n}} x_{k}(0)\right)^{2} \\
& =\sum_{i=1}^{n} \hat{\pi}_{i}(0) d^{2}(\boldsymbol{x}(0)) \\
& =d^{2}(\boldsymbol{x}(0)) \\
& \leq n^{2} \varepsilon^{2},
\end{aligned}
$$


em que $d(\boldsymbol{x}(0))=\max _{i \in \underline{n}} x_{i}(0)-\min _{j \in \underline{n}} x_{j}(0)$. A última desigualdade deve-se ao fato de supormos apenas perfis $\varepsilon$ para $\boldsymbol{x}(0)$ já que se, ao ordenarmos $x_{1}(0), \ldots, x_{n}(0)$, houver valores consecutivos tais que a distância entre estes é maior que $\varepsilon$, podemos considerar perfis $\varepsilon$ independentes e, portanto, também dinâmicas independentes.

Assim, considerando o pior caso (mais demorado), ficamos com

$$
T \leq 32 n^{4}+2
$$

da ordem de $n^{4}$, melhor que o limite encontrado por Bullo et al [7].

No mesmo ano, em 2012, Bhattacharyya et al [3] encontraram outro limite superior menor que o de Bullo et al [7], mostrando que o sistema converge em $O\left(n^{3}\right)$ passos. Mais precisamente, o tempo de encerramento não passa de $2\left(n+2 n^{3}\right)$.

Os autores, no mesmo trabalho, ainda consideram a possibilidade de limites de confiança assimétricos, ou seja, como na Equação (3.10). Os níveis de confiança $\varepsilon_{e}$ e $\varepsilon_{d}-$ à esquerda e à direita, respectivamente - são os mesmos para todos os agentes. É mostrado que o sistema também converge em $O\left(n^{3}\right)$ passos.

Outro ponto é a análise do caso com opinião multidimensional. Para tanto, é considerada a seguinte regra de atualização:

$$
x_{i}(t+1)=\frac{\sum_{j:\left\|x_{i}(t)-x_{j}(t)\right\| \leq \varepsilon} x_{j}(t)}{\left|\left\{j:|| x_{i}(t)-x_{j}(t) \| \leq \varepsilon\right\}\right|},
$$

em que $\|\cdot\|$ representa a distância euclidiana. A mudança básica na regra de atualização é, portanto, o uso da distância euclidiana para definir os elementos no conjunto de confiança de cada agente. Bhattacharyya et al [3] provam o seguinte teorema sobre o limite superior do tempo de encerramento para o modelo de HK com opinião multidimensional.

Teorema 3.6 (Bhattacharyya et al [3]). O modelo de HK com opinião multidimensional (como na Equação (3.16)) converge em tempo $O\left(n^{10} d^{2}\right)$.

\subsection{Limites de confiança heterogêneos}

Lorenz [44] estudou os modelos de Hegselmann-Krause e de Deffuant-Weisbuch (abordado no próximo capítulo) com limites de confiança heterogêneos, ou seja, quando nem todos os agentes possuem o mesmo parâmetro. Mais precisamente, consideraram-se dois tipos de agentes: aqueles com mente aberta e os com mente fechada, cada um dos grupos com um valor em comum para o limite de confiança. A análise é realizada por meio de simulações e exemplos.

Primeiramente se considera um conjunto de agentes com $n=300$ separado em dois grupos: 150 agentes de mente fechada, $\operatorname{com} \varepsilon=0,11$, e 150 agentes de mente aberta, com $\varepsilon=0,19$. As opiniões iniciais são uniformes em [0,1]. Lorenz [42] já havia chegado a evidências de que o limite de confiança crítico para o modelo de HK é aproximadamente 0,19, mas tal resultado havia sido obtido por meio da abordagem baseada na densidade e, em simulações, o consenso só era atingido para distribuições com um número muito grande de classes e muito uniformes. Na simulação realizada com o modelo homogêneo baseado no agente, com 300 agentes e $\varepsilon=0,19$, não foi atingido o consenso. No entanto, o consenso é alcançado para o modelo heterogêneo, mas com o "custo" de uma opinião final ligeiramente deslocada do centro, em torno de 0,4 . 
Outra simulação foi produzida com 45 agentes de mente fechada e 5 de mente aberta. Os limites de confiança para os grupos são, respectivamente, 0,1 e 0,3. Também aqui foi atingido o consenso, e desta vez a distância final até o centro é maior do que no caso anterior. A opinião final ficou em torno de 0,2 .

Kou et al [31] procederam de forma semelhante. Em todas as simulações, as opiniões iniciais são distribuídas uniformemente em [0,1], e o número total de agentes é $n=200$. Primeiramente, consideram apenas agentes de mente fechada, com limite de confiança muito pequeno $-\varepsilon=0,01$. O perfil final de opiniões resulta fragmentado em 39 grupos, cada um com uma opinião. Quando o limite de confiança homogêneo aumenta para $\varepsilon=0,15$, emerge um padrão de polarização, com 2 opiniões finais. Para $\varepsilon=0,245$, todos os agentes chegam ao consenso. Os resultados evidenciam o raciocínio intuitivo de que, no modelo homogêneo, quanto maior o limite de confiança, maior a probabilidade de obter consenso e menos clusters serão formados. "Um grande número de simulações" indicou que o número final de clusters é uma função não decrescente do parâmetro $\varepsilon$ e que, para um dado grupo social, existe um limite inferior $\varepsilon^{*}$ tal que, para $\varepsilon \geq \varepsilon^{*}$, o perfil de opiniões final é um consenso.

Os autores também simularam o modelo variando três fatores chave: a heterogeneidade dos níveis de confiança, a distribuição inicial das opiniões e o número de agentes. Em todos esses casos, consideraram-se limites de confiança heterogêneos. A fração de agentes de mente fechada corresponde a $\alpha$.

Primeiramente, empregaram-se várias alocações dos agentes quanto aos limites de confiança (em cada caso, $\varepsilon^{(1)}=0,01 ; \varepsilon^{(2)}=0,2$ e $\varepsilon^{(3)}=0,45$, respectivamente), mantendo a quantidade de agentes de mente aberta constante: $(1 \%, 79 \%, 20 \%) ;(2 \%, 78 \%, 20 \%)$; $(5 \%, 75 \%, 20 \%) ;(10 \%, 70 \%, 20 \%)$ e $(30 \%, 50 \%, 20 \%)$. As opiniões iniciais tiveram distribuição uniforme em $[0,1]$ e os mesmos valores foram usados em todas as simulações descritas neste e no próximo parágrafo. Para $\alpha=1 \%$ e $\alpha=2 \%$, houve consenso. Já para $\alpha>2 \%$ ocorreu fragmentação, com o número de opiniões finais aumentando à medida que se aumentava $\alpha$. Parece haver, então, um valor crítico $\alpha^{*}$ tal que, para $\alpha \leq \alpha^{*}$, existe consenso e, para $\alpha>\alpha^{*}$, dá-se a fragmentação. Além disso, nos casos de consenso, a opinião final aproxima-se da opinião inicial do agente de mente fechada mais extremista.

Num segundo momento, fixou-se $\alpha$ e variou-se a fração de agentes de mente aberta. Foram consideradas as seguintes configurações: $(10 \%, 70 \%, 20 \%) ;(10 \%, 50 \%, 40 \%)$; $(10 \%, 20 \%, 70 \%)$. Ainda que, coerentemente com o exposto acima, não se tenha chegado a consenso, à medida que se aumenta a fração de agentes de mente aberta, a taxa de convergência dos agentes moderados e dos de mente aberta também sobe.

Quanto à influência das opiniões iniciais, Kou et al [31] apenas restringem o intervalo do espaço de opiniões iniciais. Com $n=200, \varepsilon^{(1)}=0,01, \varepsilon^{(2)}=0,2$ e $\varepsilon^{(3)}=0,45$, procedem a duas simulações: a primeira com $5 \%, 70 \%$ e $25 \%$ dos agentes em cada um dos grupos, e a segunda com 10\%, $70 \%$ e 20\%, respectivamente. No primeiro caso, mesmo com 10 agentes de mente fechada, a população chega ao consenso em virtude das pequenas diferenças nas opiniões iniciais. No segundo, a maior quantidade de agentes de mente fechada leva à fragmentação (ausência de consenso).

Para avaliar o efeito do número de agentes, estabeleceram-se três níveis de confiança: $5 \%$ dos agentes com $\varepsilon^{(1)}=0,01,75 \% \operatorname{com} \varepsilon^{(2)}=0,2$ e $20 \% \operatorname{com} \varepsilon^{(3)}=0,45$. Foram utilizados os seguintes tamanhos para a população: $n=20,40, \ldots, 300,400,500,600,800,1000$. Realizaram-se 100 simulações com cada valor de $n$ e calculou-se a média dos números de opiniões finais para cada caso. Observou-se que o número médio de opiniões finais cresce a uma taxa constante a partir de um certo tamanho crítico $n_{0}$, e essa taxa é igual 
à proporção de agentes de mente fechada. Ou seja, temos a seguinte relação:

Número médio de opiniões finais $=\alpha n, n>n_{0}$.

\subsection{Outros tipos de média}

Um questionamento natural seria o comportamento do processo no caso em que, em vez da dinâmica descrita na Equação (3.4), tivéssemos outros tipos de média como atualização de opiniões, isto é,

$$
x_{i}(t+1)=M(i, \boldsymbol{x}(t)) \text { para } t=0,1,2, \ldots
$$

em que $M(i, \boldsymbol{x}(t))$ denota qualquer média tomada sobre os $x_{j}(t)$ tais que $j \in I(i, \boldsymbol{x}(t))$.

Esse problema foi abordado por Hegselmann e Krause [28]. Primeiramente, são citados alguns tipos de médias. Dado um conjunto de dados $a_{1}, \ldots, a_{n}$, podemos calcular, por exemplo:

$$
\begin{array}{ll}
\text { Média aritmética } & A\left(a_{1}, \ldots, a_{n}\right)=\frac{1}{n}\left(a_{1}+\ldots+a_{n}\right) \\
\text { Média geométrica } & G\left(a_{1}, \ldots, a_{n}\right)=\sqrt[n]{a_{1} \ldots a_{n}} \\
\text { Média harmônica } & H\left(a_{1}, \ldots, a_{n}\right)=\frac{n}{\frac{1}{a_{1}}+\ldots+\frac{1}{a_{n}}} \\
\text { Média potencial (ou de Hölder) } & \\
\text { com parâmetro } \mathbf{p} \neq \mathbf{0} & P_{p}\left(a_{1}, \ldots, a_{n}\right)=\left[\frac{1}{n}\left(a_{1}^{p}+\ldots+a_{n}^{p}\right)\right]^{\frac{1}{p}}
\end{array}
$$

As médias acima são denominadas médias concretas (em oposição às médias abstratas, definidas mais adiante). Observemos que as três primeiras média são casos particulares da média potencial:

$$
A=P_{1}, H=P_{-1} \text { e } G=\lim _{p \rightarrow 0} P_{p}=: P_{0} .
$$

Também podemos estabelecer as desigualdades clássicas

$$
H \leq G \leq A \leq P_{p} \text { para todo } p \geq 1 \text {. }
$$

Além disso, temos as seguintes desigualdades sanduíche para todos os tipos de média acima:

$$
\min \left\{a_{1}, \ldots, a_{n}\right\} \leq M\left(a_{1}, \ldots, a_{n}\right) \leq \max \left\{a_{1}, \ldots, a_{n}\right\}
$$

Também são válidas as seguintes igualdades:

$$
\begin{aligned}
\min \left\{a_{1}, \ldots, a_{n}\right\} & =\lim _{p \rightarrow-\infty} P_{p}\left(a_{1}, \ldots, a_{n}\right)=: P_{-\infty} \\
\max \left\{a_{1}, \ldots, a_{n}\right\} & =\lim _{p \rightarrow \infty} P_{p}\left(a_{1}, \ldots, a_{n}\right)=: P_{\infty}
\end{aligned}
$$

Assim, ao juntar (3.18), (3.19), (3.20) e (3.21), chega-se a

$$
P_{-\infty} \leq P_{-1} \leq P_{0} \leq P_{1} \leq P_{p} \leq P_{\infty} \text { para } p \geq 1
$$

E pode-se ir mais além, com a desigualdade fundamental

$$
P_{p, w} \leq P_{q, w} \text { para todo } p \leq q \text { e } \boldsymbol{w}=\left(w_{1}, \ldots, w_{n}\right),
$$

em que $w_{1}, \ldots, w_{n}$ são pesos não negativos, $w_{1}+\ldots+w_{n}=1$, e $P_{p, w}\left(a_{1}, \ldots, a_{n}\right)=\left(w_{1} a_{1}^{p}+\right.$ $\left.\ldots+w_{n} a_{n}^{p}\right)^{\frac{1}{p}}$. 
Também se pode construir novas médias mistas a partir de médias já existentes, como, por exemplo, a média heroniana: $M H(a, b)=\frac{1}{3}(a+b+\sqrt{a b})$. E, de uma forma mais geral, poderíamos utilizar a definição de média abstrata (Borwein e Borwein [6]), a qual corresponde a uma função $M\left(a_{1}, \ldots, a_{n}\right)$, que depende continuamente dos números $a_{i}>0$ e satisfaz as desigualdades sanduíche. A média abstrata é dita estrita se as desigualdades sanduíche forem estritas para $a_{i}$ 's não todos iguais.

No que diz respeito à dinâmica de opiniões, a média que determina a opinião atualizada do agente $i$ é calculada tendo como base apenas os valores das opiniões dos agentes que estão no conjunto de confiança do agente $i$, ou seja, $I=\left\{j:\left|a_{i}-a_{j}\right|<\varepsilon_{i}\right\}$, sendo $a_{i}$ e $a_{j}$ as opiniões dos agentes $i$ e $j$, respectivamente. Assim, generalizando a Equação (3.4), teríamos

$$
x_{i}(t+1)=M(i, \boldsymbol{x}(t)),
$$

em que $M(i, \boldsymbol{x}(t))$ é uma média arbitrária que satisfaz as desigualdades sanduíche:

$$
\min \left\{x_{j}(t): j \in I(i, \boldsymbol{x}(t))\right\} \leq M(i, \boldsymbol{x}(t)) \leq \max \left\{x_{j}(t): j \in I(i, \boldsymbol{x}(t))\right\} .
$$

Hegselmann e Krause [28] estudaram por meio de simulações o comportamento do sistema de acordo com os diferentes tipos de médias - aritmética $(\mathrm{A})$, geométrica $(\mathrm{G})$, harmônica $(\mathrm{H})$, potencial (P) e aleatória (R, de random, "aleatório" em inglês). As quatro primeiras foram definidas acima. Na média aleatória, por sua vez, se ainda não há consenso, o agente $i$ seleciona, na etapa $t+1$, de maneira aleatória, uma opinião estritamente entre $\min \left\{x_{i}(t): 1 \leq i \leq n\right\}$ e $\max \left\{x_{i}(t): 1 \leq i \leq n\right\}$; se já houver consenso, todas as opiniões permanecem inalteradas.

Para as simulações, foram observados os seguintes procedimentos:

(i) Intervalos de confiança homogêneos $\left(\varepsilon_{1}=\ldots=\varepsilon_{n}=\varepsilon\right)$ e simétricos (mesmo comprimento à esquerda e à direita).

(ii) Opiniões contínuas e unidimensionais no intervalo $[0,1]$.

(iii) Parâmetro $\varepsilon$ é incrementado, de forma gradual: $0 ; 0,01 ; 0,02 ; 0,03 ; \ldots ; 0,4$. Os autores observam que não há nenhum comportamento novo ou interessante para $\varepsilon>0,4$, isto é, o comportamento do processo é o mesmo para $\varepsilon=0,4$ e $\varepsilon>0,4$.

(iv) Para cada um dos 41 valores de $\varepsilon$ acima, repete-se a simulação 50 vezes - sempre sorteando, a cada vez, os valores iniciais das opiniões. Cada execução continua até que a dinâmica fique estável.

(v) Inicia-se sempre com uma amostra i.i.d. de 625 opiniões distribuídas uniformemente no intervalo $[0,1]$.

(vi) Atualizações simultâneas.

Considerando as frequências relativas médias em cada um dos intervalos $[0 ; 0,01]$, $(0,01 ; 0,02], \ldots,(0,99 ; 1]$, temos os seguintes resultados:

- Para coeficientes de confiança muito pequenos $(\varepsilon \leq 0,04)$, encontramos uma pequena fração das opiniões em cada intervalo do espaço de opinião. (Pluralidade $=$ várias opiniõe sobrevivem)

- Para valores maiores de $\varepsilon$ (aproximadamente entre 0,18 e 0,20 ), à medida que se aumentam os coeficientes de confiança, a distribuição média das frequências relativas estabilizadas torna-se cada vez menos uniforme. "Montanhas" de alturas crescentes emergem à esquerda e à direita do centro. (Polarização = apenas duas opiniões sobrevivem) 
- Aproximadamente a partir de $\varepsilon=0,25$, as "montanhas" à direita e à esquerda desaparecem abruptamente, e surge uma "montanha" bastante alta ao meio. Exceto no centro, quase todos os intervalos de opinião são vazios, e as correspondentes opiniões são eliminadas. (Consenso $=$ exatamente uma opinião sobrevive)

Ao analisarem outros tipos de médias, Hegselmann e Krause [28] continuam utilizando atualizações simultâneas, número de agentes igual a 625 e número de possíveis valores de $\varepsilon$ (começando de 0) igual a 41 - exceto para a média harmônica, para a qual se fizeram simulações com valores de $\varepsilon$ variando até 1 . Para procurar ter evidências do efeito do tipo de média, foram realizadas simulações com cinco tipos de médias: aritmética $(A)$, geométrica $(G)$, harmônica $(H)$, potencial $(P)$ e aleatória $(R)$. No caso da média potencial, foram rodadas simulações com os valores de expoentes 0,01 e 100. Para a média harmônica, o espaço de opiniões foi reduzido para ]0,1[ uma vez que tal tipo de média não é definido para opiniões iguais a zero. Para $A, G, H, P_{0,01}$ e $P_{100}$, o tamanho do passo foi 0,01 . Para a média aleatória, 0,001 .

Os resultados das simulações sugerem as seguintes observações:

1. Para todas as médias, o número de classes ocupadas diminui exponencialmente. As simulações ilustram a existência de um valor mínimo $\varepsilon^{*}$ do coeficiente de confiança a partir do qual inevitavelmente ocorre consenso e sugerem a seguinte ordem:

$$
\varepsilon^{*}(R)<\varepsilon^{*}\left(P_{100}\right)<\varepsilon^{*}(A)<\varepsilon^{*}(G) \approx \varepsilon^{*}\left(P_{0,01}\right)<\varepsilon^{*}(H),
$$

o que corresponde à ordem inversa em relação a (3.22).

2. A, $G, H$ e $P_{0,01}$ possuem regiões de polarização, ou seja, intervalos para o coeficiente de confiança tais que ocorre polarização, isto é, a existência de duas opiniões no fim do processo.

3. Para as médias $P_{100}$ e $R$, parece não haver essa região de polarização.

4. A polarização nos casos de $A, G$ e $P_{0,01}$ difere do caso da média harmônica. Nos primeiros três casos, um conjunto de agentes reside significativamente à esquerda e outro, significativamente à direita do centro. Quando se trata de média harmônica, um grupo localiza-se pouco à direita do centro, e outro, muito à esquerda. Isso se deve ao fato de, na média harmônica, os valores pequenos terem muito mais influência do que os grandes sobre o resultado da média.

5. Pode-se demonstrar que o tempo de estabilização para as médias $A, G, H, P_{0,01}$ e $P_{100}$ é finito. Nas simulações, observa-se que ele é bastante pequeno - geralmente, menos de 20 passos. Em geral, $R$ é muito mais lenta, em termos de convergência, que as outras médias.

Além das ponderações acima, baseadas em simulações, Hegselmann e Krause [28] também apresentam resultados analíticos. Antes de apresentá-los, porém, é necessário introduzir algumas definições. Seja $\boldsymbol{f}(\boldsymbol{x})=\left(f_{1}(\boldsymbol{x}), \ldots, f_{n}(\boldsymbol{x})\right)$ um automapeamento de $K$, o conjunto de todos os perfis de opinião, isto é, o conjuntos de todas as $n$-uplas $\boldsymbol{x}=\left(x_{1}, \ldots, x_{n}\right)$ com $x_{i}>0$ para todo $i$. Ao automapeamento $\boldsymbol{f}$ chamamos média parcial abstrata (MPA) se vale que

$$
\min \left\{x_{j} \mid j \in I(i, \boldsymbol{x})\right\} \leq f_{i}(\boldsymbol{x}) \leq \max \left\{x_{j} \mid j \in I(i, \boldsymbol{x})\right\}
$$

Considere um subconjunto não vazio qualquer $J$ de $I$ e qualquer $\boldsymbol{x} \in K$. $J$ é dito absorvente para $\boldsymbol{x}$ se $i \in J$ implicar $I(i, \boldsymbol{x}) \subset J$. O perfil $\boldsymbol{x}$ é um consenso em $J$ se 
os $x_{j}$ para $j \in J$ forem todos iguais. Além disso, uma MPA é chamada niveladora se existir um nível $\delta>0$ tal que, para quaisquer $J \subset I$ e $\boldsymbol{x} \in K$ com $J$ absorvente para $\boldsymbol{x}$ e $\left|x_{i}-x_{j}\right|<\delta$ para todo $i, j \in J$, seguir que $f(\boldsymbol{x})$ é um consenso em $J$. Por fim, no caso em que a confiança não é limitada, isto é, $I(i, \boldsymbol{x})=\underline{n}$ para todo $i \in \underline{n}$ e todo $\boldsymbol{x}$, teremos uma média abstrata global.

Com essas definições em mente, segue um teorema sobre condições para convergência das opiniões de cada agente.

Teorema 3.7 (Teorema sobre a estabilização de opinião (Hegselmann e Krause [28])). Seja $\boldsymbol{f}$ uma MPA com conjuntos de confiança $I(i, \boldsymbol{x})$ dados por algum nível de confiança $\varepsilon>0$ fixado, e sejam $\boldsymbol{x} \in K, \boldsymbol{x}(t)=\boldsymbol{f}^{t}(\boldsymbol{x}(t-1))$ para todo $t \in T$. Então, podemos reordenar as coordenadas de $\boldsymbol{x}(t)$ de tal modo que existam números naturais $1=n_{0}<$ $n_{1}<n_{2}<\ldots<n_{k}<n_{k+1}=n+1$ e números reais positivos $c_{j}$ para $j \in\{0,1, \ldots, k\}$ tais que $\lim _{t \rightarrow \infty} x_{i}(t)=c_{j}$ para todo $j \in\{0,1, \ldots, k\}, i \in\left\{n_{j}, \ldots, n_{j+1}-1\right\}$. Em outras palavras, os agentes serão particionados de forma que as opiniões dos agentes de cada grupo convirjam para um número real distinto das opiniões-limite dos outros grupos.

Se, ademais, $\boldsymbol{f}$ for uma MPA niveladora, então esse padrão estável de opinião será atingido em tempo finito.

A cada etapa, cada cadeia $\varepsilon$ se mantém ou se quebra em duas ou mais cadeias. Como o número de agentes é finito, o número de quebras também é finito e, portanto, haverá também um tempo finito a partir do qual não haverá mais rupturas. As opiniões de cada uma dessas cadeias $\varepsilon$ convergirão para um determinado valor. Dessa forma, se $J$ for um desses grupos, então haverá $c_{j}$ tal que $\lim _{t \rightarrow \infty} x_{i}(t)=c_{j}$ para todo $i \in J$. Logo, também existirá $\bar{t} \in \mathbb{N}_{0}$ tal que $\left|x_{i}(t)-x_{j}(t)\right|<\delta$ para todos $i, j \in J$ e todo $t \geq \bar{t}-1$. Assim, no caso de MPA niveladora, $\boldsymbol{x}(t+1)=f(\boldsymbol{x}(t))$ será um consenso em $J$ para $t \geq \bar{t}-1$.

Por último, o seguinte teorema, exposto em forma de corolário, estabelece a ocorrência de consenso para o processo de HK com médias abstratas globais ou locais.

Teorema 3.8 (Hegselmann e Krause [28]). No processo de HK homogêneo:

(i) para toda MPA $f$ e todo perfil inicial $\boldsymbol{x} \in K$, existe um valor crítico do limite de confiança, $\varepsilon^{*}=\varepsilon^{*}(f, x) \geq 0$, tal que $\boldsymbol{x}(t)=f^{t}(\boldsymbol{x})$ se aproxima de um consenso, para conjuntos de confiança $I(i, \boldsymbol{x})=\left\{j \in I:\left|x_{i}-x_{j}\right| \leq \varepsilon\right\}$;

(ii) para uma média abstrata global e qualquer perfil inicial, $\boldsymbol{x}(t)$ sempre se aproxima de um consenso.

\subsection{Outros grafos}

Ao longo de todo este capítulo, quando se omite o grafo que une os agentes, estamos supondo um grafo completo, isto é, todos agentes mantêm contato uns com os outros e podem atualizar suas opiniões com base na opinião dos demais. Entretanto, nada nos impede de considerar outros tipos de grafos, dispondo os agentes em configurações tais que, a cada etapa, eles podem atualizar suas opiniões com base apenas nas opiniões de seus vizinhos no grafo - que não difiram das suas por mais que seu nível de confiança, claro. Tal abordagem foi considerada por Fortunato [16].

Adota-se aí um grafo $G$ e realiza-se repetidamente uma varredura ordenada por todo o grafo. Vale ressaltar que um outro método seria a escolha aleatória, em cada passo, do 
agente a ter a opinião atualizada. Esse outro método poderia alterar a probabilidade de conenso.

Seja $I(i, \boldsymbol{x})$ o conjunto dos vizinhos de $i$ cuja opinião não difere de $x_{i}$ por mais de $\varepsilon_{i}$, ou seja,

$$
I_{G}(i, \boldsymbol{x})=\left\{j \in \underline{n}: j \sim i \text { e }\left|x_{i}-x_{j}\right| \leq \varepsilon_{i}\right\} .
$$

Na vez do vértice $i$, no passo $t+1$, sua nova opinião será dada pela seguinte regra:

$$
x_{i}(t+1)=\frac{1}{\left|I_{G}(i, \boldsymbol{x}(t))\right|} \sum_{j \in I_{G}(i, \boldsymbol{x}(t))} x_{j}(t)
$$

Os grafos estudados por Fortunato [16] foram os seguintes:

- um grafo completo;

- um reticulado quadrado;

- um grafo livre de escala à la Barabási-Albert;

- um grafo aleatório à la Erdős-Rényi;

- um grafo em forma de estrela em que um dos vértices está conecatado a todos os demais, e não há mais conexões.

Para estimar a probabilidade de consenso para cada grafo, adotou-se o seguinte procedimento: para cada combinação de $n$ e $\varepsilon$, obtiveram-se 1000 configurações. A fração dessas configurações em que houve consenso constitui a estimativa da probabilidade $P_{c}$ de consenso completo como função de $\varepsilon$.

O primeiro tipo de grafo analisado é o grafo completo. Vê-se que, quando aumenta o número de agentes, o gráfico aproxima-se da forma de uma função escada, sugerindo a existência de um valor crítico do limite de confiança, o qual parece encontrar-se no intervalo $[0,195 ; 0,202]$.

No reticulado quadrado com condições de fronteira periódicas (como num toro), também se observa a aproximação do gráfico em direção a uma função escada, mas desta vez o limite de confiança crítico parece ser $1 / 2$, o que contrasta com os valores obtidos para o grafo completo e evidencia que o valor crítico não é universal para todos os grafos.

Também realizamos simulações para o grafo completo e o reticulado quadrado. Porém, ao contrário da varredura sequencial adotada por Fortunato [16], sorteamos a cada etapa o elo cujos vértices poderiam ter as opiniões atualizadas. Os gráficos resultantes encontramse nas Figuras 3.4 e 3.5 e corroboram as simulações de Fortunato [16]. Foram realizadas 100 repetições para cada valor de $n$ empregado.

O grafo subsequente é o livre de escala à la Barabási-Albert, construído como segue. Inicia-se com um grafo completo de $m$ vértices. A cada iteração, um novo vértice é adicionado, e $m$ vértices são construídos entre o novo vértice e os antigos de modo que a probabilidade de conexão a algum vértice antigo $i$ seja proporcional ao grau de $i$. O procedimento é repetido até que se atinja o número desejado de vértices - mais precisamente, $n$, o número de agentes. Quanto ao gráfico das probabilidades de consenso estimadas por Fortunato [16], ele apresenta o mesmo padrão observado para o reticulado quadrado. Em comum os dois grafos possuem o fato de terem grau médio finito (igual a 4 para o reticulado e $2 m$ para o grafo à la Barabási-Albert), levando à seguinte conjectura:

Conjectura 3.1 (Fortunato [16]). Há apenas dois valores possíveis para o valor crítico do limite de confiança $\varepsilon^{*}$ no modelo de Hegselmann-Krause: se o grau médio d do grafo permanecer finito à medida que $n$ diverge, então $\varepsilon^{*}=1 / 2$; caso contrário, $\varepsilon^{*} \approx 0,2$. 
Modelo de HK, opiniões iniciais i.i.d. U(0, 1), grafo completo

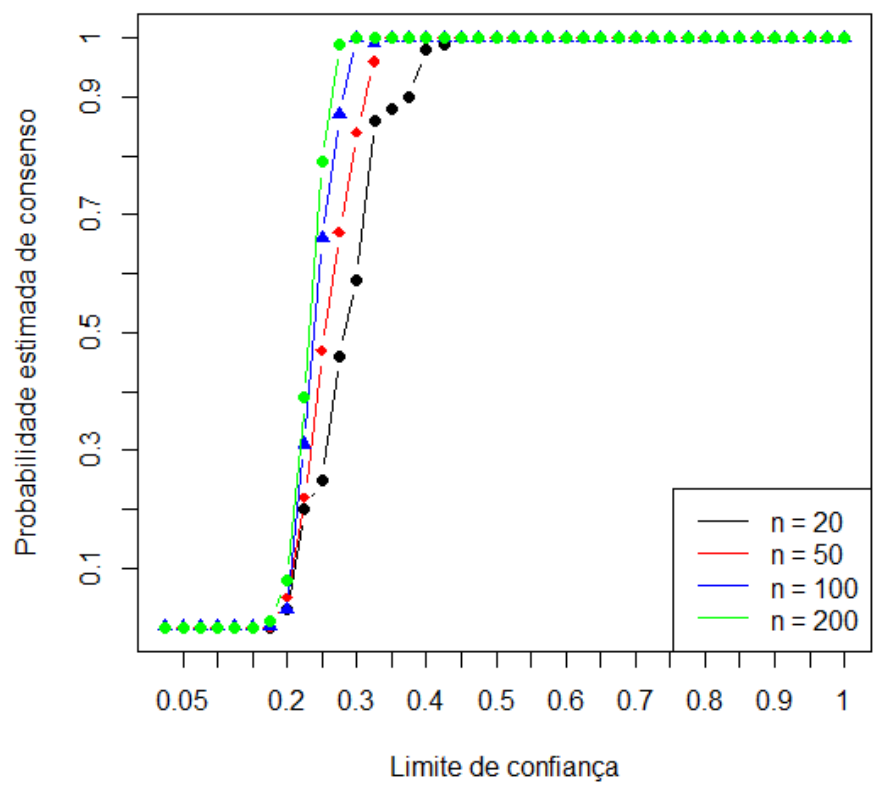

Figura 3.4: Simulação do modelo de Hegselmann-Krause no grafo completo

Modelo de HK, opiniões iniciais i.i.d. U(0, 1), grafo reticulado quadrado

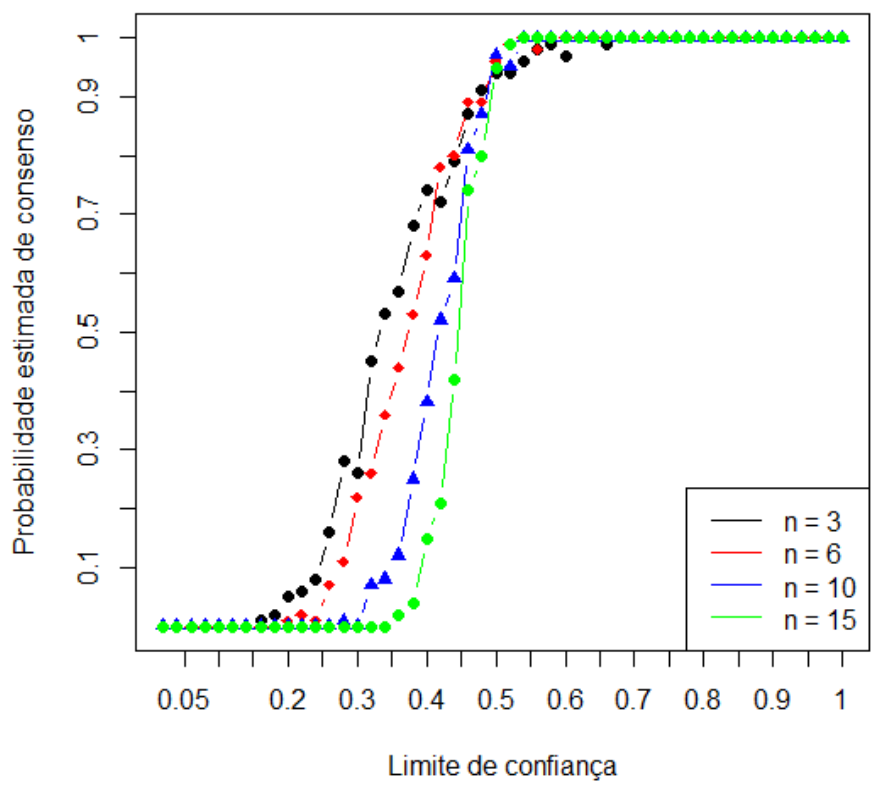

Figura 3.5: Simulação do modelo de Hegselmann-Krause no grafo reticulado quadrado com condições de fronteira periódicas 
Para coletar mais evidências da propriedade acima, seria ideal passar suavemente da classe de grafos com grau finito $\left(\mathcal{G}_{F}\right)$ para a classe de grafos com grau infinito $\left(\mathcal{G}_{I}\right)$. Um tipo de grafo propício a esse "teste" seria, então, o grafo aleatório de Erdős-Rényi, no qual cada um dos $n$ vértices tem probabilidade $p$ de estar conectado a cada um dos demais vértices. Dessa forma, o número total de elos é $p n(n-1) / 2$, e o grau médio é $d=p(n-1)$, aproximado por $p n$ quando $n \longrightarrow \infty$. Se fixarmos $p>0$ e fizermos $n \longrightarrow \infty$, então $d=p(n-1) \longrightarrow \infty$, e os grafos pertencerão a $\mathcal{G}_{I}$. Por outro lado, se $p \longrightarrow 0$ quando $n \longrightarrow \infty$ de modo que $p(n-1)$ se mantenha constante, então $d$ será finito, e os grafos pertencerão a $\mathcal{G}_{F}$.

Nas simulações, mantendo pn constante igual a 2 quando $n$ aumenta, percebemos que o gráfico se aproxima daquele de uma função escada com descontinuidade em $1 / 2$ quando $n \longrightarrow \infty$, comportamento característico de grafos em $\mathcal{G}_{F}$. No entanto, quando se fixa $p=0,002$ e se deixa $p n$ aumentar de acordo $\operatorname{com} n$, a variação de $P_{c}$ fica cada vez mais íngreme. Para $n=50.000$, a estimativa de $P_{c}$ é aproximadamente zero para $\varepsilon=0,194 \mathrm{e}$ aproximadamente 1 para $\varepsilon=0,202$, em concordância, portanto, com os resultados para o grafo completo.

Um resultado substancialmente diferente de todos acima, porém, observa-se quando o grafo é em forma de estrela. Aqui não se tem mais a convergência para uma função escada. Pode-se mostrar que, para o caso teórico com infinitos agentes, a probabilidade de consenso em função do nível de confiança fica

$$
P_{c}(\varepsilon)= \begin{cases}0 & \text { para } \varepsilon<1 / 2 \\ 6 \varepsilon-3 & \text { para } 1 / 2 \leq \varepsilon \leq 1 \\ 1 & \text { para } \varepsilon>1\end{cases}
$$

Com $n=1.000$ e $n=10.000$, já se observa nitidamente o comportamento descrito acima.

\subsection{Modelo hierárquico}

Uma variação do modelo original de Hegselmann-Krause foi estudada por Dittmer [12]. Trata-se do modelo hierárquico de confiança limitada. Para que se entenda o modelo, faz-se necessário expor, primeiramente, o conceito de hierarquia neste contexto.

Definição 3.3. Uma hierarquia $\mathcal{H}$ entre $n$ agentes é um conjunto ordenado de subconjuntos desses agentes formando uma partição de $\underline{n}$. Tais subconjuntos são denominados grupos $h$.

No que segue, o grupo $h$ máximo será denotado por $M$. Se o agente $i$ estiver num grupo $h$ superior ao do agente $j$, dizemos que $i$ é um ídolo de $j$.

Uma matriz de hierarquia $A$ é uma matriz de confiança que satisfaz as seguintes condições.

- Todos os agentes - exceto os agentes de $M$ - devem ter ao menos um ídolo.

- Todos os agentes de grupos $h$ superiores a um dado grupo são ídolos desse grupo.

- Cada agente confia apenas nos agentes de grupos $h$ superiores e nos agentes de seu próprio grupo.

- $A$ é uma matriz estocástica (por linhas). 
- Cada agente tem confiança positiva em si mesmo.

- Os agentes de um grupo $h$ confiam uns nos outros de acordo com um modelo de confiança limitada local.

Para efeito de clareza, vamos exemplificar. Suponhamos que temos um conjunto total de agentes $\{1, \ldots, 12\}$ e três grupos $h: G_{1}=\{1,2,3\}, G_{2}=\{4,5,6\}$ e $G_{3}=$ $\{7,8,9,10,11,12\}$. Consideremos ainda que $G_{1}$ é o grupo $h$ superior, isto é, $M=G_{1}$; que $G_{2}$ é inferior a $G_{1}$, e $G_{3}$ é inferior a $G_{2}$ e $G_{1}$. Assim, o esboço de um exemplo de matriz de hierarquia é

\begin{tabular}{|c|c|c|c|}
\hline \multirow{8}{*}{$A=$} & $\begin{array}{c}\text { Modelo local } \\
\text { de confiança } \\
\text { limitada }\end{array}$ & 0 & 0 \\
\hline & $\begin{array}{lll}\frac{1}{4} & 0 & 0 \\
\frac{1}{8} & \frac{1}{8} & 0 \\
0 & 0 & \frac{1}{2}\end{array}$ & $\begin{array}{c}\text { Modelo local } \\
\text { de confiança } \\
\text { limitada escalado }\end{array}$ & 0 \\
\hline & $\begin{array}{lll}0 & 0 & 0\end{array}$ & $0 \quad 0 \quad \frac{1}{3}$ & \\
\hline & $\begin{array}{lll}0 & 0 & 0\end{array}$ & $\begin{array}{lll}0 & 0 & \frac{1}{3}\end{array}$ & \\
\hline & $\begin{array}{lll}0 & 0 & 0\end{array}$ & $\begin{array}{lll}0 & 0 & \frac{1}{5}\end{array}$ & Modelo local \\
\hline & $\begin{array}{lll}0 & 0 & \frac{1}{4}\end{array}$ & $\begin{array}{lll}0 & 0 & 0 \\
0\end{array}$ & de confiança \\
\hline & $\begin{array}{lll}0 & \frac{1}{4} & 0\end{array}$ & $\begin{array}{lll}0 & 0 & 0\end{array}$ & \\
\hline & $\begin{array}{lll}\frac{1}{6} & 0 & 0\end{array}$ & $\begin{array}{lll}0 & 0 & 0\end{array}$ & \\
\hline
\end{tabular}

Na matriz acima, modelo local de confiança limitada é o modelo de confiança limitada (ou modelo de Hegselmann-Krause) circunscrito aos agentes desse grupo $h$. Porém, ao considerarmos todos os grupos conjuntamente, temos o modelo local de confiança limitada escalado, que corresponde ao mesmo modelo, porém com os pesos não necessariamente somando menos que 1 na horizontal para os respectivos blocos, já que parte da confiança total de cada agente pode ser direcionada a grupos $h$ hierarquicamente superiores. Observemos que os agentes foram numerados de modo que os agentes 1, 2 e 3 formassem o grupo $G_{1}=M$, os agentes 4,5 e 6 formassem o grupo $G_{2}$, e o mesmo para os integrantes de $G_{3}$. Podemos evidenciar ainda mais tal característica na seguinte notação:

$$
A=H+F(H) W(\boldsymbol{x})=A(\boldsymbol{x}, H)
$$

Na expressão acima, $H$ contém os pesos hierárquicos (atribuídos aos ídolos de cada agente) nos blocos abaixo da diagonal. $W(\boldsymbol{x})$ é uma matriz diagonal em blocos que contém os pesos, bloco a bloco, de modelos de confiança limitada convencionais. Por fim, $F(H)$ é um fator de escala para que se obtenha uma matriz $A$ estocástica por linhas. Dessa forma, podemos escrever o modelo de confiança limitada hierárquico como um sistema dinâmico discreto

$$
\boldsymbol{x}(t+1)=A\left(\boldsymbol{x}(t), H_{t}\right) \boldsymbol{x}(t)
$$

Como a existência de consenso entre todos os agentes implica o consenso em $M$, que, por sua vez, segue um modelo de confiança limitada tradicional, podemos concluir que uma condição necessária para o consenso em $\underline{n}$ é que $M$ seja sempre uma cadeia $\varepsilon$. Isso se deve ao fato de que, como visto antes, um modelo de confiança limitada atinge o consenso se e somente se o conjunto de agentes constitui uma cadeia $\varepsilon$ em todos os passos. Para que se garanta o consenso geral, pode-se incluir mais uma hipótese, como no teorema a seguir. 
Teorema 3.9 (Dittmer [12]). No modelo de confiança limitado hierárquico com n agentes, o consenso será atingido se $M$ chegar a um consenso e a seguinte condição valer:

$$
\sum_{k=0}^{\infty} \min _{i=1, \ldots, n} \sum_{j \in M}\left(A_{k}\right)_{i j}=\infty
$$

\subsection{Modelo baseado na densidade}

Em Fortunato et al [18], podemos ver um estudo brevemente analítico e mais numérico do modelo de Hegselmann-Krause baseado na densidade. A equação de taxas do modelo homogêneo em relação ao limite de confiança é dada por

$$
\frac{\partial}{\partial t} P(x, t)=\int_{0}^{1} \mathrm{~d} x_{1} P\left(x_{1}, t\right) \times\left[\delta\left(x-\frac{\int_{x_{1}-\varepsilon}^{x+\varepsilon} \mathrm{d} x^{\prime} x^{\prime} P\left(x^{\prime}, t\right)}{\int_{x_{1}-\varepsilon}^{x+\varepsilon} \mathrm{d} x^{\prime} P\left(x^{\prime}, t\right)}\right)-\delta\left(x-x_{1}\right)\right]
$$

A fim de simplificar a notação, é conveniente denotar por $\bar{x}$ a fração na equação acima. Essa quantidade é equivalente à média das opiniões dos agentes compatíveis com um agente de opinião $x_{1}$. Para que se possa ter uma interpretação física, é interessante que a população total de agentes $N(t)=\int_{0}^{1} P(x, t) \mathrm{d} x$ se mantenha constante, e podemos verificar na equação seguinte que isso verdadeiramente ocorre.

$$
\frac{\partial}{\partial t} \int_{0}^{1} \mathrm{~d} x P(x, t)=\int_{0}^{1} \int_{0}^{1} \mathrm{~d} x \mathrm{~d} x_{1} P\left(x_{1}, t\right)\left[\delta\left(x-\bar{x}\left(x_{1}, t\right)\right)-\delta\left(x-x_{1}\right)\right]
$$

Ao integrar em relação a $x$ no lado direito, percebemos que a dependência com respeito a $x$ está presente apenas nas funções $\delta$, atuando as duas em sentidos opostos de modo a se anularem.

Da mesma forma, podemos verificar que o primeiro momento também se mantém constante ao longo de todo o processo adotando um procedimento semelhante ao exposto acima:

$$
\begin{aligned}
\frac{\partial}{\partial t} \int_{0}^{1} \mathrm{~d} x x P(x, t) & =\int_{0}^{1} \int_{0}^{1} \mathrm{~d} x \mathrm{~d} x_{1} x P\left(x_{1}, t\right)\left[\delta\left(x-\bar{x}\left(x_{1}, t\right)\right)-\delta\left(x-x_{1}\right)\right] \\
& =\int_{0}^{1} \mathrm{~d} x_{1} P\left(x_{1}, t\right)\left[\bar{x}\left(x_{1}, t\right)-x_{1}\right] .
\end{aligned}
$$

Fazendo a transformação da variável $x_{1}$ para $1-x_{1}$ e observando as relações $P\left(x_{1}, t\right)=$ $P\left(1-x_{1}, t\right)$ e $\bar{x}\left(1-x_{1}, t\right)=1-\bar{x}\left(x_{1}, t\right)$, ficamos com

$$
\begin{aligned}
\int_{0}^{1} \mathrm{~d} x_{1} P\left(x_{1}, t\right)\left[\bar{x}\left(x_{1}, t\right)-x_{1}\right] & =-\int_{1}^{0} \mathrm{~d} x_{1} P\left(1-x_{1}, t\right)\left[\bar{x}\left(1-x_{1}, t\right)-\left(1-x_{1}\right)\right] \\
& =\int_{1}^{0} \mathrm{~d} x_{1} P\left(x_{1}, t\right)\left[\bar{x}\left(x_{1}, t\right)-x_{1}\right] \\
& =-\int_{0}^{1} \mathrm{~d} x_{1} P\left(x_{1}, t\right)\left[\bar{x}\left(x_{1}, t\right)-x_{1}\right] \\
\Rightarrow \int_{0}^{1} \mathrm{~d} x_{1} P\left(x_{1}, t\right)\left[\bar{x}\left(x_{1}, t\right)-x_{1}\right] & =0,
\end{aligned}
$$

que pode ser substituído na Equação (3.35) para obter o resultado desejado. Convém ressaltar que a conservação da média das opiniões também vale para o modelo de Deffuant, a ser exposto no próximo capítulo. Uma importante implicação desse resultado, para ambos os modelos, é que o consenso, caso seja atingido, será sempre na opinião média inicial. 


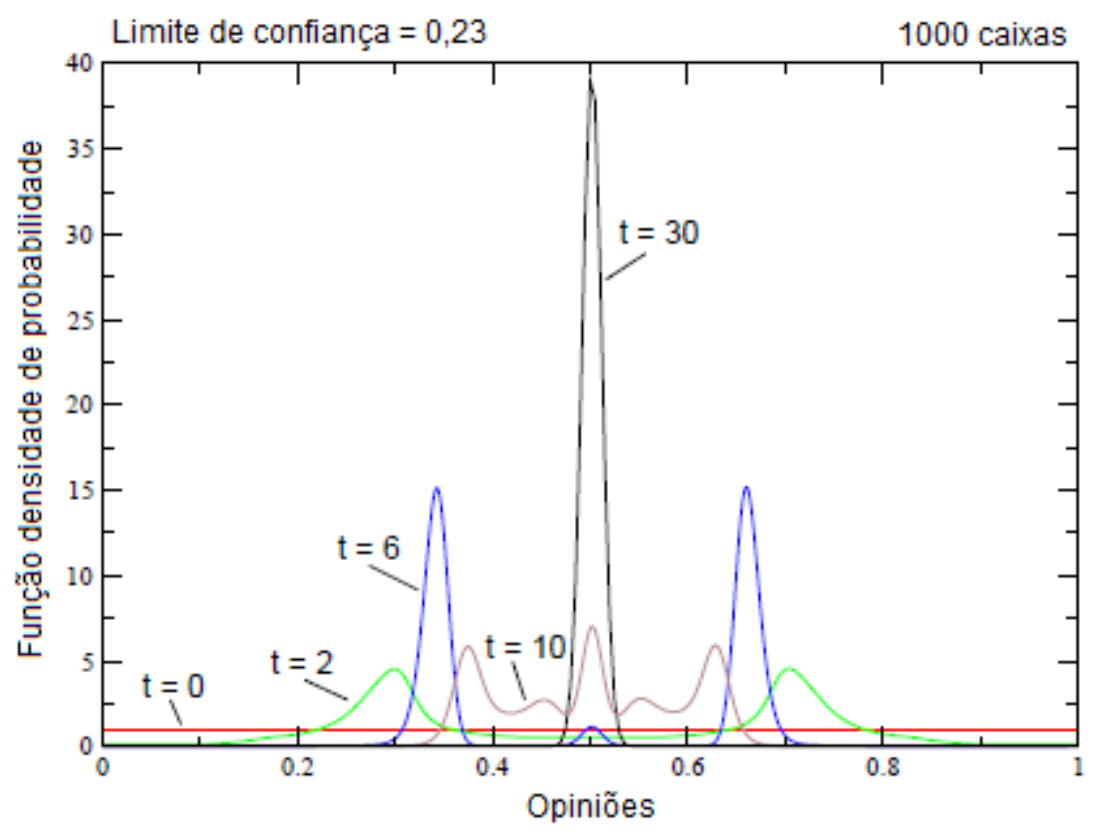

Figura 3.6: Simulação do modelo de Hegselmann-Krause baseado na densidade com $\varepsilon=0,23$

Para a simulação do modelo de Hegselmann-Krause unidimensional, Fortunato et al [18] utilizaram o algoritmo de Runge-Kutta. O espaço de opinião é o intervalo $[0,1]$, o qual foi subdividido em 1000 "caixas". Em todas as simulações, a distribuição inicial das opiniões é determinística e igual ao longo de todo o intervalo $[0,1]$, ou seja, $P(x, t=$ $0)=$ constante para todo $x \in[0,1]$. A Figura 3.6 exibe a evolução temporal do processo para $\varepsilon=0,23$. Inicialmente são formados dois clusters. Posteriormente esses dois clusters exibem uma aproximação graças a agentes com opiniões próximas ao centro e por último, após um longo tempo, é formado um único cluster centrado em 1/2. Esses agentes centrais antes do consenso funcionam como agregadores de opinião, aproximando agentes com opiniões de cada um dos lados, mesmo quando o consenso não é atingido, atuando, nesse caso, na redução do número de clusters.

Tal característica é exclusiva do modelo de Hegselmann-Krause, não se aplicando ao modelo de Deffuant, no qual, a cada iteração, apenas dois agentes interagem entre si, e por isso não há agentes intermediários. Essa é a principal razão pela qual o limite de confiança crítico no modelo de Hegselmann-Krause é inferior ao mesmo valor crítico no modelo de Deffuant. Como se nota na Figura 3.7, a estimativa para o valor crítico de Epara o modelo de Hegselmann-Krause obtida na simulação de Fortunato et al [18] é algo em torno de 0,22, enquanto para o modelo de Deffuant é algo em torno de 0,27 conforme simulações de Fortunato [17] abordadas no próximo capítulo.

\subsection{Cadeias de Markov interativas}

Nesta seção, trataremos do modelo de Hegselmann-Krause baseado na densidade - mais precisamente, o tipo de modelos a que se costuma chamar "cadeias de Markov interativas". Sejam $S \in \mathbb{R}^{d}$ um espaço de opinião, $\left[\varepsilon_{1}, \varepsilon_{2}\right]$ um intervalo de possíveis limites de confiança e a função de densidade de opiniões inicial $P(\cdot, 0, \cdot): S \times\left[\varepsilon_{1}, \varepsilon_{2}\right] \rightarrow[0, \infty]$ com $\int_{S} \int_{\varepsilon_{1}}^{\varepsilon_{2}} \mathrm{~d} x \mathrm{~d} \varepsilon P(x, 0, \varepsilon)=1$. Para simplificar a notação, abreviaremos $\int_{\varepsilon_{1}}^{\varepsilon_{2}} \mathrm{~d} \varepsilon P(x, t, \varepsilon)$ por 


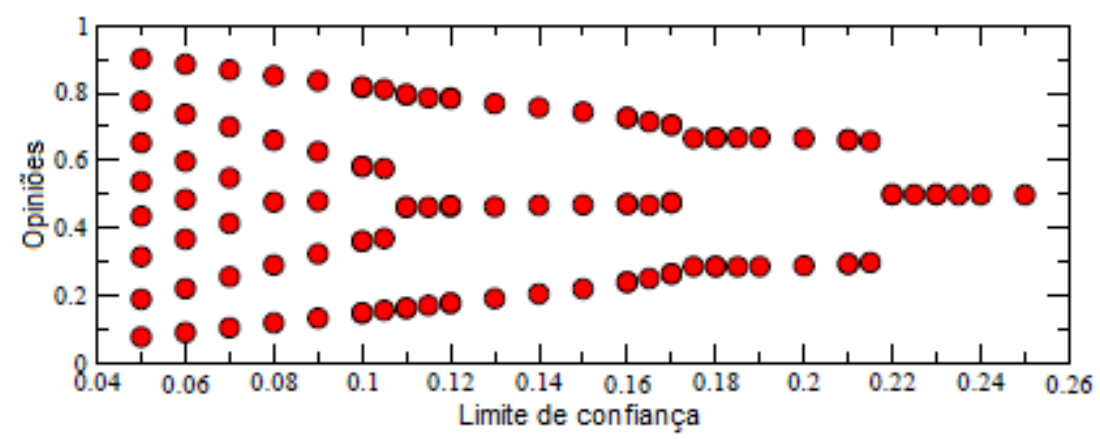

Figura 3.7: Clusters no equilíbrio para diversos valores do limite de confiança

$P(x, t)$. Seja, ainda, a média $\varepsilon$-local definida como

$$
M_{1}(x, P(\cdot, t), \varepsilon)=\frac{\int_{x-\varepsilon}^{x+\varepsilon} y P(y, t) \mathrm{d} y}{\int_{x-\varepsilon}^{x+\varepsilon} P(y, t) \mathrm{d} y} .
$$

Dessa forma, podemos definir a seguinte equação diferencial:

$$
\begin{array}{r}
\frac{\partial}{\partial t} P(x, t, \varepsilon)=\int_{S} \mathrm{~d} y\left[\left(\int_{\varepsilon_{1}}^{\varepsilon_{2}} \mathrm{~d} \bar{\varepsilon} P(y, t, \bar{\varepsilon}) \delta\left(x-M_{1}(y, P(t, \cdot), \bar{\varepsilon})\right)\right)\right. \\
\left.-P(x, t, \varepsilon) \delta\left(y-M_{1}(x, P(t, \cdot), \varepsilon)\right)\right]
\end{array}
$$

Para um limite de confiança homogêneo $\varepsilon$, a Equação (3.38) pode ser reescrita como

$$
\frac{\partial}{\partial t} P(x, t)=\int_{S}\left[\delta\left(M_{1}(y, P(\cdot, t), \varepsilon)-x\right) P(y, t)-\delta\left(M_{1}(x, P(\cdot, t), \varepsilon)-y\right) P(x, t)\right] \mathrm{d} y .
$$

O integrando acima corresponde à diferença entre a fração que passa a pertencer ao estado $x$ e a fração que deixa o estado $x$. Podemos reescrever (3.39) como

$$
\frac{\partial}{\partial t} P(x, t)=\left(\int_{\substack{y \text { é raiz de } \\ x-M_{1}(y, P(\cdot, t), \varepsilon)}} \delta(y) \frac{P(y, t)}{\left|M_{1}^{\prime}(y, P(\cdot, t), \varepsilon)\right|} \mathrm{d} y\right)-P(x, t) .
$$

Um estudo do modelo de Hegselmann-Krause baseado na densidade foi desenvolvido por Lorenz [41], o qual analisa o modelo de Hegselmann-Krause em termos de cadeias de Markov interativas. Para isso, em vez de considerar $n$ agentes no processo, vamos supor que haja uma população idealizada infinita, a qual dividiremos em $n$ classes de opiniões. Ademais, no lugar de um perfil de opinião $\boldsymbol{x}(t) \in \mathbb{R}^{n}$, adotamos uma distribuição de opinião discreta $P(t) \in S^{n}:=\left\{P \in[0,1]^{1 \times n}\right.$ com $\left.\sum_{i=1}^{n} P_{i}=1\right\}$ como o estado do sistema no passo $t \in \mathbb{N}$. Em palavras, podemos descrever $S^{n}$ como o simplex $(n-1)$ dimensional de vetores linha - ao contrário dos perfis de opinião, que são vetores coluna. Por conveniência e completude, definimos $P_{i}=0$ para todo $i \notin \underline{n}$.

As probabilidades de transição $b_{i j}(P) \in[0,1]$ são definidas como a probabilidade de um dado agente na classe de opinião $i$ passar para a classe $j$. Para todo $i \in \underline{n}$ deve valer que $\sum_{j=1}^{n} b_{i j}(P)=1$, pois, para cada $i \in \underline{n}, b_{i j}$ é uma distribuição de probabilidade. Assim, a matriz de transição $B(P)=\left[b_{i j}(p)\right]$ é estocástica por linhas. A cadeia de Markov 
interativa para uma distribuição de opiniões inicial $P(0)$ é a sequência de distribuições de opinião $(P(t))_{t \in \mathbb{N}_{0}}$ definida pela seguinte equação de recorrência:

$$
P(t+1)=P(t) B(P(t))
$$

A cadeia acima definida recebe o nome interativa porque a matriz de transição depende do estado do sistema no passo atual.

Analogamente ao coeficiente de confiança $\varepsilon$ do modelo original (contínuo), nesta formulação vamos definir um limite de confiança discreto $k \in \mathbb{N}$. Se um agente pertencer à classe de opiniões $i$, então ele só poderá ser afetado por agentes pertencentes às classes de opinião $i-k, i-k+1, \ldots, i+k-1, i+k$.

Suponhamos que o espaço de opiniões para cada agente seja o intervalo $[0,1]$ e consideremos a partição de intervalos de igual amplitude $\left[0, \frac{1}{n}\right) ;\left[\frac{1}{n}, \frac{2}{n}\right) ; \ldots ;\left[\frac{n-1}{n}, 1\right]$. Podemos, então, considerar a relação heurística $\frac{k}{n} \leftrightarrow \varepsilon$. Assim, podemos dizer que, quando $k, n \rightarrow \infty$ $\operatorname{com} \frac{k}{n} \rightarrow \varepsilon$, o sistema "converge" para um modelo baseado no agente com infinitos agentes, intervalo de opiniões $[0,1]$ e limite de confiança $\varepsilon$.

Alguns questionamentos pertinentes a este modelo são:

(i) A cadeia de Markov interativa produz o mesmo comportamento dinâmico que os modelos baseados no agente?

(ii) Que conclusões podemos tirar a partir das populações idealizadas infinitas nas cadeias de Markov para os sistemas finitos baseados em agentes?

(iii) Qual é o efeito da precisão $n$ das cadeias de Markov?

Antes de analisar as questões acima, vamos definir a cadeia de Markov interativa para o modelo de Hegselmann-Krause.

Definição 3.4. [Cadeia de Markov interativa para o modelo de Hegselmann-Krause] Sejam $p \in S^{n}$ uma distribuição de opinião e $k \in \mathbb{N}$ um limite de confiança discreto. A média $k$-local de $p$ em $i \in \underline{n}$ é

$$
M_{i}(p, k):=\frac{\sum_{m \in \underline{n},|i-m| \leq k} m p_{m}}{\sum_{m \in \underline{n},|i-m| \leq k} p_{m}} .
$$

Abreviando $M_{i}(p, k)$ por $M_{i}$, as probabilidades de transição da cadeia de Markov interativa para o processo de HK são definidas como

$$
b_{i j}(p, k):= \begin{cases}1 & \text { se } j=M_{i} ; \\ \left\lceil M_{i}\right\rceil-M_{i} & \text { se } j=\left\lfloor M_{i}\right\rfloor, j \neq M_{i} \\ M_{i}-\left\lfloor M_{i}\right\rfloor & \text { se } j=\left\lceil M_{i}\right\rceil, j \neq M_{i} \\ 0 & \text { caso contrário }\end{cases}
$$

A população com opiniões na classe $i$ vai completamente para a média de opinião $k$-local se esta for inteira. Senão, distribui-se entre as duas classes adjacentes de acordo com a proximidade das classes de opinião superior e inferior.

Definimos uma distribuição estabilizada $P^{*} \in S^{n}$ como um ponto fixo, isto é, uma distribuição tal que $P^{*}=P^{*} B\left(P^{*}\right)$. Não há apenas uma distribuição estabilizada. 


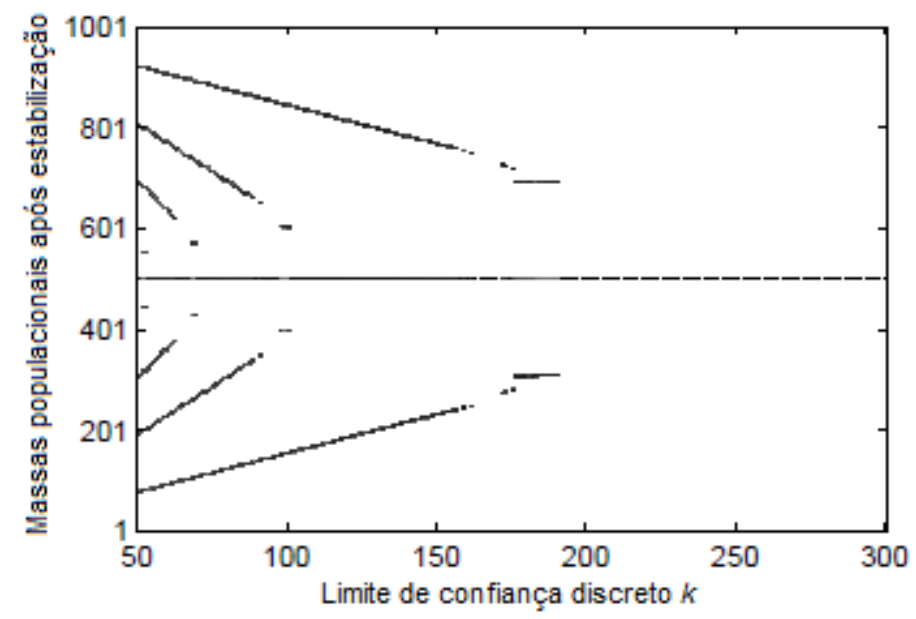

Figura 3.8: Diagrama de bifurcação para o modelo de HK.

$$
n=1001 ; k=50, \ldots, 300 \text {. }
$$

Num primeiro momento, vamos focar na distribuição inicial $P(0) \in S^{n}$ que é distribuída igualmente com $P_{1}=\ldots=P_{n}=\frac{1}{n}$. Para $n=101$, Lorenz [41] verifica por meio de simulação que a convergência se dá lentamente, o que também se observa no modelo baseado em agentes. A distribuição estabilizada, com três clusters maiores, é atingida em $t=327$. Convém lembrar que, dada a distribuição inicial, o modelo de HK é determinístico. Assim, o resultado é uma conclusão sobre o processo e não apenas uma evidência.

Com uma distribuição análoga à de $p(0)$ acima, mas com $n=1001$, realizou-se um diagrama de bifurcação para ter uma visão mais completa de como os perfis estabilizados mudam de acordo com $k$, mais precisamente $k=50,51, \ldots, 300$ - o que corresponderia a valores de $\varepsilon$ aproximadamente iguais a 0,$05 ; \ldots ; 0,3$. O termo bifurcação corresponde aqui a uma mudança abrupta no perfil estabilizado entre dois valores consecutivos do parâmetro $k$. Analisando o gráfico de $k=300$ em direção a $k=50$, na Figura 3.8, nota-se que uma bifurcação ocorre em $k=190$, dando origem a dois grandes clusters, e pouca massa permanece no cluster central. Posteriormente, para alguns valores entre aproximadamente 165 e 175, o consenso volta a dominar para depois voltarem os dois clusters exteriores. Em seguida, o que se observa repetidamente é o deslocamento dos clusters em direção aos extremos do espaço de opiniões e a formação de clusters intermediários.

Uma característica interessante para diagramas de bifurcação é o comportamento diferenciado do sistema em relação ao perfil estabilizado quando o número de classes é par ou ímpar. Um padrão que se vê com pares de $n, n+1$ é que a bifurcação de consenso para polarização ocorre antes para $n$ par (observando o gráfico da direita para a esquerda, isto é, com $k$ decrescente). Ademais, também se observa uma nítida diferença no estados metaestáveis, isto é, aqueles que parecem estáveis, com alguns clusters já formados e quase todo o restante das classes de opinião sem massa. Para $n$ ímpar, tem-se apenas um cluster central, o qual consiste de apenas uma classe de opinião. Para $n$ par, o cluster central consiste de duas classes de opinião. Tal fato torna o consenso mais fácil para $n$ ímpar, já que a massa se concentraria em apenas uma "caixa", ao contrário do caso com $n$ par, em que a massa se dividiria em duas classes e, com isso, pode ser dividida mais facilmente.

Um estudo analítico sobre os pontos fixos - distribuições $p^{*}$ tais que $p^{*}=p^{*} B\left(p^{*}, k\right)$ 
- no modelo de Hegselmann-Krause e no modelo de Deffuant-Weisbuch, estudado no capítulo seguinte, foi realizado por Lorenz [43]. Apresentamos, a seguir, seu principal teorema.

Teorema 3.10 (Lorenz [43]). Uma distribuição de opinião $P \in \Delta^{n-1} \subset \mathbb{R}^{n}$ é um ponto fixo da cadeia de Markov interativa

$$
P(t+1)=(t) B(P(t), k)
$$

com matriz de transição do modelo de $H K$ e limite de confiança discreto $k \in \mathbb{N}$ se $e$ somente se, para todo $i \in \underline{n}$, valer que

$$
P_{i}>0 \Rightarrow P_{m}=0 \text { para todo } m \in\{i-k, \ldots, i-2, i+2, \ldots, i+k\} \cap \underline{n}
$$

Em outras palavras, um ponto (configuração) será fixo se e só se houver apenas uma classe de opinião com massa positiva ou se existirem duas classes nessa condição e essas classes forem vizinhas.

\subsection{Opinião multidimensional}

A abordagem multidimensional para a opinião dos agentes foi tratada por Urbig e Malitz [54]. Os autores apontam que, por exemplo, na teoria do consumidor, este é descrito por processos cognitivos e processos ativadores. O primeiro tipo diz respeito ao processamento de informações; já o segundo guia diretamente o comportamento do indivíduo. Segundo Ajzen [1] apud Urbig e Malitz [54], uma atitude é composta de diferentes impressões, as quais, por sua vez, são compostas de dois elementos: cognições ou crenças sobre a presença de alguns atributos e avaliações desses atributos. Assim, justifica-se incluir a multidimensionalidade em modelos de dinâmica de opinião não como um conjunto de opiniões, mas como vários elementos da mesma opinião ou atitude.

Fortunato et al [18] estudaram o modelo de Hegselmann-Krause baseado na densidade incluindo opiniões multidimensionais - mais precisamente, bidimensionais. O espaço de opiniões é o quadrado $[0,1] \times[0,1]$. A distribuição das opiniões do modelo de HK em tempo contínuo é representada pela função $P((x, y), t)$, sendo $P((x, y), t) \mathrm{d} x \mathrm{~d} y$ a fração dos agentes cujas opiniões se encontram na região $[x, x+\mathrm{d} x] \times[y, y+\mathrm{d} y]$ no instante $t$, de modo que $\int_{[0,1]^{2}} P((x, y), t) \mathrm{d} x \mathrm{~d} y=1$ para todo $t \in \mathbb{N}_{0}$. A equação de taxa do modelo é

$$
\frac{\partial}{\partial t} P(\mathbf{x}, t)=\int_{0}^{1} \mathrm{~d} \mathbf{x}_{1} P\left(\mathbf{x}_{1}, t\right)\left[\delta\left(\mathbf{x}-\frac{\int_{\Omega\left(\mathbf{x}_{1}\right)} \mathrm{d} \mathbf{x}_{0} \mathbf{x}_{0} P\left(\mathbf{x}_{0}, t\right)}{\int_{\Omega\left(\mathbf{x}_{1}\right)} \mathrm{d} \mathbf{x}_{0} P\left(\mathbf{x}_{0}, t\right)}\right)-\delta\left(\mathbf{x}-\mathbf{x}_{1}\right)\right]
$$

$\mathrm{Na}$ equação acima, a integral do lado direito é uma integral múltipla $d$-dimensional, e $\delta(\mathbf{x})=\delta\left(x_{1}\right) \delta\left(x_{2}\right) \ldots \delta\left(x_{n}\right)$. No primeiro $\delta$ multidimensional, para obter o $i$-ésimo componente da razão de integrais procede-se da seguinte maneira: as integrais devem ser calculadas dentro do hipervolume $\Omega\left(\mathbf{x}_{1}\right)$ - no nosso caso, uma hipercaixa ou uma hiperesfera centrada em $\mathbf{x}_{1}$ e com lado ou diâmetro $2 \varepsilon-$; na integral do numerador, deve-se substituir o termo $\mathbf{x}_{0}$ pelo correspondente $i$-ésimo componente $x_{0 i}$.

A forma da região de confiança - isto é, o conjunto de pontos do espaço de opinião que representa as opiniões compatíveis com a de um dado agente - pode ser escolhida de forma arbitrária. Fortunato et al [18] consideram duas possibilidades para a forma da 
região de confiança: circular e quadrada. No primeiro cenário, a região de confiança do agente $i$ com opinião $x_{i}=\left(x_{i}^{(1)}, x_{i}^{(2)}\right)$ é

$$
R C\left(x_{i}\right)=\left\{y \in[0,1] \times[0,1]:\left|x_{i}^{(1)}-y_{1}\right|^{2}+\left|x_{i}^{(2)}-y_{2}\right|^{2} \leq \varepsilon\right\}
$$

No segundo, temos

$$
R Q\left(x_{i}\right)=\left\{y \in[0,1] \times[0,1]:\left|x_{i}^{(1)}-y_{1}\right| \leq \varepsilon \mathrm{e}\left|x_{i}^{(2)}-y_{2}\right| \leq \varepsilon\right\}
$$

A Equação (3.46) foi resolvida numericamente pelo integrador de Runge-Kutta de quarta ordem. As simulações foram iniciadas com uma distribuição "flat", isto é, $P((x, y), t=0)=$ constante. O espaço de opinião quadrado foi reduzido a uma grade com $100 \times 100$ compartimentos. Para $\varepsilon=0,22$, quatro clusters principais são logo formados, mas, após algum tempo, unem-se num só cluster. Porém, para limites de confiança menores, vários clusters sobrevivem. As massas nos clusters são diferentes entre si, porém preservam a simetria ao longo do quadrado do espaço de opiniões. A estimativa para o valor crítico de $\varepsilon$ foi $\varepsilon^{*}=0,215$, em concordância com o caso de opiniões unidimensionais.

A Tabela 3.1 mostra o número de clusters formados em função do valor do limite de confiança.

Tabela 3.1: Número final de clusters nas simulações de Fortunato et al [18] para o modelo de Deffuant com opiniões bidimensionais no quadrado $[0,1]^{2}$

\begin{tabular}{cc}
\hline Limite de confiança & Clusters no equilíbrio \\
\hline 0,04 & 100 \\
0,07 & 25 \\
0,08 & 29 \\
0,09 & 24 \\
0,095 & 21 \\
0,10 & 13 \\
0,12 & 9 \\
0,20 & 4 \\
0,22 & 1 \\
\hline
\end{tabular}

Quando a região de confiança é um círculo de raio $\varepsilon$, os dois componentes, $x$ e $y$, são necessariamente correlacionados. Observa-se que o número de clusters, sua ordenação no espaço de opiniões e as razões das massas dos clusters são parecidas com o caso da região de confiança quadrada dados os valores de $\varepsilon$. O valor crítico para o limite de confiança é apenas ligeiramente maior que na situação anterior, ficando em torno de 0,23. Isso se deve basicamente a dois fatores: a superfície do círculo é próxima daquela do quadrado, e a dinâmica sempre se inicia no entorno do espaço de opiniões, em que a distribuição de opiniões é necessariamente inomogênea, de modo que é basicamente a forma do espaço de opiniões que governa a simetria do terreno de opiniões. Da mesma forma que com a região de confiança quadrada, para alguns valores de $\varepsilon$ abaixo do nível de confiança crítico, alguns pequenos clusters sobrevivem. Na Tabela 3.1 temos a quantidade de clusters finais para vários valores de $\varepsilon$.

A abordagem acima para opiniões multidimensionais considera que cada coordenada da opinião de cada agente pode assumir qualquer valor na respectiva coordenada do espaço de opiniões não importando os valores das opiniões sobre os outros tópicos em 
Tabela 3.2: Número final de clusters nas simulações de Fortunato et al [18] para o modelo de Deffuant com opiniões bidimensionais no círculo de raio unitário

\begin{tabular}{cc}
\hline Limite de confiança & Clusters no equilíbrio \\
\hline 0,06 & 49 \\
0,08 & 28 \\
0,09 & 25 \\
0,10 & 17 \\
0,12 & 12 \\
0,15 & 9 \\
0,20 & 5 \\
0,22 & 4 \\
0,24 & 1 \\
\hline
\end{tabular}

discussão. Uma outra forma de pensar é considerar que as opiniões sobre os diferentes tópicos constituem alocações de um recurso com soma predeterminada. Um exemplo trivial seria a alocação de dinheiro entre alguns projetos. No modelo de HegselmannKrause convencional (unidimensional) com espaço de opiniões $S=[0,1]$, a opinião $x$ de um agente pode ser, por exemplo, a quantidade de reais, em milhões, alocada em um determinado projeto. Havendo dois projetos e $\mathrm{R} \$ 1$ milhão disponível, $1-x$ representaria a quantidade alocada no outro projeto. Com $p$ projetos, poderíamos fazer uma distribuição da forma $x^{(1)}, x^{(2)}, \ldots, x^{(p-1)}, 1-\sum_{i=1}^{p-1} x^{(i)}$, sendo $0 \leq x^{(i)} \leq 1$ para $i=1, \ldots, p$, resultando num simplex.

Lorenz [45] simulou essa dinâmica para $p=3$ com regiões de confiança definidas como se segue:

$$
R S\left(x_{i}\right)=\left\{y \in[0,1]^{2}:\left|x_{i}^{(1)}-y^{(1)}\right|+\left|x_{i}^{(2)}-y^{(2)}\right|+\left|x_{i}^{(3)}-y^{(3)}\right| \leq \varepsilon\right\}
$$

Cada uma das 2000 simulações envolve 150 agentes cujas opiniões iniciais se encontram no simplex $\left\{x^{(1)}, x^{(2)}, x^{(3)}: x^{(1)}+x^{(2)}+x^{(3)}=1\right\}$. A distribuição inicial das opiniões é uniforme (porém aleatória) nessa região.

\subsection{Estabilidade com respeito a um agente pertur- bador}

Blondel et al [4] abordaram a seguinte questão: o que ocorreria se, após o sistema estabilizar-se, entrasse mais um agente na dinâmica? Para tanto, primeiramente estabelecem uma generalização que consiste em associar pesos aos agentes. Esses pesos não dependem da configuração do sistema nem de como um agente é percebido por outros a cada etapa; tais pesos são intrínsecos a cada agente, permanecem constantes ao longo de todo o processo e são utilizados no cálculo da média das opiniões dos vizinhos quando da atualização da opinião de algum agente. Consideremos, então, que ao agente $j \in \underline{n}$ corresponde o peso $w_{j}>0$. Desse modo, a regra de atualização da opinião do agente $i$ 
fica

$$
x_{i}(t+1)=\frac{\sum_{j \in I(i, \boldsymbol{x}(t))} w_{j} x_{j}(t)}{\sum_{j \in I(i, \boldsymbol{x}(t))} w_{j}} .
$$

Chamando cluster a cada grupo de agentes com opiniões em comum no momento em que o processo se estabiliza, os autores usam o termo peso do cluster para referir-se à soma dos pesos de todos os agentes num dado cluster. Denotaremos por $W_{A}$ o peso do cluster $A$. A diferença entre as opiniões finais de dois clusters recebe o nome de distância interclusters.

Seja $\overline{\boldsymbol{x}}$ o vetor das opiniões dos agentes $1, \ldots, n$ no equilíbrio. Suponhamos que se adicione um agente perturbador, indexado por 0 , com peso $\delta$ e opinião inicial $\tilde{x}_{0}$, e o sistema evolua novamente a partir daí até atingir novo equilíbrio. Retira-se, então, o agente perturbador, e o perfil $\overline{\boldsymbol{x}}^{\prime}$ assim obtido é novamente um equilíbrio. Definimos $\Delta_{\bar{x}_{0}, \delta}=\sum_{i} w_{i}\left|\bar{x}_{i}-\bar{x}_{i}^{\prime}\right|$, uma medida da distância entre o equilíbrio original e o perturbado. Dizemos que $\overline{\boldsymbol{x}}$ é estável se $\sup _{\bar{x}_{0}} \Delta_{\bar{x}_{0}, \delta} \longrightarrow 0$ quando $\delta \longrightarrow 0$. O teorema a seguir nos dá uma condição necessária e suficiente para que um equilíbrio seja estável.

Teorema 3.11 (Blondel et al [4]). Um equilíbrio é estável se e somente se, para dois clusters quaisquer $A$ e $B$ com pesos $W_{A}$ e $W_{B}$, respectivamente, valer uma das duas afirmações:

- $W_{A}=W_{B}$ e a distância interclusters é maior ou igual a $2 \varepsilon$ ou

- $W_{A} \neq W_{B}$ e a distância interclusters é estritamente maior que $\left(1+\frac{\min \left\{W_{A}, W_{B}\right\}}{\max \left\{W_{A}, W_{B}\right\}}\right) \varepsilon$.

Blondel et al [5], em outro trabalho, assinalam que, por suas observações, o equilíbrio do sistema costuma ser estável quando o número de agentes é suficientemente grande. Com isso, lançam a seguinte conjectura.

Conjectura 3.2 (Blondel et al [5]). A probabilidade de convergência para um equilíbrio estável tende a 1 quando o número de agentes aumenta, para opiniões iniciais aleatoriamente distribuídas de acordo com uma função de probabilidade contínua com suporte conexo. 


\section{Capítulo 4}

\section{Modelo de Deffuant-Weisbuch}

O modelo de Deffuant-Weisbuch apareceu pela primeira vez em 2000 em Deffuant et al [10], tendo como motivação principal uma alternativa aos modelos de dinâmica de opinião então existentes, os quais em sua maioria tratavam as opiniões como variáveis binárias. Nesse artigo, consideravam-se opiniões contínuas entre 0 e 1 , as quais poderiam caracterizar pontos de um espectro de opiniões com dois extremos (à esquerda e à direita, por exemplo). Assim como o modelo de Hegselmann-Krause, tratado no capítulo anterior, o modelo de Deffuant incorpora o conceito de confiança limitada. No entanto, a diferença básica para o modelo anterior é que, a cada iteração, apenas dois agentes conversam entre si para eventualmente atualizarem suas opiniões.

\subsection{Caracterização do modelo}

O modelo de Deffuant-Weisbuch - ou simplesmente modelo de Deffuant - apresenta dois parâmetros: o limite de confiança $\varepsilon>0$ e o parâmetro de convergência $\mu \in\left(0, \frac{1}{2}\right]$. (Referimo-nos aqui ao modelo homogêneo para ambos os parâmetros, o mais usual; também se pode considerar parâmetros diferentes para cada agente.) O primeiro dos parâmetros indica até que ponto as diferenças de opinião dos agentes são aceitáveis para que um consiga interferir na opinião do outro. Já $\mu$ reflete a disposição dos agentes a aproximarem suas opiniões em relação às dos outros indivíduos.

Agora a dinâmica do processo, isto é, suas regras de interação. Da mesma forma que no modelo de Hegselmann-Krause, inicialmente, a cada vértice (ou agente) é atribuído um número real representando uma opinião. Especificamente, a atribuição das opiniões iniciais pode dar-se de maneira i.i.d. entre os agentes. Mais particularmente, essa distribuição (para cada agente) pode ser uniforme contínua no intervalo [0,1]. Se o tempo for contínuo, a cada elo costuma-se associar um processo de Poisson de taxa unitária e independente dos respectivos processos de Poisson nos outros elos e dos valores das opiniões iniciais. A esses processos, quando existem, chamamos "processos de encontro". Denotemos a opinião do agente $i$ no instante $t$ por $x_{i}(t)$. Tal opinião permanecerá inalterada até que, num instante $t^{\prime}$, ocorra um evento do processo de Poisson em algum elo incidente em $i$ - digamos, $e=\langle i, j\rangle$. Sejam $a:=x_{i}\left(t^{\prime-}\right)=\lim _{s \uparrow t^{\prime}} x_{i}(s)$ e $b:=x_{j}\left(t^{\prime-}\right)=\lim _{s \uparrow t^{\prime}} x_{j}(s)$ as opiniões de $i$ e $j$, respectivamente, imediatamente antes do encontro entre os dois agentes.

Se a diferença entre as opiniões, isto é, $|a-b|$, for maior que o limite de confiança $\varepsilon$, suas opiniões permanecem inalteradas. Caso contrário, as opiniões de ambos os agentes aproximam-se simetricamente de acordo com o parâmetro $\mu$. Em símbolos, temos: 


$$
\begin{aligned}
& x_{i}(t)= \begin{cases}a+\mu(b-a) & \text { se }|a-b| \leq \varepsilon ; \\
a & \text { caso contrário }\end{cases} \\
& x_{j}(t)= \begin{cases}b+\mu(a-b) & \text { se }|a-b| \leq \varepsilon ; \\
b & \text { caso contrário }\end{cases}
\end{aligned}
$$

No caso em que o número de agentes é finito, e o tempo, discreto, pode-se abrir mão do processo de Poisson e sortear, a cada etapa (discreta) do processo, um par de agentes conectados.

No modelo de Hegselmann-Krause - ao menos nas variações encontradas na literatura -, o tempo é quase sempre discreto, e o número de agentes é finito. O modelo de Deffuant, porém, é apresentado e analisado numa imensa variedade de versões. As seguintes variações costumam ser estudadas:

- modelo em tempo discreto ou em tempo contínuo;

- número finito de agentes ou número infinito de agentes;

- opiniões contínuas ou opiniões discretas;

- opiniões unidimensionais ou opiniões multidimensionais;

- modelo baseado no agente ou modelo baseado na densidade.

Procederemos à análise, portanto, separando este capítulo em quatro seções principais:

- número finito de agentes, opinião unidimensional

- número finito de agentes, opinião multidimensional

- número infinito de agentes, opinião unidimensional

- número infinito de agentes, opinião multidimensional

As categorias acima são as que mais dividem os pesquisadores. Em cada uma delas, mostraremos os resultados cabíveis, como comportamento do sistema, fragmentação ou consenso, tempo de encerramento, condições para o consenso, etc.

Quanto ao tempo ser contínuo ou discreto, se o número de agentes for finito, podemos facilmente extrapolar as conclusões de um caso para o outro considerando que o elo no qual ocorre o $k$-ésimo evento de Poisson, no modelo com tempo contínuo, seja o $k$ ésimo elo sorteado no modelo com tempo discreto; assim, apenas procuraremos assinalar qual das formas está sob análise. Em geral, trabalharemos com modelos baseados no agente; quando o modelo for baseado na densidade, procuraremos deixar claro esse fato. Por último, o modelo de Deffuant foi originalmente concebido para tratar de opiniões contínuas; variações do modelo com opiniões discretas serão tratadas como casos especiais.

\subsection{Número finito de agentes, opinião unidimensio- nal}

No artigo original de Deffuant et al [10], temos várias simulações do processo. Em todos os casos, é utilizado um grafo completo. Num primeiro momento, tomam-se $n=1000$, $\mu=0,5$ e duas alternativas de valores para $\varepsilon: 0,2$ e 0,5 . 


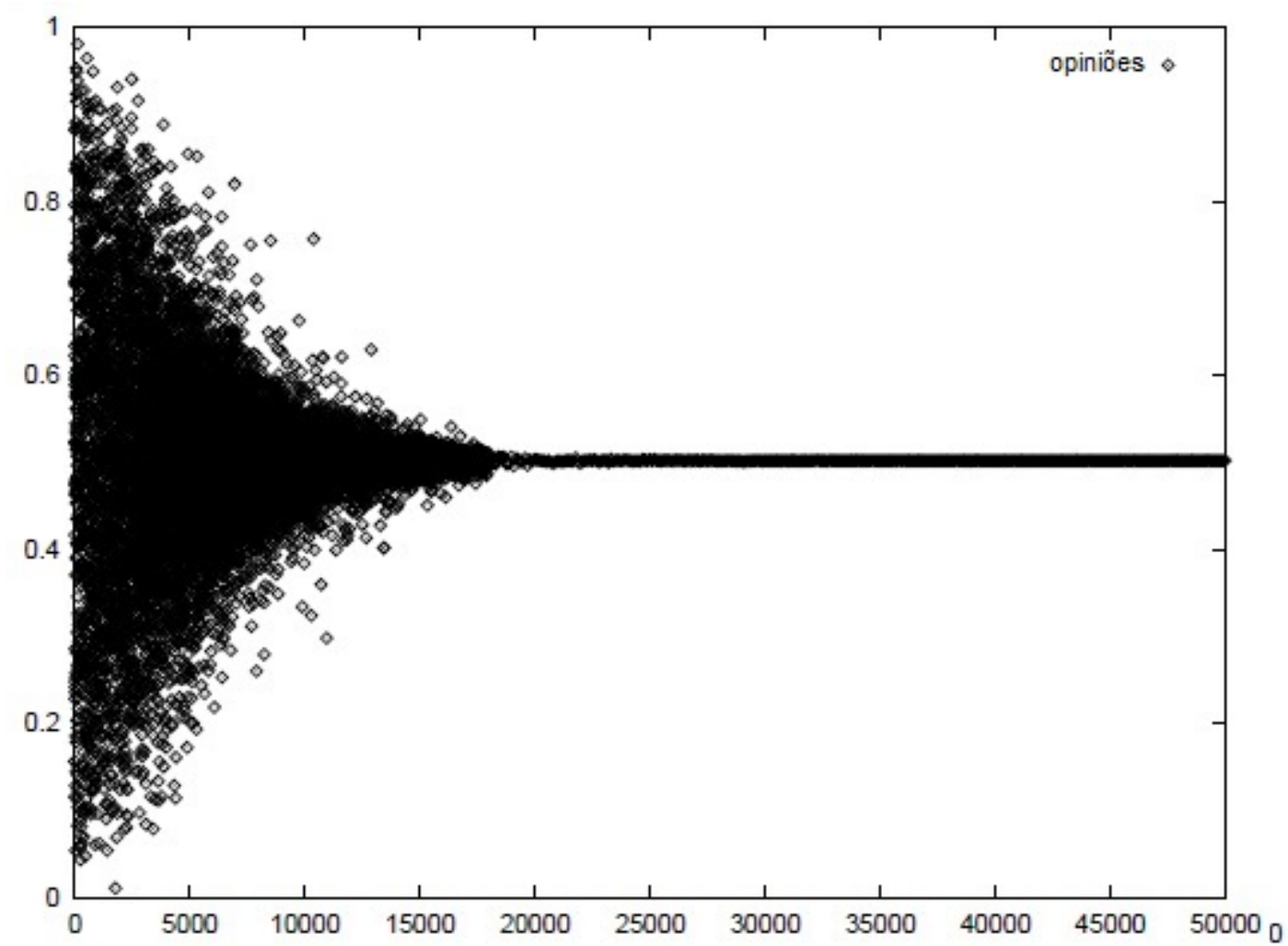

Figura 4.1: Opiniões dos agentes em função do tempo para os parâmetros $\varepsilon=0,5, \mu=0,5, n=1000$. Uma unidade de tempo equivale à amostragem de 1000 pares de agentes

Os valores iniciais são gerados de maneira independente para cada agente a partir da distribuição uniforme contínua no intervalo $[0,1]$. As simulações para $(\varepsilon=0,5 ; \mu=$ $0,5 ; n=1000)$ e $(\varepsilon=0,2 ; \mu=0,5 ; n=1000)$ mostram que, em ambos os casos, as opiniões dos agentes convergem para algum valor, isto é, para todo $i \in \underline{n}$, haverá $x(i)$ tal que

$$
\lim _{t \rightarrow \infty} x_{i}(t)=c_{i}
$$

Porém, esses valores limite coincidem, isto é, $c_{1}=\ldots=c_{n}$ apenas no primeiro caso, ou seja, $\operatorname{com} \varepsilon=0,5$ (Figura 4.1). Para $\varepsilon=0,2$, dá-se a fragmentação das opiniões finais (Figura 4.2).

Após a realização de um grande número de simulações variando os valores de $n, \mu$ e $\varepsilon$ (não se explicitam os valores no artigo), Deffuant et al [10] observam que $\mu$ e $n$ parecem influenciar apenas o tempo de convergência e a amplitude da distribuição das opiniões finais. Já $\varepsilon$ controla o número de picos da distribuição final. Entende-se por "pico" aqui cada um dos valores para os quais as opiniões dos agentes convergem quando $t \rightarrow \infty$.

Posteriormente, os autores abordam a possibilidade de o grafo representar uma rede social, de modo que só haveria interação direta dos agentes se eles fossem vizinhos no grafo, o qual representaria uma relação social pré-existente - e não necessariamente corresponderia a um grafo completo. Alegando ser difícil inventar um exemplo verossímil de rede social, Deffuant et al [10] adotam uma simplificação padrão ao usarem um reticulado quadriculado. As razões da escolha são a simplicidade, a visualização fácil das configurações de opiniões e a grande quantidade de ciclos curtos (assim como nas redes sociais reais). "Ciclos" aqui se refere a caminhos fechados no reticulado. 


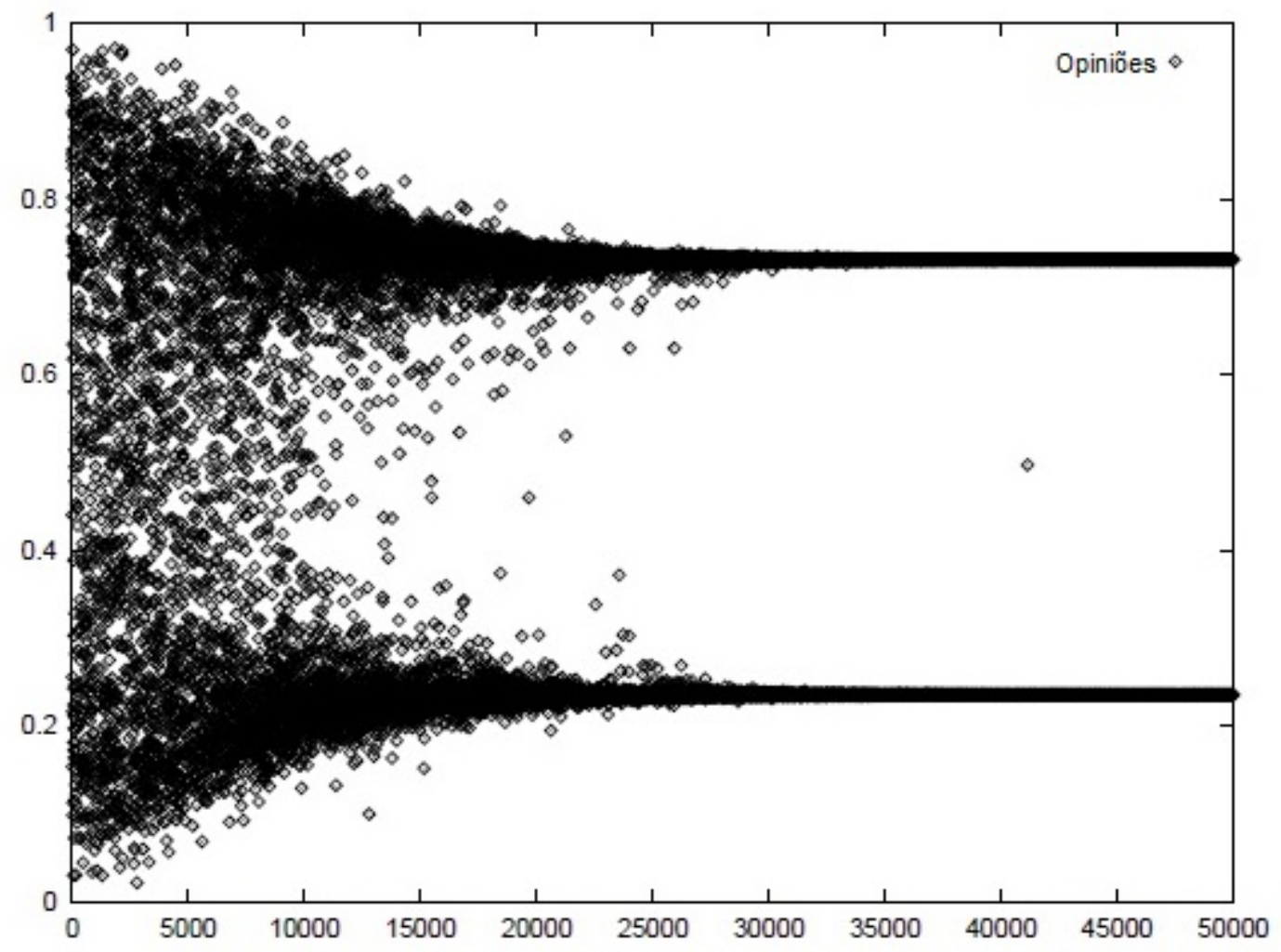

Figura 4.2: Opiniões dos agentes em função do tempo para os parâmetros $\varepsilon=0,2, \mu=0,5, n=1000$. Uma unidade de tempo equivale à amostragem de 1000 pares de agentes 


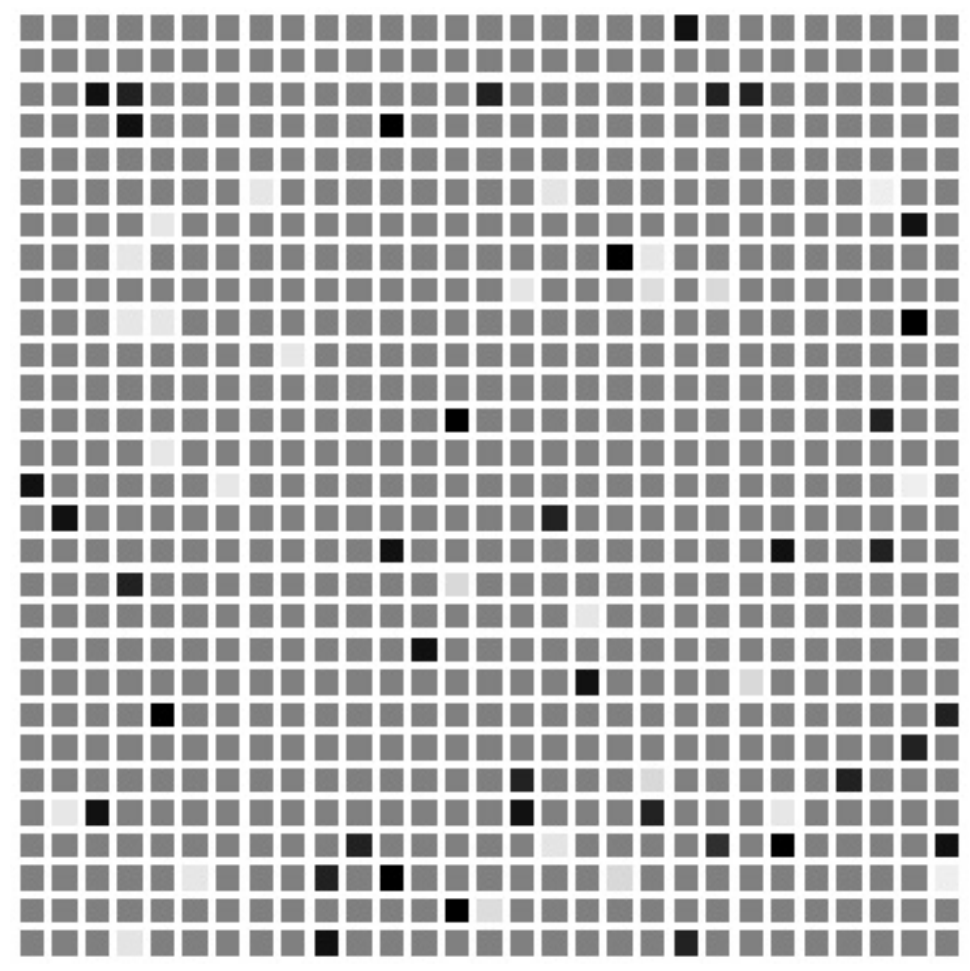

Figura 4.3: Opiniões finais dos agentes dispostos nos vértices de um quadriculado de tamanho 29 por 29. Valores dos parâmetros: $\varepsilon=0,3, \mu=0,3$. Número de iterações: 100.000 .

Começam, então, com uma grade de agentes quadriculada e bimensional. Neste caso, cada agente pode interagir diretamente com quatro outros agentes. Aqui, novamente, as distribuições das opiniões iniciais são uniformes no intervalo $[0,1]$ e independentes. A cada passo, um par de agentes conectados é selecionado ao acaso, e suas opiniões são atualizadas, isto é, modificadas de acordo com (4.1) e (4.2) se atenderem à condição de que a diferença entre elas é menor que $\varepsilon$. Para valores maiores de $\varepsilon$ - mais precisamente, $\varepsilon>0,3-$, a grande maioria dos agentes convergiu para o consenso em torno da opinião 0,5 , e alguns poucos agentes adotaram posições extremistas (próximas a 0 ou 1 ) no equilíbrio. Já para valores menores de $\varepsilon(\varepsilon<0,3)$, notou-se a formação de clusters de agentes, havendo consenso dentro de cada cluster, mas não entre clusters distintos.

Abordando o mesmo modelo de Deffuant - opiniões iniciais i.i.d. com distribuição uniforme contínua no intervalo $(0,1)$-, Fortunato [17] exibe o resultado de simulações em quatro tipos de grafos:

- grafo completo;

- reticulado quadrado;

- um grafo aleatório à la Erdös-Rényi;

- um grafo livre de escala à la Barabási-Albert.

A título de informação, convém observar que o grafo aleatório de Erdös-Rényi $G(n, p)$ é obtido ao se conectar cada par de vértices de um conjunto de $n$ vértices com probabilidade $p$ e independentemente dos demais vértices.

O grafo livre de escala de Barabási-Albert, por sua vez, é obtido por meio de um procedimento dinâmico. Inicia-se com $m$ vértices, todos conectados entre si. Então, 


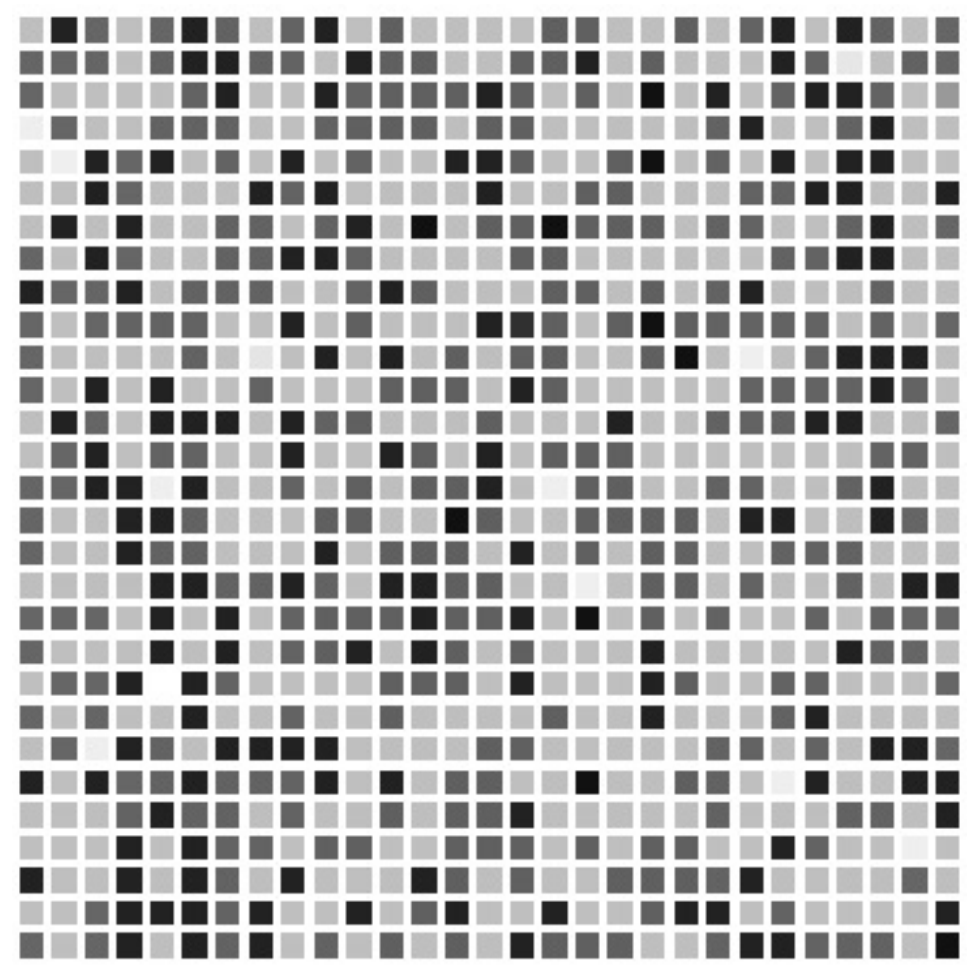

Figura 4.4: Opiniões finais dos agentes dispostos nos vértices de um quadriculado de tamanho 29 por 29. Valores dos parâmetros: $\varepsilon=0,15, \mu=0,3$. Número de iterações:

100.000.

adiciona-se um vértice por vez. Cada vértice adicionado (após os $m$ iniciais) será conectado aleatoriamente a $m-1$ vértices dos já existentes no grafo. O procedimento é repetido até que todos os $n$ vértices tenham sido dispostos. Uma propriedade interessante de tal construção é que, independentemente do valor de $m$, o número de vértices com grau $k$ (isto é, com $k$ vizinhos) é assintoticamente proporcional a $k^{-3}$.

Uma simples - porém relevante - observação teórica de Fortunato [17] trata das configurações estáveis. Essas configurações são tais que, ao tomarmos dois agentes vizinhos (conectados por elo) quaisquer, suas opiniões são idênticas ou diferem mais de $\varepsilon$. Esse fenômeno dá origem aos clusters - conjuntos de vértices vizinhos com a mesma opinião final. O número de clusters na configuração final depende diretamente de $\varepsilon$. Quanto maior o valor de $\varepsilon$, maior a tendência à formação de apenas um cluster. No caso com grafo finito, as configurações limite são estáveis no sentido de que todas as opiniões convergem para algum valor.

Uma diferença crucial a ser observada no método de simulação usado por Fortunato [17] é que, em vez de, a cada passo, selecionar ao acaso um entre todos os elos do grafo, a seleção em cada etapa dá-se de maneira sequencial. Mais precisamente, a cada passo, escolhe-se, de acordo com uma ordem predeterminada, um vértice (que fará o papel de agente $i$ ) e, entre os vizinhos deste, seleciona-se de maneira equiprovável o parceiro de interação (que corresponderá ao agente $j$ ).

Denominando de $P_{c}$ a proporção de casos (das simulações) em que houve convergência para um único cluster, pôde-se observar, para todos os tipos de grafo empregados nas simulações por Fortunato [17], que, à medida que se aumenta $n$, o gráfico de $P_{c}$ em função de $\varepsilon$ converge para uma função escada $P_{c}(\varepsilon)=0$ para $\theta<1 / 2$ e $P_{c}(\varepsilon)=1$ para $\varepsilon>1 / 2$, o que aponta para evidências de que o valor crítico de $\varepsilon$ possa ser $1 / 2$. 
Como exemplo, mostramos o gráfico (Figura 4.5) da estimativa de consenso completo para diferentes valores do limite de confiança e números de agentes no grafo reticulado quadrado com condições de fronteira periódicas (como num toro) . O comportamento é semelhante para os outros tipos de grafo.

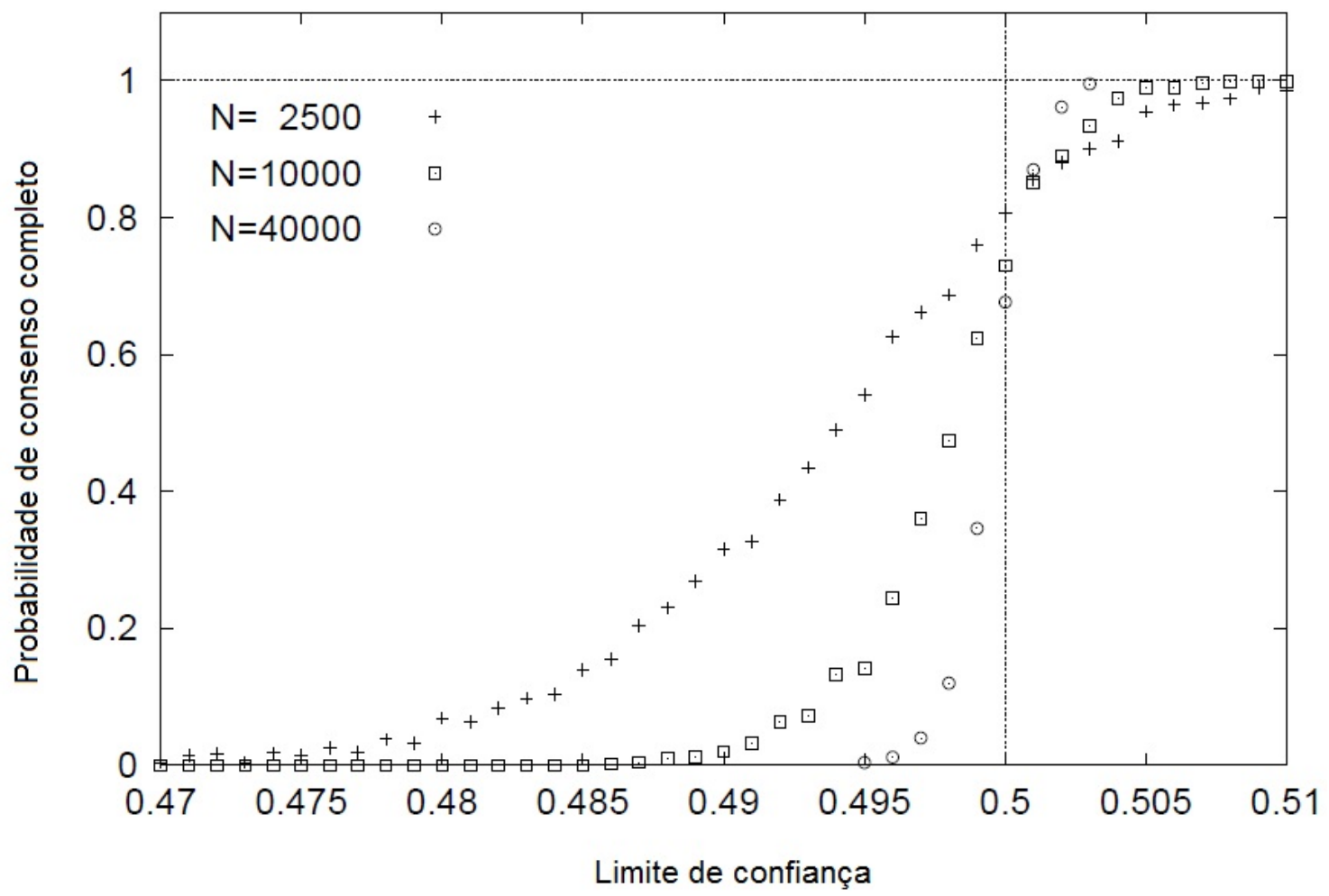

Figura 4.5: Estimativas para a probabilidade de consenso para o modelo de Deffuant no grafo reticulado quadrado com condições de fronteira periódicas

Realizamos algumas simulações adicionais (100 repetições para cada valor de $n$ ), desta vez para o modelo de Deffuant num grafo com os vértices em linha - ou seja, um subconjunto de vértices consecutivos de $\mathbb{Z}$. Porém, ao contrário de Fortunato [17], sorteamos, a cada etapa, um elo entre todos os $n-1$ elos do grafo. O resultado é exposto na Figura 4.6, em que se percebe a mesma característica descrita acima.

Stauffer e Meyer-Ortmanns [50] analisaram o grafo aleatório de Barabási-Albert nas versões direcionada e não direcionada. Eles também consideram opiniões iniciais i.i.d. uniformemente distribuídas no intervalo $[0,1]$. O modelo de Deffuant no grafo não direcionado funciona como descrito acima e estudado por Fortunato [17]. Na versão direcionada, cada agente só tem a sua opinião influenciada pelos $m-1$ agentes inicialmente selecionados por ele (na formação do grafo) como amigos. Para o grafo não direcionado, a cada iteração um agente é sorteado, e é escolhido também um agente vizinho a este. No caso do grafo direcionado, esse segundo agente é selecionado entre aqueles que escolheram o primeiro na formação do grafo ou foram escolhidos por ele. Adotaram-se $\mu=0,3$ e 100 repetições de cada combinação de $n \operatorname{com} \varepsilon$. O resultado obtido é que, nos dois casos, para $\varepsilon$ maior que 0,4 , é obtido o consenso, restando apenas uma opinião no equilíbrio. Para valores menores de $\varepsilon$, o número $F$ de opiniões remanescentes aumenta à medida que se diminui $\varepsilon$. Além disso, quando se aumenta o valor de $n, F$ aumenta proporcionalmente a $n$ para $n$ grande.

Laguna et al [35] também fizeram simulações com o modelo completo, como Fortu- 
Modelo de DW, opiniões iniciais i.i.d. U(0,1), grafo em linha

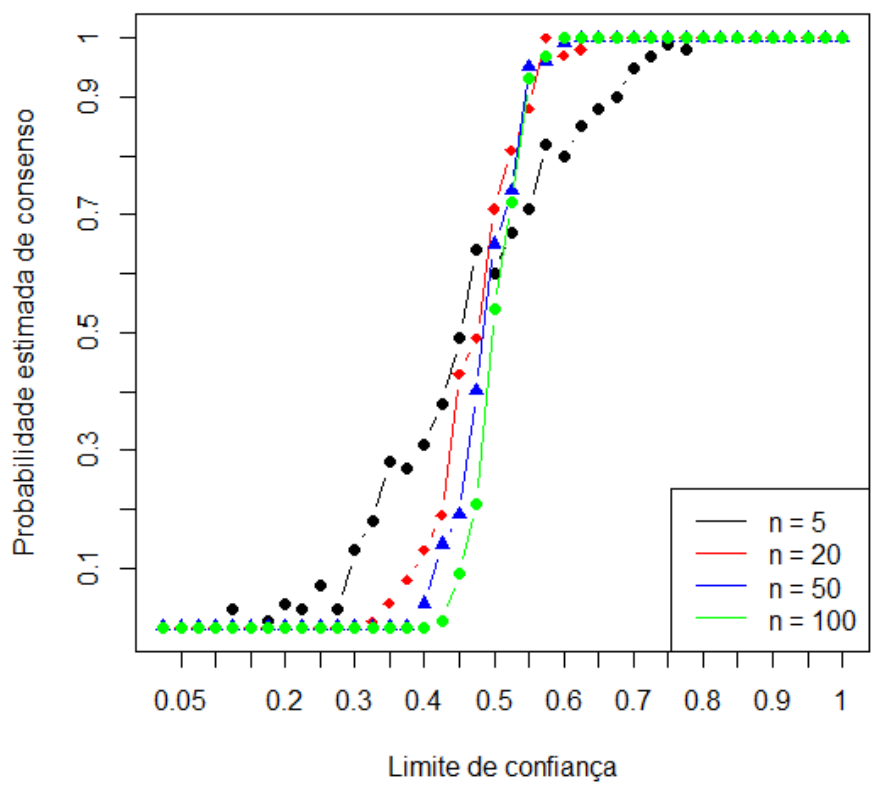

Figura 4.6: Estimativas para a probabilidade de consenso para o modelo de Deffuant no grafo reticulado quadrado com condições de fronteira periódicas

nato [17], mas estudaram a influência dos dois parâmetros - $\varepsilon$ e $\mu$ - sobre a dinâmica e o resultado do sistema no equilíbrio. Novamente as opiniões iniciais são uniformemente distribuídas no intervalo [0,1]. Entre os resultados das simulações, o mais destacável é a influência de $\mu$ não só sobre a velocidade de convergência do processo, mas também devido a essa velocidade - sobre a formação dos clusters no equilíbrio. Na Figura 4.7, clusters maiores (com mais de $10 \%$ da população) são representados por pontos cheios, e clusters menores (os demais), por pontos vazios. Como se observa na figura, valores mais altos de $\mu$ levam ao surgimento de clusters menores nos extremos do espaço de opinião para $\varepsilon<1 / 2$. Isso se deve ao fato de que, ao se aumentar $\mu$, diminui-se o tempo de convergência, e agentes intermediários não têm tempo suficiente para atrair agentes com opiniões mais extremas em direção à opinião consensual.

O primeiro resultado analítico sobre o comportamento do sistema quando o tempo tende a infinito foi demonstrado por Lorenz [40]. É o Teorema 3.4 do capítulo anterior, também aplicável ao modelo de DW, uma vez que as condições necessárias i a iii também são satisfeitas neste processo.

\subsection{Número finito de agentes, opinião multidimensi- onal}

Uma extensão natural do modelo proposto acima é o estudo de vetores de opinião - em vez de apenas uma opinião por agente. Assim, cada um dos $n$ agentes pode ter opiniões sobre $F$ tópicos distintos. Para fins de simplificação, Deffuant et al [10] reduzem o problema a opiniões binárias sobre cada tópico. No artigo, só é tratado o caso em que qualquer dupla de agentes pode ser selecionada a cada passo com igual probabilidade. O grafo 


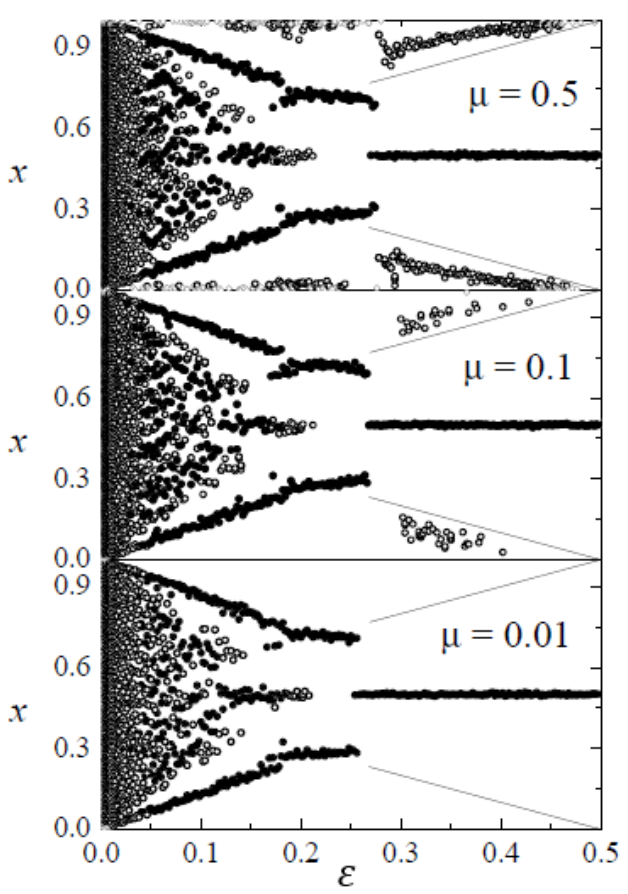

Figura 4.7: Valores das opiniões no equilíbrio para diferentes valores de $\varepsilon$ e $\mu$

subjacente seria, pois, um grafo completo.

Para determinar a distância entre dois vetores de opiniões, foi usada a distância de Hamming - a qual corresponde ao número de bits distintos entre os dois vetores. Quando uma dupla é sorteada, o ajuste de suas opiniões ocorre se a distância de Hamming entre seus vetores de opinião é menor que $\varepsilon$, isto é, se há pelo menos $F-\varepsilon$ tópicos em que suas opiniões sejam iguais. Nesse caso, a regra de atualização das opiniões é um tanto diferente do modo anterior. Aqui, para cada tópico em que haja concordância, as opiniões dos dois agentes mantêm-se. Porém, caso haja dissonância, o procedimento é o seguinte: sorteia-se ao acaso um agente (com probabilidade 1/2 para cada lado) e, com probabilidade $\mu$, esse agente adota a opinião de seu interlocutor.

O principal interesse quanto à dinâmica de vetores de opinião é como se dá a aglomeração dos agentes. Pelas simulações realizadas por Deffuant et al [10], nota-se que $\mu$ e $n$ afetam apenas o tempo de convergência para o equilíbrio; os fatores mais influentes seriam a barreira $\varepsilon$ e o número de assuntos em discussão $m$. Os resultados a seguir referem-se a simulações com $F=13$ e $n=1000$ :

- Quando $\varepsilon>7$, ocorre convergência em direção a uma única opinião.

- Quando $4 \leq \varepsilon \leq 7$, uma convergência parecida é observada em mais de 99,5\% dos agentes.

- Com $\varepsilon=3$, são observados de 2 a 7 picos significantes (cada um com pelo menos $1 \%$ da população) mais algumas opiniões isoladas.

- Com $\varepsilon=2$, é observado um grande número (em torno de 500) de pequenos aglomerados.

Os resultados para valores maiores de $F$ mostram um mesmo padrão de convergência: regimes com uniformidade de opiniões para valores maiores de $\varepsilon$ e grande diversidade 
para valores menores de $\varepsilon$ são separados por um valor $\varepsilon^{*}$ crítico para o qual um número pequeno de aglomerados é observado. Além disso, $\varepsilon^{*}$ parece aumentar conforme $n$.

Outro resultado importante é que não se observa polarização de opiniões, isto é, os vetores com as opiniões de cada agente não convergem para vetores de opiniões opostos. Em vez disso, o processo de aglomeração resulta na ortogonalização das opiniões com uma distância média em torno de 6 (para $F=13$ ), e os vetores de opiniões não apresentam correlação positiva nem negativa.

Realizamos simulações com outras quantidades de tópicos: $F=20, F=50$ e $F=100$.

Modelo de DW, opinião multidimensional binária, 20 tópicos, grafo completo

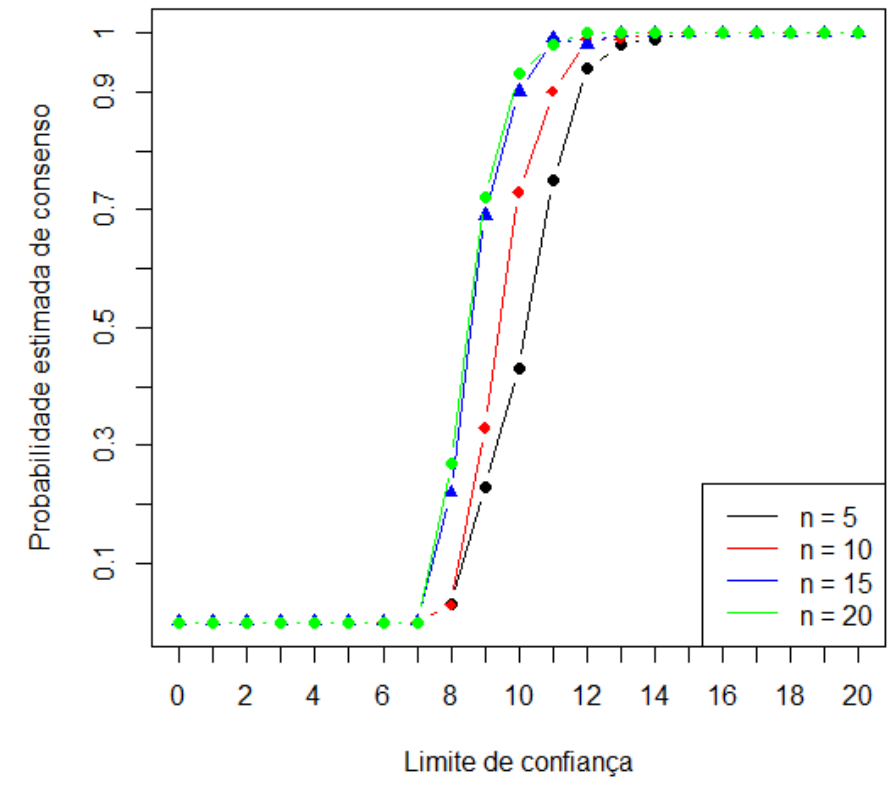

Figura 4.8: Simulação para o modelo de Deffuant no grafo completo com opinião multidimensional com 20 tópicos com opiniões binárias. $n=5,10,15,20$.

\subsection{Número infinito de agentes, opinião unidimensi- onal}

Voltando ao cenário com opiniões unidimensionais e opiniões iniciais i.i.d. uniformemente distribuídas no intervalo [0,1], Lanchier [36] deu um grande passo na análise teórica ao considerar um grafo infinito - nomeadamente, $\mathbb{Z}$. Outra particularidade foi o emprego da abordagem de Harris [29] ao construir o modelo com o auxílio de processos de Poisson independentes e com taxa unitária associados a cada vértice do grafo - ou seja, a cada ponto $i \in \mathbb{Z}$ - para indicar os encontros (interações) entre os agentes. Denotando por $N_{i}(t)$ o processo de Poisson associado ao vértice $i$, o conjunto dos instantes em que ocorre algum evento de Poisson nesse vértice (ou seja, dos tempos de chegada do processo) é dado por

$$
\Lambda(i):=\left\{t: N_{i}\left(t^{-}\right) \neq N_{i}(t)\right\} .
$$

Porém, como é sorteado um elo a cada etapa do modelo (e não um vértice), associa-se biunivocamente o elo $\langle i, i+1\rangle$ ao vértice $i$ para determinar o par de agentes cujas opiniões 
poderão sofrer atualização.

Usando argumentos geométricos, Lanchier [36] demonstra o seguinte lema acerca do valor crítico de $\varepsilon$ :

Teorema 4.1 (Lanchier [36]). No modelo de Deffuant em $\mathbb{Z}$, se as opiniões iniciais são independentes e uniformemente distribuídas - cada uma com distribuição uniforme contínua no intervalo $[0,1]$-, então, independentemente do valor de $\mu>0$, o limite de confiança crítico será $\varepsilon^{*}=1 / 2$. Em outras palavras:

- para $\varepsilon>1 / 2$, o processo converge para um consenso global no sentido de que

$$
\lim _{t \rightarrow \infty} \mathbb{P}\left(\left|x_{i}(t)-x_{i+1}(t)\right|<\varepsilon\right)=1, \forall i \in \mathbb{Z}
$$

- para $\varepsilon<1 / 2$, ocorre a coexistência de diferentes limites para as opiniões dos agentes quando $t \rightarrow \infty$.

Ainda com as mesmas condições iniciais e mesmo processo de encontro, também Häggström [25] mostra, usando um procedimento de própria autoria denominado de Sharing a drink (Dividindo um drinque em português e abreviado como $S A D$ ), que o valor crítico de $\varepsilon$ é $1 / 2$. Tal método consiste num processo estocástico auxiliar que possibilita escrever o valor da opinião de um agente num dado instante como média ponderada das opiniões iniciais dos agentes vizinhos e da dele próprio. O teorema a seguir é uma junção de dois teoremas e uma proposição em Häggström [25].

Teorema 4.2 (Häggström [25]). Para o modelo de Deffuant em $\mathbb{Z}$ com opiniões iniciais i.i.d. $\mathcal{U}([0,1])$ e com $\varepsilon<1 / 2$, temos q.c. que, para todo $i \in \mathbb{Z}$, o valor limite $x_{i}(\infty)=\lim _{t \rightarrow \infty} x_{i}(t)$ existe e que a configuração limite $\left\{x_{i}(\infty)\right\}, i \in \mathbb{Z}$ satisfaz $\left\{\left|x_{i}(\infty)-x_{i+1}(\infty)\right|\right\} \in\{0\} \cup[\varepsilon, 1]$ para todo $i \in \mathbb{Z}$.

Com $\varepsilon>1 / 2$, temos q.c., para todo $i \in \mathbb{Z}$, que $\lim _{t \rightarrow \infty}\left|x_{i}(t)-x_{i+1}(t)\right|=0$ e $\lim _{t \rightarrow \infty} x_{i}(t)=1 / 2$.

A demonstração da primeira parte consiste em mostrar que há infinitos intervalos (conjuntos de vértices consecutivos) $\left\{i_{1}, i_{1}+1, \ldots, i_{2}\right\}$ tais que, a partir de algum instante $T\left(i_{1}, i_{2}\right)$, não há comunicação de vértices dentro do intervalo com vértices fora do intervalo devido ao fato de as diferenças de opiniões entre os extremos do intervalo e seus vizinhos serem permanentemente maiores que $\varepsilon$. As opiniões dos vértices de dentro do intervalo isto é, dos vértices no conjunto $\left\{i_{1}+1, i_{1}+2, \ldots, i_{2}-1\right\}$ convergirão para um valor comum equivalente à média das respectivas opiniões no tempo $T\left(i_{1}, i_{2}\right)$.

$\mathrm{Na}$ prova da segunda parte, é empregado o conceito definido a seguir.

Definição 4.1. Dados $\varepsilon>0$ e uma configuração inicial $\left\{x_{i}(0)\right\}_{i \in \mathbb{Z}}$ do modelo de Deffuant em $\mathbb{Z}$, dizemos que $i$ é um ponto $\delta$-plano bilateralmente se, para todos $m, n \geq 0$, tivermos

$$
\frac{1}{m+n+1} \sum_{j=i-m}^{i+n} x_{j}(0) \in\left[\frac{1}{2}-\delta, \frac{1}{2}+\delta\right] \text {. }
$$

Häggström [25] mostra que a probabilidade de um ponto qualquer ser $\delta$-plano bilateralmente é positiva. Logo, pela ergodicidade, haveria infinitos $i \in \mathbb{Z} \delta$-planos bilateralmente. No mesmo artigo, o autor ainda mostra que, se $i$ é $\delta$-plano bilateralmente com relação à configuração inicial $\boldsymbol{x}(0)$, então

$$
x_{i}(t) \in\left[\frac{1}{2}-6 \delta, \frac{1}{2}+6 \delta\right] \text { para todo } t \geq 0 .
$$


Logo, se tomarmos $\varepsilon>\frac{1}{2}+6 \delta$, os vizinhos do vértice $i, \delta$-plano bilateralmente, deverão ter seus valores limite $x_{i-1}(\infty)$ e $x_{i+1}(\infty)$ também dentro do intervalo $\left[\frac{1}{2}-6 \delta, \frac{1}{2}+6 \delta\right]$, pois, caso contrário, suas opiniões deveriam ser menores que 0 ou maiores que 1 , algo impossível no modelo com opiniões iniciais no intervalo $[0,1]$.

Sendo $i$ um vértice $\delta$-plano bilateralmente e $j$ um outro vértice qualquer, podemos aplicar $\lim _{t \rightarrow \infty}\left|x_{i}(t)-x_{i+1}(t)\right|=0$ a cada um dos finitos elos entre $i$ e $j$, de modo que $x_{j}(t) \in\left[\frac{1}{2}-7 \delta, \frac{1}{2}+7 \delta\right]$ para $t$ suficientemente grande. Da arbitrariedade de $\delta$ segue que $\lim _{t \rightarrow \infty} x_{j}(t)=\frac{1}{2}$.

Percebe-se que, além do mesmo resultado obtido por Lanchier [36], Häggström [25] ainda inclui o limite dos valores das opiniões no caso supercrítico. Veremos mais à frente que, não por acaso, tal valor corresponde a $\mathbb{E} x(0)$, sendo $x(0)$ uma variável aleatória com a mesma distribuição de probabilidade que a de cada opinião inicial.

Para o mesmo grafo $(\mathbb{Z})$, Häggström e Hirscher [26] apresentam resultados mais gerais quanto à distribuição inicial das opiniões. Antes de estudar os teoremas aí abordados, vamos apresentar os diferentes tipos de consenso por eles descritos:

Definição 4.2. Possíveis tipos de consenso (opiniões unidimensionais):

(i) Ausência de consenso

Há elos para sempre bloqueados, i.e., elos $e=\langle i, j\rangle$ tais que

$$
\left|x_{i}(t)-x_{j}(t)\right|>\varepsilon
$$

para todo $t$ suficientemente grande. Dessa forma, obviamente, os agente (vértices) não terão a mesma opinião nunca mais a partir de um certo $T \geq 0$ aleatório.

(ii) Consenso fraco

Todo par de vizinhos $\{i, j\}$ tenderá à concordância, ou seja,

$$
\lim _{t \rightarrow \infty}\left|x_{i}(t)-x_{j}(t)\right|=0
$$

(iii) Consenso forte

$\mathrm{O}$ valor de cada vértice converge, quando $t \rightarrow \infty$, para um limite comum $L$, em que

$$
L= \begin{cases}\text { média dos valores das opiniões iniciais } & \text { se } G \text { for finito } \\ \mathbb{E} x(0) & \text { se } G \text { for infinito }\end{cases}
$$

em que $x(0)$ é uma variável aleatória com a mesma distribuição que cada $x_{i}(0)$, $i \in \mathbb{Z}$.

Com essas definições em mente, passemos à apresentação dos teoremas acerca do parâmetro crítico $\varepsilon^{*}$. Primeiramente, consideram-se as opiniões iniciais independentes e identicamente distribuídas - não necessariamente com distribuição uniforme no intervalo $[0,1]$ :

Teorema 4.3 (Häggström e Hirscher [26]). Consideremos o modelo de Deffuant em $\mathbb{Z}$ com distribuição inicial das opiniões i.i.d. $\mathcal{L}(x(0))$ tal que exista $\mathbb{E}(x(0)$ ) (finita ou infinita). 
(a) Se $\mathcal{L}(x(0))$ for limitada, seja $[a, b]$ o menor intervalo fechado contendo seu suporte. Se $\mathbb{E}(x(0))$ não pertencer ao suporte de $\mathcal{L}(x(0))$, defina $I=(\alpha, \beta)$ como o maior intervalo aberto contido em $[a, b]$ tal que $\mathbb{E}(x(0)) \in I$ e $\mathbb{P}(x(0) \in I)=0$. Defina, então, $h$ como o comprimento de $I$.

Por outro lado, se $\mathbb{E}(x(0))$ pertencer ao suporte de $\mathcal{L}(x(0))$, defina $h=0$.

Então, o valor crítico de $\varepsilon, \varepsilon^{*}$, tal que, para $\varepsilon<\varepsilon^{*}$, q.c. não ocorre consenso e, para $\varepsilon>\varepsilon^{*}$, q.c. ocorre consenso forte é dado por $\varepsilon^{*}=\max \{\mathbb{E}(x(0))-a, b-\mathbb{E}(x(0)), h\}$.

No caso em que $h>0$, é possivel estabelecer o comportamento do sistema no ponto crítico quando $t \rightarrow \infty$. Se tanto $\mathbb{P}(x(0)=\alpha)>0$ como $\mathbb{P}(x(0)=\beta)>0$, então haverá consenso q.c. Porém, caso $\mathbb{P}(x(0)=\alpha)=0$ ou $\mathbb{P}(x(0)=\beta)=0$, então q.c. não haverá consenso.

(b) Se $\mathcal{L}(x(0))$ não for limitada, mas tiver a esperança bem definida (finita ou infinita), então o modelo de Deffuant para qualquer parâmetro $\varepsilon \in(0, \infty)$ q.c. não convergirá para consenso.

Se as opiniões iniciais não forem independentes, ainda assim, sob algumas condições, Häggström e Hirscher [26] estabelecem as mesmas conclusões do Teorema 4.3. Vamos, então, descrever que condições seriam essas. Comecemos com a definição de processo estocástico estacionário extraída de Durrett [14].

Definição 4.3. Dizemos que $X_{0}, X_{1}, \ldots$ é uma sequência estacionária se, para todo $k$, a sequência deslocada $\left\{X_{k+n}, n \geq 0\right\}$ tiver a mesma distribuição, ou seja, se para todo $m \geq 0,\left(X_{0}, \ldots, X_{m}\right)$ e $\left(X_{k}, \ldots, X_{k+m}\right)$ têm a mesma distribuição.

Definição 4.4. Uma transformação $\varphi$ preservadora de medida em $(\Omega, \mathcal{F}, \mathbb{P})$ é dita ergódica se $\mathcal{I}$ (classe de eventos invariantes) é trivial, isto é, para todo $A \in \mathcal{I}, \mathbb{P}(A) \in\{0,1\}$.

Um evento $A \in \mathcal{F}$ é invariante com relação à transformação $\varphi$, ou seja, $A \in \mathcal{I}$, se $\varphi^{-1} A=A$.

Definição 4.5. Uma sequência estacionária de variáveis aleatórias $\left\{\xi_{i}\right\}_{i \in \mathbb{Z}}$ satisfaz a condição de energia finita se admite probabilidades condicionais tais que a distribuição condicional de $\xi_{0}$ dados $\left\{\xi_{i}\right\}_{i \in \mathbb{Z} \backslash\{0\}}$ q.c. tem o mesmo suporte que a distribuição marginal (não condicional) de $\xi_{0}$.

Estamos agora preparados para apresentar a versão mais geral do Teorema 4.3:

Teorema 4.4 (Häggström e Hirscher [26]). Para o modelo de Deffuant em $\mathbb{Z}$ com opiniões iniciais $\left\{x_{i}(0)\right\}_{i \in \mathbb{Z}}$, se $\left\{x_{i}(0)\right\}_{i \in \mathbb{Z}}$ for uma sequência estacionária de variáveis aleatórias, ergódica com respeito a shifts e satisfazendo a condição de energia finita, então os resultados do Teorema 4.3 valem.

No caso em que o grafo é $\mathbb{Z}^{d}$, sob as hipóteses do Teorema 4.4, Häggström e Hirscher [26] mostram o seguinte teorema a respeito dos valores de $\varepsilon$ que garantem consenso fraco:

Teorema 4.5 (Häggström e Hirscher [26]). Considere o modelo de Deffuant em $\mathbb{Z}^{d}$ tal que a distribuição das opiniões iniciais $\left\{x_{v}(0)\right\}_{v \in \mathbb{Z}^{d}}$ é estacionária com relação a shifts do tipo $T_{v}: v \mapsto e_{i}$, em que $e_{i}$ é o $i$-ésimo vetor da base canônica de $\mathbb{R}^{d}, i \in\{1, \ldots, d\}$. 
(a) Se os valores iniciais são distribuídos uniformemente em $[0,1]$ e $\varepsilon>\frac{3}{4}$, o processo chegará q.c. ao consenso fraco, i.e.

$$
\mathbb{P}\left(\lim _{t \rightarrow \infty}\left|x_{i}(t)-x_{j}(t)\right|=0\right)=1
$$

para todos $i, j \in \mathbb{Z}^{d}$ tais que $\langle i, j\rangle$ forma um elo.

(b) Para distribuições iniciais em $[0,1]$ em geral, o intervalo de variação de $\varepsilon$ em que o consenso é eventualmente garantido é não trivial, i.e., inclui valores menores que 1 , ao menos que os valores iniciais estejam concentrados em 0 e 1, assumindo ambos os valores com probabilidade positiva.

Um operador shift $\varphi$, citado acima, tem como função transladar uma sequência. Por exemplo, $\varphi\left(\omega_{0}, \omega_{1}, \ldots\right)=\left(\omega_{1}, \omega_{2}, \ldots\right)$.

\subsection{Número infinito de agentes, opinião multidimen- sional}

Mais recentemente, em 2014, Lanchier e Scarlatos [37] obtiveram resultados analíticos para o modelo de Deffuant com opiniões multidimensionais e binárias em cada coordenada e $\mathbb{Z}$ como grafo dos agentes. Cada agente, a uma taxa unitária, escolhe um vizinho de maneira equiprovável e copia a opinião desse vizinho num tópico escolhido uniformemente ao acaso entre os tópicos nos quais eles discordam, exceto se o número de tópicos discordantes (distância de Hamming) for maior que o limite de confiança $\varepsilon$.

Antes de passar aos teoremas, vamos introduzir nomenclaturas convenientes:

Definição 4.6. Dizemos que o sistema se aglomera quando

$$
\lim _{t \rightarrow \infty} \mathbb{P}\left(x_{i}(t)=x_{j}(t)\right)=1 \text { para todos } i, j \in \mathbb{Z} .
$$

Por outro lado, o sistema coexiste devido a fixação quando

$$
\mathbb{P}\left(x_{i}(t)=x_{i}(\infty) \text { eventualmente em } t\right)=1 \text { para todo } i \in \mathbb{Z}
$$

para alguma configuração $\boldsymbol{x}(\infty)$ tal que $\mathbb{P}\left(\operatorname{card}\left\{\mathrm{x}_{\mathrm{i}}(\infty): \mathrm{i} \in \mathbb{Z}\right\}=2^{\mathrm{F}}\right)=1$, em que card corresponde a "cardinalidade" - o número de elementos de um dado conjunto. Ou seja, todos os estados possíveis estão representados na configuração de equilíbrio q.c.

Os dois teoremas a seguir tratam da aglomeração e coexistência no modelo de Deffuant nas condições aqui exposto e foram provados por meio do artifício da criação de passeios aleatórios aniquilantes. O conjunto das opiniões de cada agente é pensado como uma coleção de $F$ níveis, cada um com dois possíveis estados (0 ou 1). Parte-se do pressuposto de que a distribuição inicial das opiniões, para cada agente, é equiprovável em $\{0,1\}^{F}$ e independente dos demais, ou seja,

$$
\mathbb{P}\left(x_{i}(0)=u\right)=\left(\frac{1}{2}\right)^{F} \quad \text { para todo } i \in \mathbb{Z}, u \in\{0,1\}^{F} .
$$

Teorema 4.6 (Lanchier e Scarlatos [37]). Supondo 4.3, se $F=\varepsilon+1$, então o sistema aglomera-se. 
Teorema 4.7 (Lanchier e Scarlatos [37]). Supondo (4.3), se $F \geq 4 \varepsilon-1$, então o sistema coexiste.

Deve-se notar que a combinação dos dois teoremas acima implica pelo menos uma transição de fase entre consenso e coexistência em algum ponto crítico $\varepsilon^{*}$ com a seguinte propriedade:

$$
\varepsilon^{*} \in\left(\frac{F+1}{4}, F-1\right) \text { para todo } F \geq 2 .
$$

Realizamos algumas simulações do processo. Porém, para "acelerar" a dinâmica, adotamos a regra de atualização de Deffuant et al [10], isto é, quando o número de tópicos discordantes entre as opiniões dos agentes sorteados é menor ou igual ao coeficiente de confiança crítico, todos os tópicos são atualizados. Para cada tópico, os agentes escolhem, com igual probabilidade e independentemente dos demais tópicos, em que opinião se basearão. Como o conjunto $\mathbb{Z}$ é infinito, adotamos sucessivamente grafos com os vértices em linha - tal como um conjunto de vértices consecutivos em $\mathbb{Z}$ - com cada vez mais agentes. Foram executadas simulações para três quantidades diferentes de tópicos: $F=20$, $F=50$ e $F=100$. Os valores de $n$ constam nos respectivos gráficos (Figuras 4.9, 4.10 e 4.11). O padrão que observamos é que as estimativas das probabilidades de consenso parecem convergir para uma função do tipo escada valendo zero até $F / 2$ e 1 para valores de $\varepsilon$ maiores que $F / 2$. Assim, uma conjectura razoável é que o valor crítico de $\varepsilon$ para o grafo $\mathbb{Z}$ é $F / 2$, não ficando claro, porém, se $\operatorname{com} \varepsilon=F / 2$ (para $F$ par) haveria ou não consenso.

\section{Modelo de DW, opinião multidimensional binária,} 20 tópicos, grafo em linha

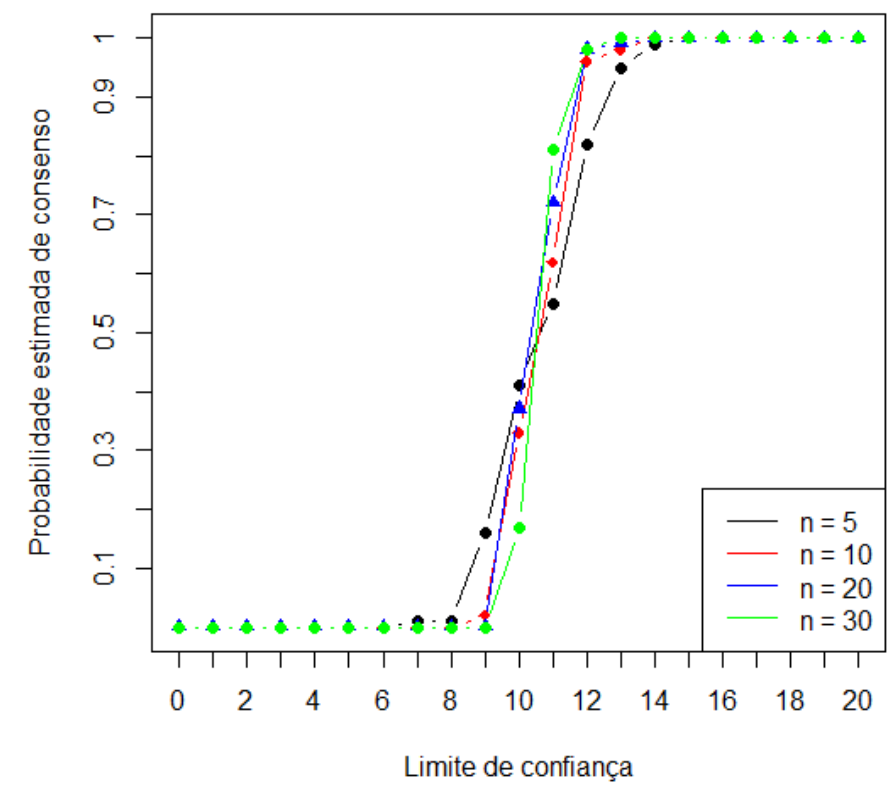

Figura 4.9: Simulação para o modelo de Deffuant com opinião multidimensional com 20 tópicos com opiniões binárias. $n=5,10,20,30$.

Passando para o caso em que as opiniões em cada coordenada do vetor são contínuas, temos o trabalho de Hirscher [29]. Também aí o modelo ocorre em $\mathbb{Z}$, e processos de Poisson em cada elo marcam os instantes em que os agentes vizinhos interagem. 


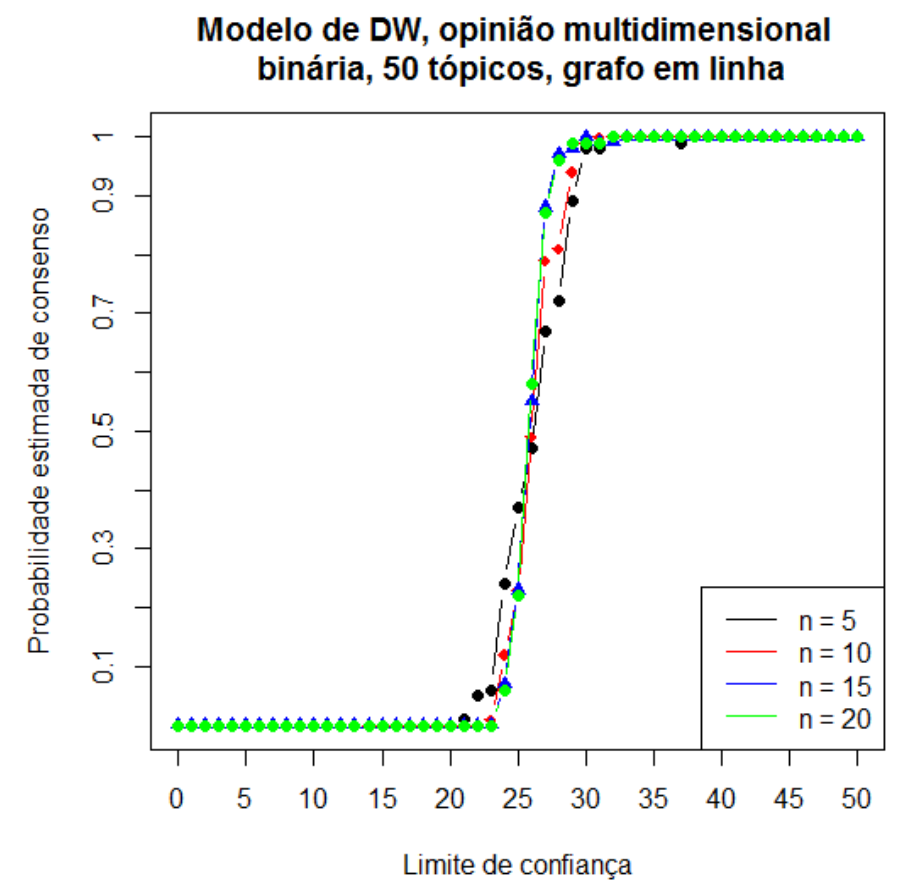

Figura 4.10: Simulação para o modelo de Deffuant com opinião multidimensional com 50 tópicos com opiniões binárias. $n=5,10,15,20$.

Modelo de DW, opinião multidimensional binária, 100 tópicos, grafo em linha

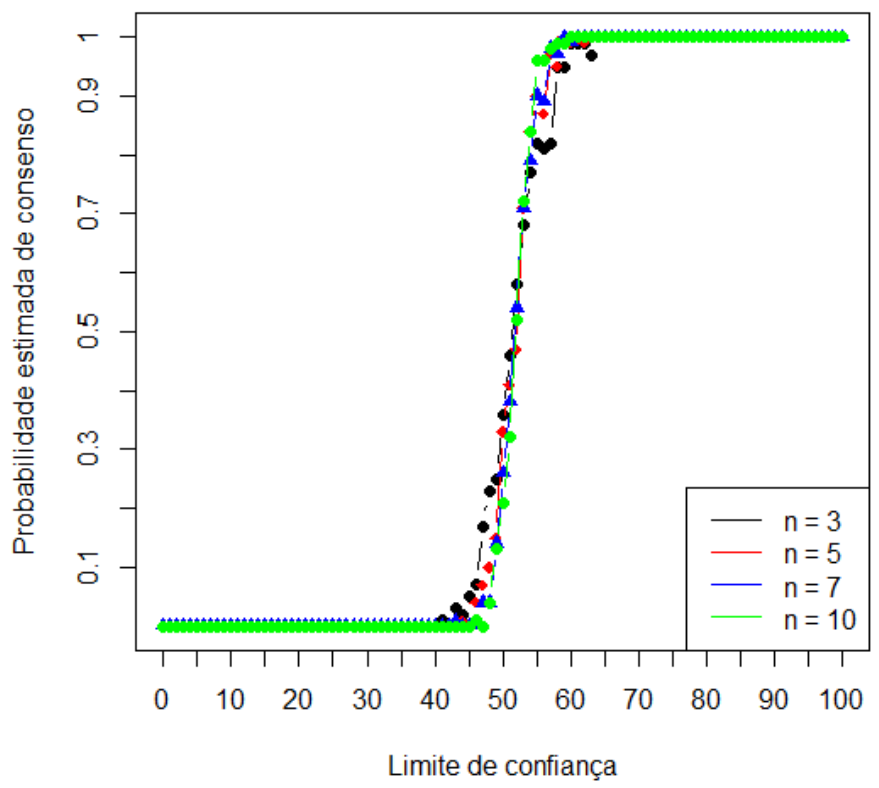

Figura 4.11: Simulação para o modelo de Deffuant com opinião multidimensional com 100 tópicos com opiniões binárias. $n=3,5,7,10$. 
A distância entre dois vetores de opinião aqui é a distância euclidiana entre eles, isto é, se $x_{i}(t)=\left(x_{i}^{(1)}(t), \ldots, x_{i}^{(F)}(t)\right)$ e $x_{j}(t)=\left(x_{j}^{(1)}(t), \ldots, x_{j}^{(F)}(t)\right)$, então

$$
d\left(x_{i}(t), x_{j}(t)\right)=\left\|x_{i}(t)-x_{j}(t)\right\|_{2}=\sqrt{\sum_{f=1}^{F}\left(x_{i}^{(f)}(t)-x_{j}^{(f)}(t)\right)^{2}} .
$$

Quando ocorre um evento de Poisson num elo, digamos $\langle i, j\rangle$, com opiniões respectivamente iguais a $x_{i}\left(t^{-}\right)$e $x_{j}\left(t^{-}\right)$imediatamente antes do instante $t$, suas opiniões são atualizadas (ou não) da seguinte forma:

$$
\begin{aligned}
& x_{i}(t)= \begin{cases}\mu x_{j}\left(t^{-}\right)+(1-\mu) x_{i}\left(t^{-}\right) & \text {se }\left\|x_{i}\left(t^{-}\right)-x_{j}\left(t^{-}\right)\right\|_{2} \leq \varepsilon \\
x_{i}\left(t^{-}\right) & \text {caso contrário }\end{cases} \\
& x_{j}(t)= \begin{cases}\mu x_{i}\left(t^{-}\right)+(1-\mu) x_{j}\left(t^{-}\right) & \text {se }\left\|x_{i}\left(t^{-}\right)-x_{j}\left(t^{-}\right)\right\|_{2} \leq \varepsilon \\
x_{j}\left(t^{-}\right) & \text {caso contrário }\end{cases}
\end{aligned}
$$

Como no caso com opiniões unidimensionais, a opinião atualizada de cada agente sobre cada assunto é uma média ponderada das opiniões dos dois agentes do elo sobre o mesmo tópico.

Quanto aos possíveis cenários em relação ao consenso (ou ausência dele) quando $t \rightarrow$ $\infty$, temos as definições seguintes.

Definição 4.7. Possíveis tipos de consenso:

(i) Ausência de consenso

Existem elos para sempre bloqueados, isto é, elos $\langle i, j\rangle$ tais que

$$
\left\|x_{i}(t)-x_{j}(t)\right\|_{2}>\varepsilon
$$

para todo $t$ maior que algum $T_{0}(i, j)<\infty$.

(ii) Consenso fraco

Para todos os elos $\langle i, j\rangle \in E$,

$$
\lim _{t \rightarrow \infty}\left\|x_{i}(t)-x_{j}(t)\right\|_{2}=0
$$

ou seja, para todos $\langle i, j\rangle \in E$ e $\varepsilon>0$, há $T_{f r}(\langle i, j\rangle, \varepsilon)<\infty$ tal que, se $t>$ $T_{f r}(\langle i, j\rangle, \varepsilon)$, então

$$
\left\|x_{i}(t)-x_{j}(t)\right\|_{2}<\varepsilon
$$

(iii) Consenso forte

Para todo vértice $i \in V$,

$$
\lim _{t \rightarrow \infty} x_{i}(t)=\mu:= \begin{cases}\frac{\sum_{i \in V} x_{i}(0)}{\# V} & \text { se } G \text { for finito } \\ \mathbb{E} x(0) & \text { caso contrário }\end{cases}
$$

$x_{0}$ é uma variável aleatória com a mesma distribuição de $x_{0}(v), \forall v \in V$. Para futuras referências ao longo do texto, denotemos essa distribuição por $\mathcal{L}\left(x_{0}\right)$. 
Notemos que, num grafo finito, o consenso fraco implica o consenso forte. Para notar isso, lembremos primeiramente que a condição de consenso forte é equivalente a exigir que, para todo $\varepsilon>0$, exista $T(\varepsilon)<\infty$ tal que, se $t>T(\varepsilon)$, então $\left\|x_{i}(t)-\mu\right\|_{2}<\varepsilon, \forall i \in V$. Assim, para um certo $\varepsilon>0$, definamos $T:=\max _{\langle i, j\rangle \in E} T_{f r}(\langle i, j\rangle, \varepsilon) \operatorname{com} T_{f r}(\langle i, j\rangle, \varepsilon)$ como acima. Seja $n:=\# V$ o número de vértices do grafo. Então, para algum $t>T(\varepsilon)$, teremos

$$
\begin{aligned}
\left\|x_{i}(t)-\frac{\sum_{j \in V} x_{j}(t)}{n}\right\|_{2} & =\left\|\frac{n x_{i}(t)-\sum_{j \in V} x_{j}(t)}{n}\right\|_{2} \|_{2} \\
& =\left\|\frac{\sum_{j \in V}\left[x_{i}(t)-x_{j}(t)\right]}{n}\right\|^{2} \\
& =\sqrt{\sum_{f=1}^{F}\left(\frac{\sum_{j \in V}\left(x_{i}^{(f)}(t)-x_{j}^{(f)}(t)\right)}{n}\right)^{2}} \\
& =\frac{1}{n} \sqrt{\sum_{f=1}^{F}\left[\sum_{j \in V}\left(x_{i}^{(f)}(t)-x_{j}^{(f)}(t)\right)\right]^{2}} \\
& =\frac{1}{n}\left\|\sum_{j \in V}\left[x_{i}(t)-x_{j}(t)\right]\right\|_{2} \\
& \leq \frac{1}{n} \sum_{j \in V}\left\|x_{i}(t)-x_{j}(t)\right\|_{2} \\
& \leq \frac{1}{n} n \varepsilon=\varepsilon
\end{aligned}
$$

Para um grafo infinito, a implicação acima não necessariamente é verdade.

Relembrando o que já havíamos mencionado mais acima, $\mathcal{L}(x(0))$ em $\mathbb{R}^{F}$ é a distribuição de probabilidades das opiniões iniciais de cada agente, isto é, $x_{i}(0), i \in \mathbb{Z}$. $F$ é o número de tópicos que formam cada opinião. Consideremos $\mathbb{R}^{F}$ equipado com a $\sigma$-álgebra de Borel $\mathcal{B}^{F}$ gerada pela norma euclidiana.

Definição 4.8. Definiremos o raio $R$ da distribuição $\mathcal{L}_{0}(x(0))$ como o menor raio de uma bola euclidiana $F$-dimensional com centro em $\mathbb{E} x(0)$ (caso esta exista) tal que a bola tenha probabilidade 1. Matematicamente:

$$
R:=\inf \{r>0: \mathbb{P}(x(0) \in B(\mathbb{E} x(0) ; r))=1\},
$$

em que $B(x ; r):=\left\{y \in \mathbb{R}^{F}:\|x-y\|_{2} \leq r\right\}$.

O seguinte teorema é uma extensão dos Teoremas 4.2 e 4.3 para o caso com opinião unidimensional estudado por Häggström [25]:

Teorema 4.8 (Hirscher [29]). Para o modelo de Deffuant em $\mathbb{Z}$ com espaço de opinião subjacente $\left(\mathbb{R}^{F},\|\cdot\|_{2}\right)$ e distribuição inicial de opiniões $\mathcal{L}(x(0))$, temos o seguinte comportamento limite:

(a) Se $\mathcal{L}\left(x_{0}\right)$ tem raio $R$ e possui massa ao redor da sua média, i.e.,

$$
\mathbb{P}\left(x_{0} \in B(\mathbb{E} ; r)\right)>0, \quad \forall r>0,
$$

então o parâmetro crítico será $\varepsilon^{*}=R$, o que significa que, para $\varepsilon>R$, existe consenso forte q.c. e, para $\varepsilon<R$, q.c. não existe consenso de nenhum tipo. 
(b) Se pelo menos uma das coordenadas $x_{0}^{(i)}, i=1, \ldots, F$, tem distribuição marginal $\mathcal{L}\left(x_{0}^{(i)}\right)$ com suporte não limitado e $\mathbb{E}\left(x_{0}^{(i)}\right)$ existe (finita ou não), então quase certamente não haverá consenso - independentemente de $\varepsilon$.

No caso em que a distribuição das opiniões iniciais é limitada, temos o próximo teorema. Porém, antes, vamos definir o conceito de configuração finita e maior lacuna do suporte de uma distribuição.

Definição 4.9. Uma configuração finita é definida como uma tripla formada por

- uma seção finita $\{1, \ldots, n\}$ do grafo;

- uma sequência finita $\left(e_{i}\right)_{i=1}^{N}$ de elos $e_{i} \in\{\langle 1,2\rangle, \ldots,\langle n-1, n\rangle\}$

- e alguns valores $x_{1}, \ldots, x_{n}$ no suporte de $\mathcal{L}(x(0))$.

Executar a dinâmica do modelo de Deffuant com parâmetro $\varepsilon$ nessa configuração significa que tomamos $x_{1}, \ldots, x_{n}$ como opiniões iniciais, isto é, $x_{i}(0)=x_{i}, \forall i \in \underline{n}$, e então atualizamos esses valores de acordo com (4.4) e (4.5) interpretando $\left(e_{i}\right)_{i=1}^{N}$ como os elos em que ocorrem os primeiros $N$ eventos de Poisson nos elos $\langle 1,2\rangle, \ldots,\langle n-1, n\rangle$ em ordem cronológica. Dada uma distribuição inicial $\mathcal{L}(x(0))$ para as opiniões iniciais de cada agente, o comprimento da maior lacuna (gap) em seu suporte é definido como

$$
h:=\inf \left\{\varepsilon>0: \mathcal{D}_{\varepsilon}(\nu) \text { é conexo }\right\},
$$

em que $\mathcal{D}_{\varepsilon}$ denota o conjunto de vetores em $\mathbb{R}^{F}$ que os valores das opiniões das configurações finitas podem atingir coletivamente se a dinâmica for executada com limite de confiança $\varepsilon$.

Convém notar que $\mathcal{D}_{\varepsilon}(\nu)$ e o suporte da distribuição de $x(t)$ (variável aleatória identicamente distribuída a $\left.x_{i}(t), \forall i \in \mathbb{Z}\right)$ possuem uma relação intrínseca:

Proposição 4.1. Se $\varepsilon \mapsto \mathcal{D}_{\varepsilon}(\nu)$ não tem saltos em $\varepsilon>0$, a igualdade seguinte é válida para todo $t>0$ :

$$
\operatorname{supp}_{\varepsilon}(\boldsymbol{x}(t))=\mathcal{D}_{\varepsilon}(\nu) .
$$

Teorema 4.9 (Hirscher [29]). Para um modelo de Deffuant em $\mathbb{Z}$ com distribuição inicial em $\left(\mathbb{R}^{F},\|\cdot\|_{2}\right)$ limitada, isto é,

$$
R=\inf \{r>0: \mathbb{P}(x(0) \in B(\mathbb{E} x(0) ; r))=1\}<\infty,
$$

e com h sendo o comprimento da maior lacuna no seu suporte, o valor crítico do limite de confiança é $\varepsilon^{*}=\max \{R, h\}$. Ou seja, para $\varepsilon>\max \{R, h\}$, existe consenso forte q.c.; para $\varepsilon<\max \{R, h\}$, q.c. não há nenhum consenso.

Os resultados acima são válidos para o caso em que a medida de distância entre duas opiniões é dada pela norma euclidiana. Porém, também poderíamos considerar uma métrica geral $\rho$. Neste caso, Hirscher [29] também apresenta resultados análogos aos Teoremas 4.8 e 4.9. Mas antes vejamos alguns conceitos:

Definição 4.10. Consideremos uma métrica $\rho$ em $\mathbb{R}^{F}$.

(i) A métrica $\rho$ é sensível à coordenada $i$ se existir uma função $\varphi:[0, \infty) \rightarrow[0, \infty)$ tal que $\lim _{s \rightarrow \infty} \varphi(s)=\infty$ e, para quaisquer dois vetores $x, y \in \mathbb{R}^{F}$ com $\left|x_{i}-y_{i}\right|>s$, valer que $\rho(x, y)>\varphi(s)$. 
(ii) Dizemos que $\rho$ é localmente dominada pela distância euclidiana se existirem $\gamma, c>0$ tais que, para todos $x, y \in \mathbb{R}^{F} \operatorname{com}\|x-y\|_{2} \leq \gamma$, vale que

$$
\rho(x, y) \leq c\|x-y\|_{2}
$$

(iii) Chamamos fracamente convexa à medida $\rho$ se, para todos $x, y, z \in \mathbb{R}^{F}$, valer que

$$
\rho(x, \alpha y+(1-\alpha) z) \leq \max \{\rho(x, y), \rho(x, z)\} \quad \text { para todo } \alpha \in[0,1] .
$$

Teorema 4.10 (Hirscher [29]). No modelo de Deffuant em $\mathbb{Z}$ com o espaço de opiniões subjacente $\left(\mathbb{R}^{F}, \rho\right)$ e uma distribuição de opiniões inicial $\mathcal{L}(x(0))$, temos o seguinte comportamento limite:

(a) Se $\rho$ é localmente dominada pela distância euclidiana e $\mathcal{L}(x(0))$ tem segundo momento finito, raio $R_{p} \in[0, \infty)$ e massa ao redor da sua média, isto é,

$$
\mathbb{P}\left(x(0) \in B_{\rho}(\mathbb{E} x(0) ; r)\right)>0 \text { para todo } r>0,
$$

então o parâmetro crítico será $\varepsilon^{*}=R_{\rho}$, ou seja, para $\varepsilon>R_{\rho}$, haverá consenso forte quase certamente e, para $\varepsilon<R_{\rho}$, quase certamente não haverá consenso.

(b) Seja $x(0)=\left(x^{(1)}(0), \ldots, x^{(F)}(0)\right)$ o vetor de opiniões iniciais. Se uma das coordenadas tiver distribuição marginal não-limitada (com respeito ao valor absoluto), seu valor esperado existir (finito, $+\infty$ ou $-\infty$ ) e $\rho$ for sensivel a essa coordenada, o comportamento limite será, quase certamente, de ausência de consenso, independentemente de $\varepsilon$.

Também o Teorema 4.9 encontra seu correspondente no caso em que a métrica é diferente da norma euclidiana:

Teorema 4.11 (Hirscher [29]). Consideremos um modelo de Deffuant em $\mathbb{Z}$ com valores das opiniões em $\left(\mathbb{R}^{F}, \rho\right)$, em que $\rho$ é a medida correspondente e tem as propriedades de ser fracamente convexa e localmente dominada pela distância euclidiana. Suponhamos que $\mathcal{L}(x(0))$ tenha segundo momento finito e seja limitada com respeito a $\rho$, i.e.,

$$
R_{\rho}=\left\{r>0: \mathbb{P}\left(x(0) \in B_{\rho}(\mathbb{E} x(0) ; r)\right)=1\right\}<\infty .
$$

Seja $h_{\rho}$ o comprimento da maior lacuna do suporte de $\mathcal{L}(x(0))$. Então, o valor crítico do limite de confiança, em que ocorre a transição de q.c. nenhum consenso para q.c. consenso forte, é $\varepsilon^{*}=\max \left\{R_{\rho}, h_{\rho}\right\}$.

\subsection{Modelo baseado na densidade}

Sejam $S \subset \mathbb{R}^{d}$ um espaço de opiniões apropriado, $\left[\varepsilon_{1}, \varepsilon_{2}\right]$ um intervalo de possíveis limites de confiança e a função de densidade inicial $P(\cdot, 0, \cdot): S \times\left[\varepsilon_{1}, \varepsilon_{2}\right] \rightarrow[0, \infty]$ com $\int_{S} \int_{\varepsilon_{1}}^{\varepsilon_{2}} \mathrm{~d} x \mathrm{~d} \varepsilon P(x, 0, \varepsilon)=1$. Para simplificar a notação, abreviaremos $\int_{\varepsilon_{1}}^{\varepsilon_{2}} \mathrm{~d} \varepsilon P(x, t, \varepsilon)$ por 
$P(x, t)$. Dessa forma, podemos definir a seguinte equação diferencial:

$$
\begin{array}{r}
\frac{\partial}{\partial t} P(x, t, \varepsilon)=\int_{S} \mathrm{~d} x_{1}\left[\int _ { \varepsilon _ { 1 } } ^ { \varepsilon _ { 2 } } \mathrm { d } \overline { \varepsilon } \left(\int _ { \| x _ { 1 } - x _ { 2 } \| \leq \overline { \varepsilon } } \mathrm { d } x _ { 2 } \left[P\left(x_{1}, t, \bar{\varepsilon}\right) P\left(x_{2}, t\right)+\right.\right.\right. \\
\left.\left.P\left(x_{1}, t\right) P\left(x_{2}, t, \bar{\varepsilon}\right)\right] \delta\left(x-\frac{x_{1}-x_{2}}{2}\right)\right) \\
\left.-\int_{\left\|x_{1}-x_{2}\right\| \leq \bar{\varepsilon}} \mathrm{d} x_{2}\left(P\left(x_{1}, t, \varepsilon\right) P\left(x_{2}, t\right) \delta\left(x-x_{1}\right)+P\left(x_{1}, t\right) P\left(x_{2}, t, \varepsilon\right) \delta\left(x-x_{2}\right)\right)\right]
\end{array}
$$

Dado um valor inicial de $x$, o modelo de Deffuant em tempo contínuo baseado no agente é a solução da Equação (4.6). O modelo discreto, por sua vez, é a sequência $(P(\cdot, t, \cdot))_{t \in \mathbb{N}}$ definida recursivamente por

$$
P(x, t+1, \varepsilon)=P(x, t, \varepsilon)+\Delta P(x, t, \varepsilon)
$$

com $\Delta P(x, t, \varepsilon)=\frac{\partial}{\partial t} P(x, t, \varepsilon)$.

Para um limite de confiança homogêneo $\varepsilon=\left[\varepsilon_{1}, \varepsilon_{2}\right]$, a Equação (4.6) reduz-se a

$$
\begin{array}{r}
\frac{\partial}{\partial t} P(x, t)=\int_{S} \mathrm{~d} x_{1} \int_{\left\|x_{1}-x_{2}\right\| \leq \varepsilon} \mathrm{d} x_{2}\left(P ( x _ { 1 } , t ) P ( x _ { 2 } , t ) \left(2 \delta\left(x-\frac{x_{1}+x_{2}}{2}\right)\right.\right. \\
\left.\left.-\left(\delta\left(x-x_{1}\right)+\delta\left(x-x_{2}\right)\right)\right)\right)
\end{array}
$$

Ben-Naim et al [2] mostram que, enquanto a Equação (4.7) conserva a massa e a média da densidade de opiniões, a Equação (4.6) mantém apenas a massa para cada valor de $\varepsilon$ e para a densidade agregada. Os autores ainda provam que, para $S=[0,1]$ e $\varepsilon \geq 0,5, P(\cdot, t)$ na Equação (4.7) converge, com $t \rightarrow \infty$, para uma distribuição limite $P(x, \infty)=\delta\left(x-x_{0}\right)$, em que $x_{0}$ é a opinião média.

Também mostram que, para uma distribuição inicial uniforme em $[-\Delta, \Delta]$ e $\varepsilon=1$, a densidade converge para a função delta em 0 , isto é, $P(x, t) \rightarrow P_{\infty}(x)=M_{0} \delta(x)$, em que $M_{k}(t) \equiv \int x^{k} P(x, t)$, e $M_{0} \equiv M_{0}(t)=2 \Delta$, para todo $t \in \mathbb{R}$. Para $\Delta>1$, a equação de taxas não é mais solúvel analiticamente. Os autores usam então o método de Adams-Bashforth de quarta ordem e descobrem que a densidade converge para uma soma ponderada de funções delta:

$$
P(x, \infty)=\sum_{i=1}^{r} m_{i} \delta\left(x-x_{i}\right),
$$

em que $x_{1}, \ldots, x_{r}$ são as opiniões remanescentes no equilíbrio, duas a duas a uma distância maior que $\varepsilon$, e $m_{i}, 1 \leq i \leq r$, as massas dos correspondentes clusters. Pelas leis de conservação, $m_{i}=M_{0}=2 \Delta$, e $\sum m_{i} x_{i}=M_{1}=0$.

Quanto aos tipos de clusters, afirmam existirem basicamente três tipos: clusters maiores (massa maior que 1), menores (massa menor que $10^{-2}$ ) e um cluster central localizado exatamente em $x=0$. As localizações dos clusters exibem nítida regularidade, como se observa na Figura 4.12.

A Figura 4.13 corresponde ao diagrama de bifurcação para o modelo de Deffuant homogêneo baseado na densidade conforme exposto por Lorenz [42]. O diagrama foi obtido plotando o estado de equilíbrio de cadeias de Markov interativas com 1.001 classes para 


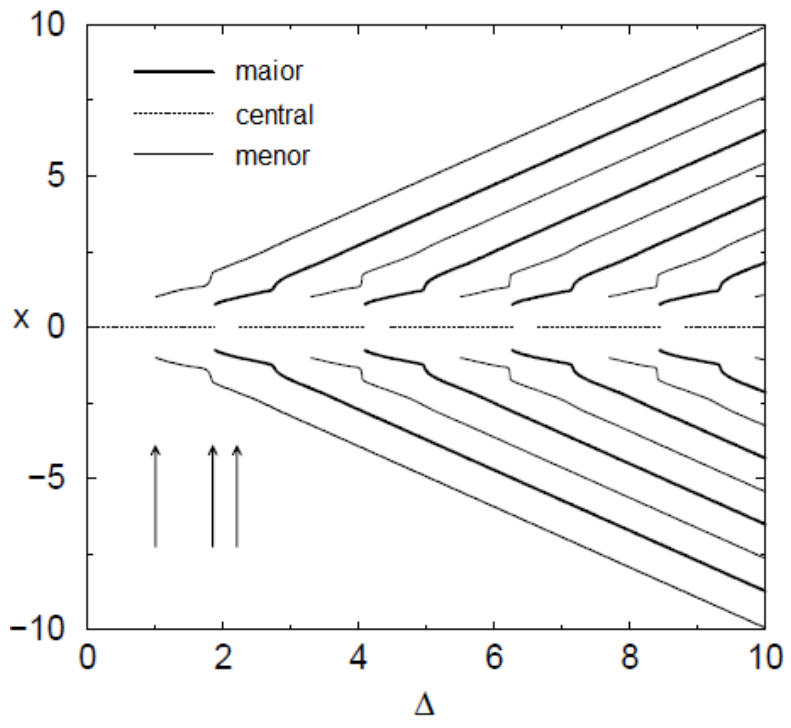

Figura 4.12: Localização dos clusters no equilíbrio em função do valor de $\Delta$. As setas indicam as três primeiras bifurcações.

diferentes valores do limite de confiança $\varepsilon$. O estado de equilíbrio é atingido quando os clusters estão distantes entre si por pelo menos $\varepsilon$ e a amplitude de cada cluster é de no máximo $\varepsilon$. Linhas mais grossas referem-se a clusters com mais massa, e linhas mais finas, a clusters com menos massa. As linhas pontilhadas são para propósito de orientação e indicam a região $[0,5-\varepsilon ; 0,5+\varepsilon]$. Um ponto importante a se observar é a existência de clusters menores nos extremos e entre clusters maiores. Tal característica não ocorre em simulações do modelo baseado no agente. Por causa dos pequenos tamanhos populacionais, clusters menores não conseguem desenvolver-se. O padrão que se observa repetidamente é o seguinte: primeiramente a formação de dois clusters menores extremos, em seguida a bifurcação do cluster central e, por último, o ressurgimento do cluster central. Outra peculiaridade que se nota ao longo de toda a faixa de valores de $\varepsilon$ é que a quantidade de clusters na configuração de equilíbrio é da ordem de $\frac{1}{\varepsilon}$, o que se assemelha à conjectura para o modelo baseado no agente exposta por Deffuant el al [10] .

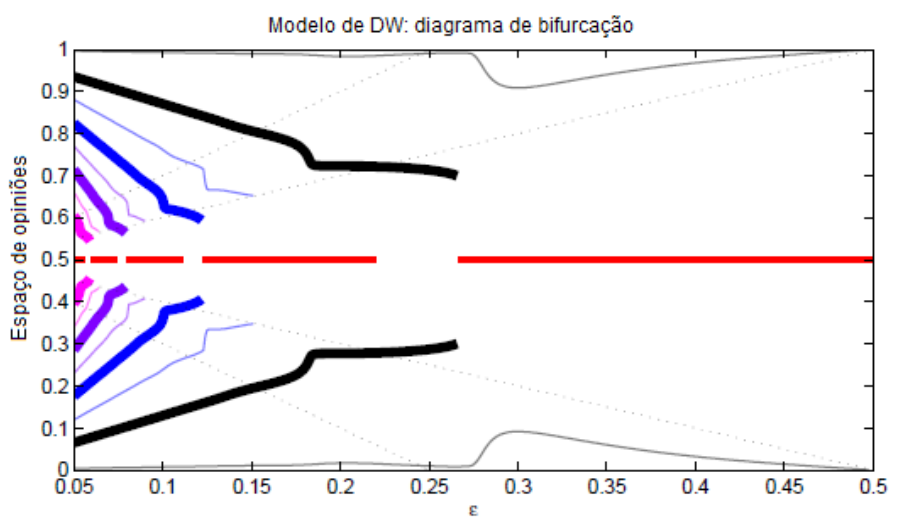

Figura 4.13: Diagrama de bifurcação para o modelo de Deffuant 


\subsection{Generalizando os modelos de Hegselmann-Krause e Deffuant}

Como já se comentou, as diferenças básicas entre os modelos de Hegselmann-Krause e de Deffuant são duas: enquanto no primeiro modelo cada agente pode considerar a opinião de todos os outros em cada passo, no segundo cada agente só pode analisar a opinião de outro agente além da sua; além disso, o modelo de Deffuant possui um parâmetro (usualmente denotado por $\mu$ ) que indica quanto as opiniões dos agente se aproximará uma da outra caso a diferença entre elas esteja dentro do limite de confiança, e tal parâmetro não existe no modelo de Hegselmann-Krause.

Com o objetivo de estabelecer uma estrutura comum a ambos os modelos, da qual eles fariam parte como casos particulares, Urbig e Lorenz [53] generalizaram esses modelos de opinião com confiança limitada da maneira que se segue. Primeiramente definem uma sequência de matrizes $C(t) \in\{0,1\}^{n \times n}$ para $t \in \mathbb{N}$ tais que a diagonal é positiva em cada matriz. Essa sequência é denominada por eles regime de comunicação. Ademais, também definem uma função peso $_{i}: \underline{n} \times \mathbb{R}^{n} \times \mathbb{N} \rightarrow[0,1]$ chamada de regra de média com as seguintes características:

- Para todo $t \in \mathbb{N}$ e para todo $\boldsymbol{x} \in \mathbb{R}^{n}, \operatorname{peso}_{i}(j, \boldsymbol{x}(t), t)=1$

- Para todo $t \in \mathbb{N}$, todo $\boldsymbol{x}(t) \in \mathbb{R}^{n}$ e todo $j \in \underline{n}, c_{i j}(t)=0 \operatorname{implica}_{\operatorname{peso}_{i}}(j, \boldsymbol{x}(t), t)=0$.

O $\operatorname{peso}_{i}(j, \boldsymbol{x}(t), t)$ é equivalente aos pesos $a_{i j}(t)$ na Equação $(2.7)$ e também representa o valor que o agente $i$ dá à opinião do agente $j$ em relação às opiniões dos demais agentes no instante $t$. A segunda condição garante que o agente só atribua peso a opiniões de agentes que ele percebe naquele momento. Dessa forma, a matriz de confiança é definida como

$$
A(t, \boldsymbol{x}(t), C(t))_{[i, j]}:=\operatorname{peso}_{i}(j, \boldsymbol{x}(t), t),
$$

de modo que o processo de dinâmica de opinião contínua é uma sequência de perfis de opinião $(\boldsymbol{x}(t))_{t \geq 0}$ definidos recursivamente por

$$
\boldsymbol{x}(t+1)=A(t, \boldsymbol{x}(t), C(t)) \boldsymbol{x}(t) .
$$

Notemos que $C(t), t \in \mathbb{N}$, corresponde a uma parte da generalização dos modelos de Hegselmann-Krause e de Deffuant. No caso do primeiro modelo, $C(t)$ é uma matriz com o número 1 em todas as posições. No segundo, para todo $t \in \mathbb{N}, C(t)$ é uma matriz simétrica com exatamente 2 linhas contendo exatamente 2 números 1 e as entradas restantes são todas nulas, exceto as diagonais, iguais a 1. De forma mais geral, podemos definir um regime de comunicação $m$ como um regime de comunicação $(C(t))_{t \in \mathbb{N}}$ tal que, para todo $t \in \mathbb{N}, C(t)$ tenha exatamente $m$ linhas com exatamente $m$ entradas 1 e o restante das entradas igual a zero com exceção das diagonais, iguais a 1.

Para incluir a noção do parâmetro de convergência $\mu$ do modelo de Deffuant, os autores introduzem a noção de autossuporte.

Definição 4.11. Sejam $C(t) \in\{0,1\}^{n}$ um regime de comunicação e $i \in \underline{n}$ um agente. Sejam ainda $\boldsymbol{x}(t)$ um perfil de opinião, $\varepsilon \in(0,1]$ e $\mu \in[0,1]$. Omitindo o tempo para 
simplificar a notação, podemos definir então a regra de média como

$$
\operatorname{peso}_{i}(j, \boldsymbol{x})= \begin{cases}\mu+\frac{1-\mu}{|I(i, \boldsymbol{x})|} & \text { se } j=i ; \\ \frac{1-\mu}{|I(i, \boldsymbol{x})|} & \text { se } j \in I(i, \boldsymbol{x}) \text { e } j \neq i ; \\ 0 & \text { caso contrário, }\end{cases}
$$

com $\varepsilon$ sendo o limite de confiança e $I(i, \boldsymbol{x}):=\left\{j \in \underline{n}: c_{i j}=1\right.$ e $\left.\left|x_{i}-x_{j}\right| \leq \varepsilon\right\}$.

É importante ressaltar que o parâmetro $\mu$ acima não corresponde diretamente ao parâmetro representado pela mesma letra na elaboração usual do modelo de Deffuant. Podemos interpretar $\mu$ aqui como a parcela da opinião do agente $i$ que não participa da média com os outros agentes, sendo mantida para a próxima etapa independentemente dos agentes nos quais $i$ confie. A outra parcela $(1-\mu)$ será constituída pela média das opiniões dos agentes em que confia $i$ - inclusive ele mesmo. Denotando por $\mu_{D} \mathrm{o}$ parâmetro do modelo de Deffuant como exposto originalmente, teríamos $\mu=1-2 \mu_{D}$. No modelo de Hegselmann-Krause usual, $\mu=0$.

Ao modelo descrito acima daremos o nome intuitivo de modelo de Urbig e Lorenz. Uma observação é a semelhança com o modelo de Friedkin e Johnsen citado por Hegselmann e Krause [27], segundo o qual o agente $i$ atualiza opinião com um determinado grau $g_{i}$ de aderência à sua opinião inicial e um grau $1-g_{i}$ de suscetibilidade à influência social. Não se trata aí de um modelo de confiança limitada. Nessa variação, a dinâmica de opinião é da forma

$$
x_{i}(t+1)=g_{i} x_{i}(0)+\left(1-g_{i}\right)\left(a_{i}^{(1)} x_{1}(t)+\ldots+a_{i}^{(n)} x_{n}(t)\right) .
$$

Urbig e Lorenz [53] realizaram uma série de simulações de seu modelo. Os principais aspectos observados foram o número final de clusters, o tempo de convergência e o tempo da última quebra (instante a partir do qual são definidos os clusters, ainda que não se tenha obtido a convergência em cada cluster). Primeiramente se analisou a influência do número $m$ de agentes comunicantes. Para tanto, manteve-se o parâmetro $\mu$ constante igual a zero. Foram executadas nove simulações, cada uma das quais combinando um valor de $\varepsilon-0,1 ; 0,2 ; 0,3-$ com um valor de $m-2,20,100=$ n. No gráfico na Figura 4.14, o eixo horizontal corresponde ao tempo, e o vertical, às opiniões. Podemos ver que o número de clusters diminui com o aumento de $\varepsilon$ e de $m$. Além disso, para valores menores de $m$, aumentam o tempo de convergência e o tempo da última quebra.

Para obterem mais evidências sobre a observação acima, os autores construíram o gráfico da Figura 4.15 baseado em diferentes cenários considerando-se 50 valores de $\varepsilon$ e 50 valores de $m$. Cada cenário foi simulado 10 mil vezes a partir de opiniões iniciais escolhidas aleatoriamente. Com algumas exceções, mais agentes se comunicando resulta em menos clusters no final. Ademais, o desvio padrão do número final de clusters tende a diminuir com o aumento de $m$ a partir de um certo $m_{0}$, que depende de $\varepsilon$.

Para analisar o efeito do autossuporte $\mu$, realizaram-se primeiramente três simulações, todas com $m=n=100$ agentes e $\varepsilon=0,25$. Foram adotados três valores distintos para o parâmetro $\mu$ : 0;0,3;0,6. Os resultados podem ser visualizados na Figura 4.16. Quando $\mu$ passa de 0 para 0,3 , o número de clusters diminui de 2 para 1 . Porém, quando se aumenta o mesmo parâmetro de 0,3 para 0,6, o número final de clusters volta para 2 . Tal fato pode ser resultado de dois efeitos antagônicos produzidos pelo crescimento do autossuporte: por um lado, os agentes com opiniões centrais tendem a demorar mais para "perderem o contato" com agentes de opiniões extremas e, com isso, forçam agentes com 

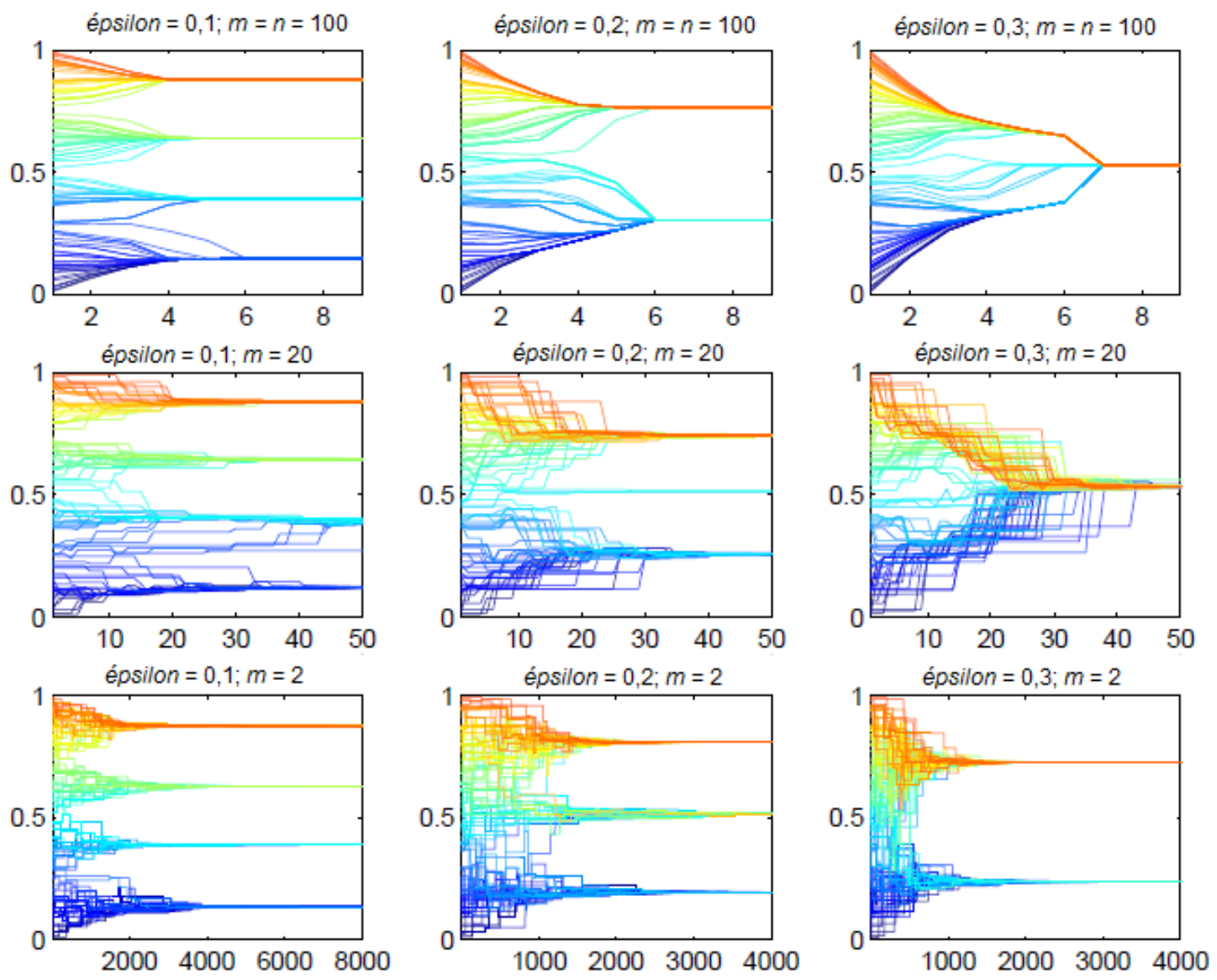

Figura 4.14: Resultados de simulações para o modelo de Urbig e Lorenz com $n=100$ com opiniões iniciais determinadas aleatoriamente
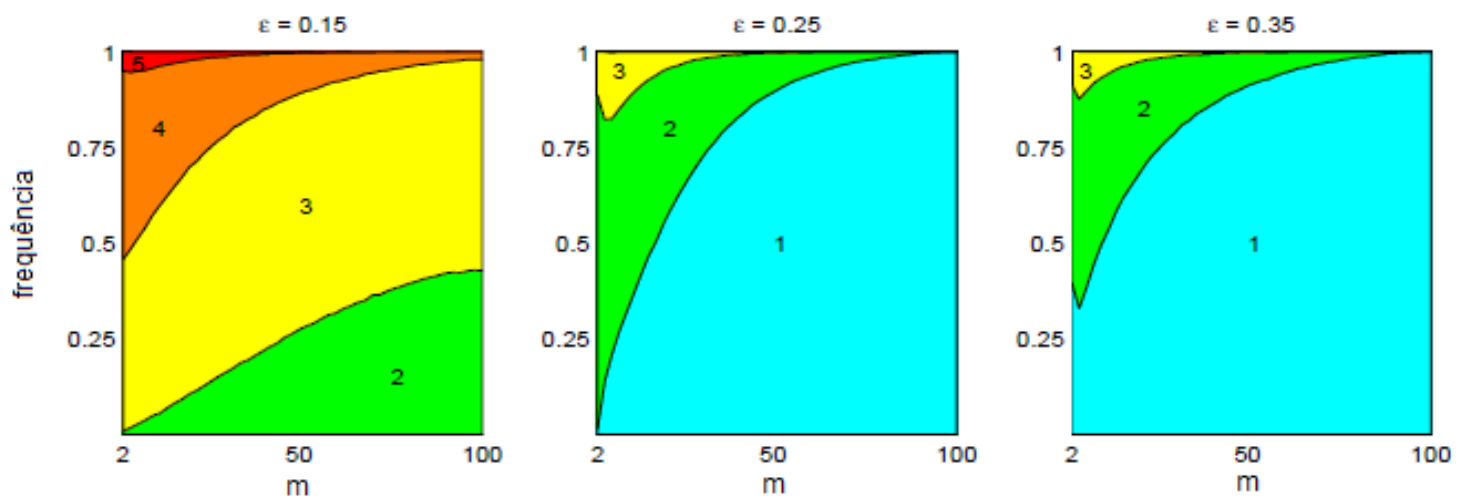

Figura 4.15: Estimativa da probabilidade de certos números de clusters em função do número de agentes comunicantes para três valores de $\varepsilon$ : 0,$15 ; 0,25 ; 0,35$ 
essas opiniões a chegarem ao consenso; por outro lado, agentes com opiniões extremas podem não aproximar-se rápido o suficiente dos agentes moderados, impossibilitando assim o consenso.
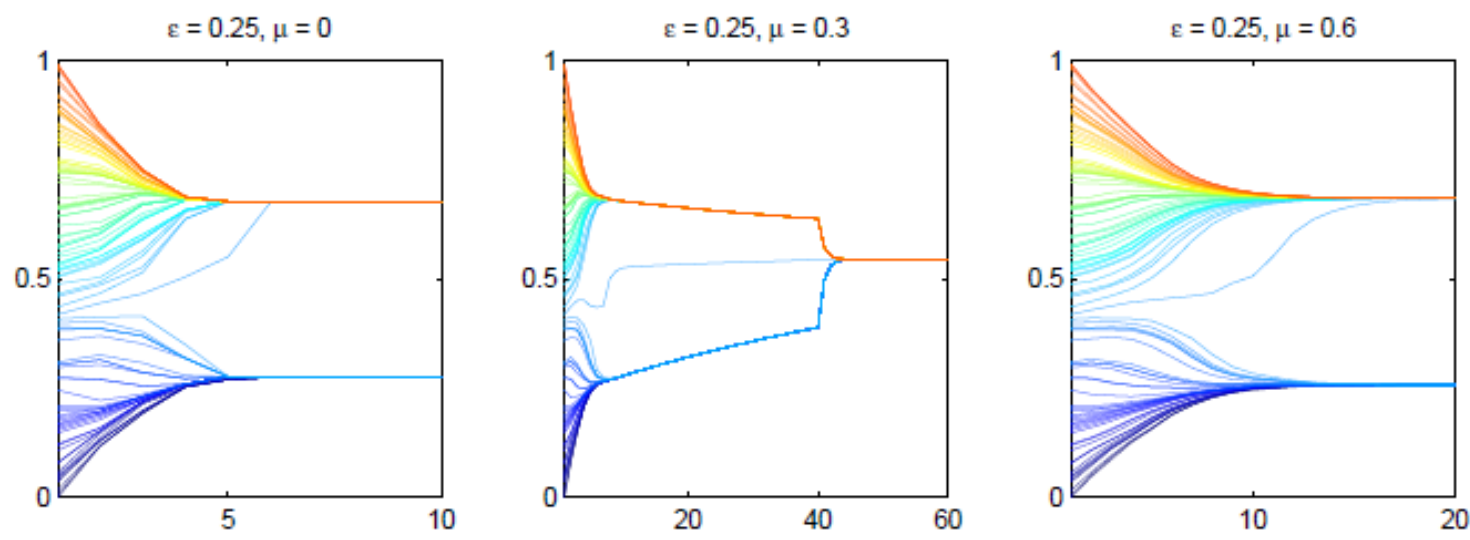

Figura 4.16: Exemplos para $\varepsilon=0,25, \mathrm{n}=\mathrm{m}=100$ e 3 valores de $\mu: 0 ; 0,3 ; 0,6$

Uma análise mais ampla pode-se observar na Figura 4.17, a qual mostra o número médio de clusters e o tempo médio de convergência para 100 agentes, com 3 possíveis valores de $m, 30$ estágios de $\varepsilon$ e também 30 estágios de $\mu$. Cada configuração foi simulada 5 mil vezes com opiniões iniciais escolhidas aleatoriamente. Para os três valores de $m$ e todos os valores de $\mu$, notamos que, ao aumentar $\varepsilon$, tem-se a diminuição do número médio de clusters. Por outro lado, dependendo do número de agentes comunicantes e do limite de confiança, o número médio de clusters pode aumentar ou diminuir com a elevação de $\mu$. Quanto ao tempo médio de convergência, apesar de se notar uma tendência global de diminuição com relação ao aumento de $\varepsilon$, tal comportamento não é mantido ao longo de toda a faixa de valores de $\varepsilon$. Porém, para os três valores de $m$ sempre ocorre elevação no tempo médio de convergência ao aumentar $\mu$. 

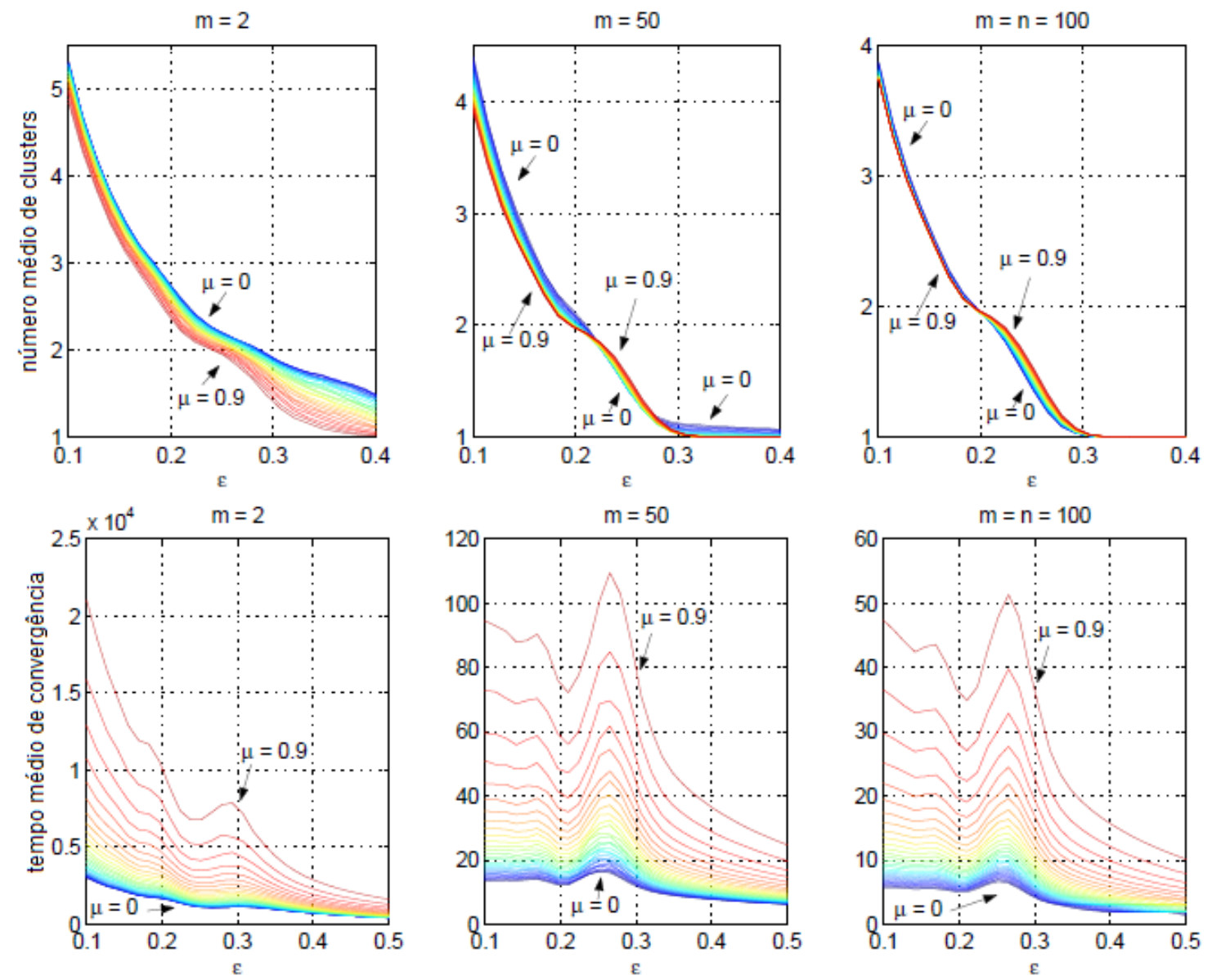

Figura 4.17: Número médio de clusters e tempo médio de convergência para diferentes valores de $\mu$ (azul representa $\mu=0$, e vermelho, $\mu=0,9$ ) e três valores de $m$ : 2,20 e $100=n$ 


\section{Capítulo 5}

\section{Conclusão}

Neste trabalho, fizemos uma revisão da literatura acerca de modelos de dinâmica de opinião, conferindo maior enfoque ao estudo de dois modelos com confiança limitada, nomeadamente os modelos de Hegselmann-Krause e de Deffuant-Weisbuch. Apesar da dependência, em ambos os casos, de um certo grau prévio de similaridade entre as opiniões dos agentes para que eles possam influenciar-se mutuamente, há basicamente duas diferenças entre os dois modelos. Enquanto, no primeiro modelo, as interações se dão entre todos os agentes conjuntamente a cada passo, no segundo as interações ocorrem entre dois agentes por vez. Além disso, no modelo de Deffuant, existe o chamado parâmetro de convergência, o qual determina a intensidade com que os agentes se basearão na opinião alheia para atualizar a sua própria.

Como se pôde notar, uma parte relevante da pesquisa atual sobre o tema consiste no estudo da convergência dos sistemas, incluindo aí a busca pelos valores críticos dos coeficientes de confiança em cada caso, além de condições para que se atinja o consenso.

Uma condição suficiente especialmente importante para o consenso no modelo de Hegselmann-Krause é que todo par de agentes tenha confiança (ou seja, suas opiniões estão a um certo grau de proximidade) em agentes em comum ao longo de todo o processo. Quanto ao valor crítico do limite de confiança, a conjectura de Fortunato [16] apresenta grande generalização ao estabelecer o provável coeficiente de confiança de acordo com o grau médio do grafo quando $n$ diverge.

No modelo de Deffuant, desde o artigo original de Deffuant et al [10] já se observava que o número final de clusters dependia do coeficiente de confiança e que parecia sempre existir (inclusive na variação com opinião multidimensional, binária em cada quesito) um valor crítico para tal parâmetro. Segundo resultado analítico de Häggström [25], esse valor crítico é $1 / 2$ no modelo em $\mathbb{Z}$ com opiniões iniciais i.i.d. com distribuição $\mathcal{U}([0,1])$. De acordo com Häggstrom e Hirscher [26], o parâmetro crítico no mesmo grafo, para outras distribuições iniciais, depende da posição da esperança da opinião inicial em relação ao suporte e se a distribuição é limitada. Ademais, o parâmetro de convergência $\mu$, ainda que receba menos foco na literatura, ainda apresenta papel relevante na dinâmica, como evidenciado por Laguna et al [35].

Como sugestão para pesquisas futuras, podemos citar o estudo de outras variações dos modelos, com diferentes grafos, distribuições de opiniões iniciais e regras de atualização. A generalização proposta por Urbig e Lorenz [53] no final do último capítulo pode ser um primeiro caminho. Também se pode sugerir um estudo mais amplo de limites de confiança heterogêneos; ainda que a homogeneidade do parâmetro facilite contas e simulações, tal situação está muito distante da realidade. 
A propósito de uma maior aplicabilidade à prática das relações humanas, trabalhos conjuntos com pesquisadores de humanas e do comportamento humano podem aumentar a plausibilidade dos modelos e permitir o estudo de situações cotidianas. Outra fonte de enriquecimento dos modelos - assim como um amplo campo de testes - é a Internet, na qual a proeminência das redes sociais permite o acompanhamento de dinâmicas de opinião de forma mais sistematizada. 


\section{Referências Bibliográficas}

[1] AJZEN, I. The theory of planned behavior. Organizational Behavior and Human Decision Processes, v. 50, pp. 179-211, 1991.

[2] BEN-NAIM, E.; KRAPIVSKY, P. L.; REDNER, S. Bifurcations and Patterns in Compromise Processes. Physica D, v. 183, pp. 190-199, 2003.

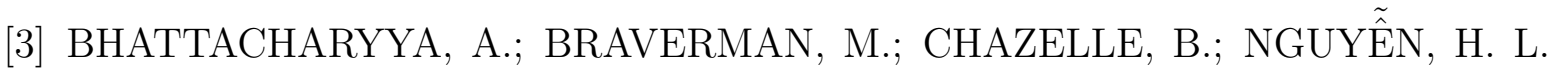
On the Convergence of the Hegselmann-Krause System. Disponível em <http:// arxiv.org/abs/1211.1909>. Submetido em novembro de 2012. Acesso em 31 de outubro de 2015.

[4] BLONDEL, V. D.; HENDRICKX, J. M.; TSITSIKLIS, J. N. On Krause's MultiAgent Consensus Model with State-Dependent Connectiviy. IEEE Transaction on Automatic Control, v. 54, n⿳⺈ 11, 2009.

[5] BLONDEL, V. D.; HENDRICKX, J. M.; TSITSIKLIS, J. N. On the 2R conjecture for multi-agent systems. In: Prévia da European Control Conference. Kos (Grécia), 2007.

[6] BorWEIn, J. M.; BORWEIN, P. B. Pi and the AGM. A Study in Analytic Number Theory and Computational Complexity, Nova York: John Wiley \& Sons, 1987.

[7] BUllo, F.; CORTÉS, J.; MARTÍNEZ, S. Distributed Control of Robotic Networks, Applied Mathematics Series, Princeton University Press, 2009.

[8] CAStellano, C.; FOrTunato, S.; LORETO, V. Statistical physics of social dynamics. Reviews of Modern Physics, v. 81, pp. 591-646, 2009.

[9] Clifford, P.; SUdBuRY, A. A Model for Spatial Conflict. Biometrika, v. 60, pp. 581-588, 1973.

[10] DEFFUANT, G.; NEAU, D.; AMBLARD, F.; WEISBUCH, G. Mixing beliefs among interacting agents. Advances in Complex Systems, v. 3, pp. 87-98, 2000.

[11] DEGROOT, M. H. Reaching a Consensus. Journal of the American Statistical Association, v. 69, n⿳0 345 , pp. 118-121, 1974.

[12] DITTMER, J. C Consensus formation under bounded confidence. Nonlinear Analysis, v.47, pp. 4615-4621, 2001.

[13] DOUVEN, I.; RIEGLER, A. Extending the Hegselmann-Krause Model I. Logic Journal of the IGPL, v. 18, $\mathrm{n}^{\mathrm{O}}$ 2, pp. 323-335, 2009. 
[14] DURRETT, R. Probability: Theory and Examples. 4. ed. Nova York: Cambridge University Press, 2010. 428 pp.

[15] FLAMM, D. History and outlook of statistical physics. In: Conference on Creativity in Physics Education. Sopron (Hungria), 23 de agosto de 1997. Disponível em $<$ http: //arxiv.org/pdf/physics/9803005v1.pdf>. Acesso em 18 de setembro de 2015.

[16] FORTUNATO, S. On the Consensus Threshold for the Opinion Dynamics of KrauseHegselmann. Disponível em <http://arxiv.org/abs/cond-mat/0408648>. Acesso em 31 de outubro de 2015.

[17] FORTUNATO, S. Universality of the threshold for complete consensus for the opinion dynamics of Deffuant et al. International Journal of Modern Physics C, v. 15, n⿳0 9, pp. 1301-1307, 2004.

[18] FORTUnATO, S.; LATORA, V.; PluChinO, A.; RAPISARDA, A. Vector Opinion Dynamics in a Bounded Confidence Consensus Model. International Journal of Modern Physics C, v. 16, n⿳0 10, pp. 1535-1551, 2005.

[19] GALAM, S. Minority opinion spreading in random geometry. The European Physics Journal B-Condensed Matter and Complex Systems, v. 25, nํㅜ 4, pp. 403-406, 2002.

[20] GALAM, S. Social paradoxes of majority rule voting and renormalization group. Journal of Statistical Physics, v. 61, nos. 3 e 4, pp. 943-951, 1990.

[21] GALAM, S. Sociophysics: a personal testimony. Physica A, v. 336, pp. 49-55, 2004.

[22] GALAM, S.; GEFEN, Y.; SHAPIR, Y. Sociophysics: A mean behavior model for the process of strike. Journal of Mathematical Sociology, v. 9, pp. 1-13, 1982.

[23] GIBBS, J. G. Elementary Principals in Statistical Mechanics. Developed with Special Reference to the Foundation of Thermodynamics, Yale University Press. 1902

[24] Group Polarization Psychology Concepts. Disponível em <http://www . psychologyconcepts.com/group-polarization/>. Acesso em 21 de novembro de 2015 .

[25] HÄGGSTRÖM, O. A Pairwise Averaging Procedure with Application to Consensus Formation in the Deffuant Model. Acta Applicandae Mathematicae, v. 119, pp. 185$201,2012$.

[26] HÄGGSTRÖM, O.; HIRSCHER, T. Further results on consensus formation in the Deffuant model. Electronic Journal of Probability, v. 19, pp. 1-26, 2014.

[27] HEGSELMANN, R.; KRAUSE, U. Opinion Dynamics and Bounded Confidence: Models, Analysis and Simulation. Journal of Artificial Societies and Social Simulation, v. 5, no 3, 2002. Disponível em <http://jasss.soc.surrey.ac.uk/5/3/2/2. pdf $>$. Acesso em 17 de setembro de 2015.

[28] HEGSELMANN, R.; KRAUSE, U. Opinion Dynamics Driven by Various Ways of Averaging. Computational Economics, v. 25, nํㅜ 4, pp. 381-405, 2004. 
[29] HIRSCHER, T. The Deffuant model on $\mathbb{Z}$ with higher-dimensional opinion spaces. ALEA, Latin American Journal of Probability and Mathematical Statistics, v. 11, pp. 409-444, 2014.

[30] HOLLEY, R. A.; LIGGETT, T. M. Ergodic Theorems for Weakly Interacting Infinite Systems and the Voter Model The Annals of Probability, v. 3, $\mathrm{n}^{\mathrm{0}}$ 4, pp. 643-663, 1975.

[31] KOU, G.; ZHAO, Y.; PENG, Y.; SHI, Y. Multi-Level Opinion Dynamics under Bounded Confidence PLoS ONE, v. 7, $\mathrm{n}^{\underline{0}}$ 9, 2012. Disponível em <http://journals.plos.org/plosone/article?id=10.1371/journal.pone. 0043507 Acesso em 30 de outubro de 2015.

[32] KRAUSE, U. A discrete non-linear and non-autonomous model of consensus formation. In ELAYDI, S.; LADAS, G.; POPENDA, J.; RAKOWSKI, J. Communications in Difference Equations, Amsterdã: Gordon and Breach Publ, 2000. pp. 227-236.

[33] KRAUSE, U. Compromise, consensus, and the iteration of means. Elemente der Mathematik, nํㅡㄹ. 63 , pp. 1-8, 2008.

[34] KRAUSE, U. Soziale Dynamiken mit vielen Interakteuren. Eine Problemskizze. Modellierung und Simulation von Dynamiken mit vielen interagierenden Akteuren, Universität Bremen, 1997. pp. 37-51.

[35] LAGUNA, M. F.; ABRAMSON, G.; ZANETTE, D. H. Minorities in a model for opinion formation. Disponível em <http://arxiv.org/abs/cond-mat/0307625v1>. Acesso em 30 de janeiro de 2016.

[36] LANCHIER, N. The critical value of the Deffuant model equals one half. ALEA, Latin American Journal of Probability and Mathematical Statistics, v. 9, $\mathrm{n}^{\mathbf{0}}$ 2, pp. 383-402, 2012.

[37] LANCHIER, N.; SCARLATOS, S. Clustering and coexistence in the one-dimensional vectorial Deffuant model. ALEA, Latin American Journal of Probability and Mathematical Statistics, v. 11, nº 2, pp. 541-564, 2014.

[38] LE BON, G. The crowd: a study of the popular mind. Atlanta, Geórgia (EUA): Cherokee Publishing Company. 219 pp. 2 ed. 1896 (reimpresso em 1982).

[39] LIGGETT, T. M. Interacting Particle Systems. Springer, 1985.

[40] LORENZ, J. A Stabilization Theorem for Dynamics of Continuous Opinions Physica A: Statistical Mechanics and Its Applications, v. 355, nº 1, pp. 217-223, 2005.

[41] LORENZ, J. Continuous Opinion Dynamics: Insights through Interactive Markov Chains In: Conferência da International Association of Science and Technology for Development (IASTED) "Modelling Simulation and Optimization" (MSO 2005). Oranjestad (Aruba), 29-31 de agosto de 2005. Disponível em <http://arxiv.org/ pdf/0708.3293v1.pdf>. Acesso em 21 de outubro de 2015.

[42] LORENZ, J. Continuous Opinion Dynamics under Bounded Confidence: A Survey International Journal of Modern Physics C, v. 18, nํㅜ 12, pp. 1819-1838, 2007. 
[43] LORENZ, J. Fixed points in models of continuous opinion dynamics under bounded confidence. In RUFFING, A.; SUHRER, A.; SUHRER, J. Communications of the Laufen Colloquium on Science 200\%, Shaker Publishing, 2007.

[44] LORENZ, J. Heterogeneous Bounds of Confidence: Meet, Discuss and Find Consensus! Complexity, v. 15, $\mathrm{n}^{\mathrm{O}}$ 4, pp. 43-52, 2010.

[45] LORENZ, J. Mehrdimensionale Meinungsdynamik bei wechselndem Vertrauen. 2003. 79 f. Trabalho de conclusão de curso. Universität Bremen, Bremen (Alemanha).

[46] MACKEY, C. Extraordinary popular delusions and the madness of crowds. Nova York: Harmony Books.

[47] MAXWELL, J. C. Illustration of the Dynamical Theory of Gases. Philosophical Magazine, v. 19, pp. 19-32, 1860.

[48] MOSCOVICI, S.; ZAVALLONI, M. The group as a polarizer of attitudes. Journal of Personality and Social Psychology, v. 12, nº 2, pp. 125-135, 1969.

[49] SNAJD-WERON, K.; SZNAJD, J. Opinion evolution in closed community. International Journal of Modern Physics C - Computational Physics and Physical Computation, v. 11, $\mathrm{n}^{\mathrm{O}}$ 6, pp. 1157-1165, 2000.

[50] STAUFFER, D.; MEYER-ORTMANNS, H. Simulation of Consensus Model of Deffuant et al on a Barabási-Albert Network. Disponível em <http://arxiv .org/abs / cond-mat/0308231v2>. Acesso em 27 de janeiro de 2016.

[51] TOURI, B. Product of random stochastic matrices and distributed averaging. 2012. Tese de doutorado. University of Illinois at Urbana-Champaign.

[52] TOURI, B.; NEDIĆ, A. Hegselmann-Krause Dynamics: An Upper-Bound on Termination Time. Prévia submetida à Conferência do IEEE sobre Decisão e Controle, 2012 .

[53] URBIG, D.; LORENZ, J. Communication regimes in opinion dynamics: Changing the number of communicating agents. In: Preparativos para a $2^{\mathrm{a}}$ Conferência $d a$ European Social Simulation Association (ESSA). Valladolid (Espanha), 16-19 de setembro de 2004.

[54] URBIG, D.; MALITZ, R. Dynamics of structured attitudes and opinions In: Preparativos para a $3^{\mathrm{a}}$ Conferência da European Social Simulation Association (ESSA). Koblenz (Alemanha), 5-9 de setembro de 2005. pp. 206-212.

[55] VAZQUEZ, F.; KRAPIVSKY, P. L.; REDNER, S. Constrained opinion dynamics: freezing and slow evolution. Journal of Physics A: Mathematical and General, v. 36, $\mathrm{n}^{\mathrm{O}}$ 3, pp. L61-L68, 2003.

[56] WEIDLICH, W. The statistical description of polarization phenomena in society. British Journal of Mathematical and Statistical Psychology, v. 24, pp. 251-266, 1971. 